NASA Contractor Report 3497

\title{
Effects of Diabatic Heating on the
} Ageostrophic Circulation of an

Upper Tropospheric Jet Streak

Dennis Arthur Keyser and Donald R. Johnson

CONTRACT NAS8-33222

JANUARY 1982 
NASA Contractor Report 3497

\section{Effects of Diabatic Heating on the Ageostrophic Circulation of an Upper Tropospheric Jet Streak}

Dennis Arthur Keyser and Donald R. Johnson University of Wisconsin - Madison Madison, Wisconsin

Prepared for Marshall Space Flight Center under Contract NAS8-33222

\section{N/Sก \\ National Aeronautics \\ and Space Administration}

Scientific and Technical Information Branch 


\section{ACKNOWLEDGMENTS}

We express our appreciation to Professors John Young and Pao Wang for their comments and constructive criticisms, to Dr. Gregory Wilson of NASA's Marshall Space Flight Center for providing the data base for this research effort, to Dr. Louis Uccellini and Jack Katzfey for helpful suggestions and to members of the Atmospheric Sciences Division, Space Sciences Laboratory, NASA Marshall Space Flight Center, for their overall assistance. The assistance of Tom Whittaker and Rich Selin for computer programming aid, Gail Turluck and Nancy Malz for typing and Jim Ferwerda and Rob Clement for drafting is also gratefully acknowledged.

This research was sponsored by the National Aeronautics and Space Administration, through NASA grant NAS8-33222. 
ABSTRACT

Interaction between the mass circulation within a Mesoscale Convective Complex (MCC) (Maddox, 1980) and a direct mass circulation in the entrance region of an upper tropospheric polar jet streak is examined within the isentropic structure to investigate mechanisms responsible for linking these two scales of motion. Twice during NASA's fourth Atmospheric Variability Experiment (AVE IV) (Fucik and Turner, 1975) maximum wind speeds within a jet streak increased nearly $15 \mathrm{~m} \mathrm{~s}^{-1}$ over three to six hours as the jet streak propagated eastward over the Great Lakes region. Severe convection, in the form of an MCC located southwest of the jet streak within the direct circulation in the entrance region, also intensified and increased in areal extent over this same time period. The results establish that latent heating in the MCC modifies the direct mass circulation in the jet streak entrance region through the diabatically induced components of ageostrophic motion analyzed within isentropic coordinates. Within the strong mesoscale mass circulation of each MCC strong horizontal mass flux convergence into the MCC at low levels is balanced by strong horizontal mass flux divergence away from the convection at upper levels. Locations of large diabatic heating rates $\left(>8 \mathrm{k}(6 \mathrm{hr} .)^{-1}\right)$ correspond well to the MCC position for each case; diabatic heating forces the upward vertical branch for the mesoscale mass circulation.

Within the MCC, diabatically induced ageostrophic components of ageostrophic motion are important contributors to the total ageostro- 
phic motion field at mid- and upper tropospheric levels. The diabatic isallobaric component of ageostrophic motion, forced through the effects of differential heating on the thermal wind, is particularly strong in the upper troposphere and dominates the opposing adiabatic isallobaric mode of adjustment. In both cases of jet streak-MCC interaction, the net isallobaric motion in the entrance region at jet streak level exceeds $8 \mathrm{~m} \mathrm{~s}^{-1}$. The intensity of the other diabatic component, the inertial ageostrophic motion induced by vertical advection of momentum in a sheared environment through heating, ranges from 5 to $10 \mathrm{~m} \mathrm{~s}^{-1}$ in the mid-and upper troposphere of the entrance region for each case. Both the isallobaric wind and the inertial diabatic component are directed from the anticyclonic to the cyclonic side of the jet streak in the entrance region at jet streak level, in the same sense as pre-existing ageostrophic motion in the upper branch of the direct mass circulation. This results in an intensification of the direct mass circulation. The resultant generation of kinetic energy ultimately produces stronger winds in the jet streak downstream.

A comparison between actual and semi-geostrophic forms for ageostrophic motion points out that the rapid evolution of ageostrophic motion within the shorter time scales of MCCs limits the applicability of semi-geostrophic theory in prescribing the structure of ageostrophic motion. Discrepancies between observed and semi-geostrophic forms for ageostrophic motion reached $20 \mathrm{~m} \mathrm{~s}^{-1}$ and were linked mainly to differences in the fields of inertial advective ageostrophic motion. 
ACKNOWLEDGMENTS ......................

ABSTRACT .......................... iv

LIST OF FIGURES ...................... vi

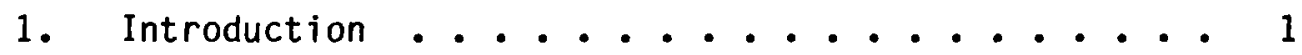

2. Dynamics of Mass and Ageostrophic Motion Fields ... 13

a. Mass Circulation and Diabatic

Heating Rates .......... 13

b. Ageostrophic Motion ........... 15

c. Components of Isallobaric Motion ....... 21

3. Data Source and Synoptic Events ......... 28

a. AVE IV Data Set ............. 28

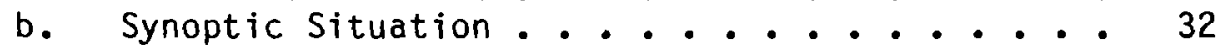

4. Results of Diagnostic Analyses ........ 49

a. Jet Streak-MCC Interaction Case of $00 Z$ to $06 Z$

24 April $1975 \ldots 50$

1) Structure of the Isentropic Mass

Circulation ............ 50

2) Structure of the Ageostrophic Motion

Field ............. 58

3) Ageostrophic Motion Estimated through

the Semi-geostrophic Momentum

Approximation ........ 67

b. Jet Streak-MCC Interaction Case of $00 Z$ to $06 Z$

25 April 1975 ............. 81

1) Structure of the Isentropic Mass

Circulation .............. 81

2) Structure of the Ageostrophic Motion

Field .......... 89

3) Ageostrophic Motion Estimated through

the Semi-geostrophic Momentum

Approximation ............. 94

c. Effects of Diabatic Heating on Mass Circulations

and Ageostrophic Motion ........ 105

5. Conclusions ........................ 114

REFERENCES ......................... 118 
1 Schematic of acceleration ( $u \partial u_{g} / \partial s$ ) and transverse ageostrophic component $\left(v_{a g}\right)$ forced by along-stream variation of pressure gradient force at the jet streak level. $\psi$ is Montgomery stream function, $s$ is along-stream coordinate, $u$ is total wind and $u_{g}$ is geostrophic wind (from Uccellini and Johnson, 1979).

2 Upper panel: Cross section through exit region of approaching jet streak (J). Lower panel: Mass divergence associated with transverse ageostrophic component with original position of $\theta_{2}$ represented by dashed surface (from Gall and Johnson, 1977).

3 Mass convergence and divergence patterns (a) at the level of the upper tropospheric jet streak and (b) at a lower level beneath the upper tropospheric jet streak. Vertical cross section (c) through entrance and exit regions depicting direct and indirect transverse mass circulations.

4 Rawinsonde stations participating in the AVE IV experiment.

5 AVE IV grid network used in diagnostic studies.

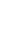

6 Locations of severe weather reports for 24-25 April 1975 (from Maddox, 1979). See Table III for details.

7 Surface synoptic analyses (from Fucik and Turner, 1975) for (a) $00 Z 24$ Apri1 1975, (b) $06 Z 24$ Apri1 1975, (c) $12 Z 24$ Apri] 1975, (d) $18 Z 24$ Apri1 1975, (e) $00 Z 25$ April 1975, (f) $06 Z 25$ Apri 1975 and (g) 12225 April 1975. Radar-observed convection is stippled and squall lines are indicated. $A$ and $B$ denote MCCs under study.

8 Observed wind isotachs (dashed, $\mathrm{m} \mathrm{s}^{-1}$ ) and Montgomery stream function field (solid, $\times 10^{3} \mathrm{~m}^{2} \mathrm{~s}^{-2}$ ) on $330 \mathrm{~K}$ isentropic surface for (a) 00224 April 1975, (b) 122 24 April 1975, (c) 00225 April 1975 and (d) 12225 April 1975. Radar-observed convection and observed wind speeds greater than $40 \mathrm{~m} \mathrm{~s}^{-1}$ are stippled. A and $B$ denote MCCs under study. 
9 Infrared satellite images over eastern half of U.S. for (a) $00 Z 24$ April 1975, (b) 02224 April 1975, (c) $04 Z 24$ April 1975, (d) $06 Z 24$ April 1975 and (e) $10 Z$ 24 Apri1 1975.

10 Infrared satellite images over eastern half of U.S. for (a) 00225 April 1975, (b) 02225 April 1975, (c) $04 Z 25$ April 1975, (d) 06225 April 1975 and (e) $10 Z$ 25 Apri1 1975.

11 Precipitation totals (inches) for 06223 April 1975 to $06 Z 25$ April 1975 (from Daily Weather Maps, U.S. Dept. of Commerce).

12 Time-averaged horizontal mass flux divergence for (a) $330 \mathrm{~K}$ isentropic surface and (b) $305 \mathrm{~K}$ isentropic surface (positive-solid, negative-dashed, $\times 10^{1} \mathrm{~g} \mathrm{~m}^{-2} \mathrm{~s}^{-1}$ ) computed for 002 to 06224 April 1975. Grid points used in areal averaging for Figure 13 are enclosed with solid line in (a). Mesoscale convective complex $A$ and observed wind speeds greater than $40 \mathrm{~m} \mathrm{~s}^{-1}$ on $330 \mathrm{~K}$ at 06224 April 1975 are stippled.

13 Vertical profile of time-areally-averaged horizontal mass flux divergence $\left(\mathrm{g} \mathrm{m}^{-2} \mathrm{~s}^{-1}\right)$ through MCC $A$ for $00 Z$ to $06 Z 24$ April 1975 time interval (see Figure 12 a for location of grid points used in areal averaging).

14 Mass tendency (positive-solid, negative-dashed, $\times 10^{1} \mathrm{~g} \mathrm{~m}^{-2} \mathrm{~s}^{-1}$ ) for (a) surface to $305 \mathrm{~K}$ isentropic layer and (b) $305 \mathrm{~K}$ to $340 \mathrm{~K}$ isentropic layer. Time period and format for jet streak and MCC $A$ same as in Figure 12 .

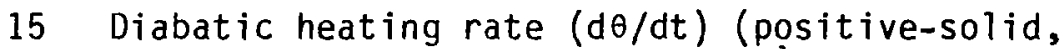
negative-dashed, deg. $\left.K(6 \mathrm{hr} .)^{-1}\right)$ for $320 \mathrm{~K}$ isentropic surface. Time period and format for jet streak and MCC A same as in Figure 12. Grid points used in areal averaging for Figure 16 are enclosed with solid line and location of vertical cross sections in Figures $17 \mathrm{a}$, b are indicated by solid line segments $A-B-C-D-E$ and $F-G-H-I$. 
16 Vertical profile of areally-averaged diabatic heating rate (deg. K $\left.(6 \mathrm{hr} .)^{-1}\right)$ through MCC A for $00 Z$ to $06 Z$ 24 April 1975 time interval (see Figure 15 for location of grid points used in areal averaging).

17 Vertical cross section through jet streak and MCC A depicting observed wind isotachs (dashed, $\mathrm{m} \mathrm{s}^{-1}$ ) and isentropes (solid, deg. K) for (a) $00 Z 24$ April 1975 and (b) $06 Z 24$ Aprit 1975. Vertical coordinate is pressure (mb) (see Figure 15 for location of cross sections).

18 Time-averaged total ageostrophic wind vectors and isotachs (dashed, $\mathrm{m} \mathrm{s}^{-1}$ ) for $330 \mathrm{~K}$ isentropic surface. Time period and format for jet streak and MCC A same as in Figure 12.

19 Time-averaged inertial advective wind vectors and isotachs (dashed, $\mathrm{m} \mathrm{s}^{-1}$ ) for $330 \mathrm{~K}$ isentropic surface. Time period and format for jet streak and MCC A same as in Figure 12.

20 Local wind tendency vectors and isotachs (dashed, $\mathrm{m} \mathrm{s}^{-1}$ ) for $330 \mathrm{~K}$ isentropic surface. Time period and format for jet streak and MCC A same as in Figure 12.

21 Inertial diabatic wind vectors and isotachs (dashed, $\mathrm{m} \mathrm{s}^{-1}$ ) for (a) $325 \mathrm{~K}$ to $330 \mathrm{~K}$ isentropic layer and (b) $320 \mathrm{~K}$ to $325 \mathrm{~K}$ isentropic layer. Time period and format for jet streak and MCC A same as in Figure 12.

22 Residual ageostrophic wind vectors and isotachs (dashed, $\mathrm{m} \mathrm{s}^{-1}$ ) for $330 \mathrm{~K}$ isentropic surface. Time period and format for jet streak and MCC A same as in Figure 12 .

23 Time-averaged semi-geostrophic inertial advective wind vectors and isotachs (dashed, $\mathrm{m} \mathrm{s}^{-1}$ ) for $330 \mathrm{~K}$ isentropic surface. Time period and format for jet streak and MCC A same as in Figure 12. 
Figure

24 Semi-geostrophic inertial diabatic wind vectors and

isotachs (dashed, $\mathrm{m} \mathrm{s}^{-1}$ ) for (a) $325 \mathrm{~K}$ to $330 \mathrm{~K}$

isentropic layer and (b) $320 \mathrm{~K}$ to $325 \mathrm{~K}$ isentropic

layer. Time period and format for jet streak and

MCC A same as in Figure 12.

25 Isallobaric wind vectors and isotachs (dashed, $\mathrm{m} \mathrm{s} \mathrm{s}^{-1}$ ) for (a) $330 \mathrm{~K}$ isentropic surface and (b) $310 \mathrm{~K}$ isentropic surface. Time period and format for jet streak and MCC A same as in Figure 12.

26 Surface pressure tendency isallobaric component vectors and isotachs (dashed, $\mathrm{m} \mathrm{s}^{-1}$ ). Time period and format for jet streak and MCC A same as in Figure 12 .

27 Integrated pressure tendency isallobaric component vectors and isotachs (dashed, $\mathrm{m} \mathrm{s}^{-1}$ ) for (a) $330 \mathrm{~K}$ isentropic surface and (b) $310 \mathrm{~K}$ isentropic surface. Time period and format for jet streak and MCC A same as in Figure 12 .

28 Adiabatic isallobaric component vectors and isotachs (dashed, $\mathrm{m} \mathrm{s}^{-1}$ ) for (a) $330 \mathrm{~K}$ isentropic surface and (b) $310 \mathrm{~K}$ isentropic surface. Time period and format for jet streak and MCC A same as in Figure 12.

29 Diabatic isallobaric component vectors and isotachs (dashed, $\mathrm{m} \mathrm{s}^{-1}$ ) for (a) $330 \mathrm{~K}$ isentropic surface and (b) $310 \mathrm{~K}$ isentropic surface. Time period and format for jet streak and MCC $A$ same as in Figure 12.

30 Difference between actual and semi-geostrophic forms of ageostrophic motion vectors and isotachs (dashed, $\mathrm{m} \mathrm{s}^{-1}$ ) for $330 \mathrm{~K}$ isentropic surface. Time period and format for jet streak and MCC A same as in Figure 12.

31 Difference between local wind tendency and isallobaric wind vectors and isotachs (dashed, $\mathrm{m} \mathrm{s}^{-1}$ ) for $330 \mathrm{~K}$ isentropic surface. Time period and format for jet streak and MCC A same as in Figure 12. 
$330 \mathrm{~K}$ isentropic surface and (b) $305 \mathrm{~K}$ isentropic surface (positive-solid, negative-dashed, $\times 10^{1} \mathrm{~g} \mathrm{~m}^{-2} \mathrm{~s}^{-1}$ ) computed for $00 \mathrm{Z}$ to $06 \mathrm{Z} 25$ April 1975. Grid points used in areal averaging for Figure 33 are enclosed with solid line in (a). Mesoscale convective complex $B$ and observed wind speeds greater than $40 \mathrm{~m} \mathrm{~s}^{-1}$ on $330 \mathrm{~K}$ at $06 \mathrm{Z} 25$ April 1975 are stippled.

33 Vertical profile of time-areally-averaged horizontal mass flux divergence $\left(\mathrm{g} \mathrm{m}^{-2} \mathrm{~s}^{-1}\right)$ through MCC $B$ for $00 z$ to 06225 April 1975 time interval (see Figure 32a for location of grid points used in areal averaging).

34 Mass tendency (positive-solid, negative-dashed, $\times 10^{1} \mathrm{~g} \mathrm{~m}^{-2} \mathrm{~s}^{-1}$ ) for (a) surface to $305 \mathrm{~K}$ isentropic layer and (b) $305 \mathrm{~K}$ to $340 \mathrm{~K}$ isentropic layer. Time period and format for jet streak and MCC B same as in Figure 32 .

35 Diabatic heating rate $(d \theta / d t)$ (positive-solid, negative-dashed, deg. $\left.K(6 \mathrm{hr} .)^{-1}\right)$ for $320 \mathrm{~K}$ isentropic surface. Time period and format for jet streak and MCC B same as in Figure 32. Grid points used in areal averaging for Figure 36 are enclosed with solid line and location of vertical cross sections in Figures $37 \mathrm{a}, \mathrm{b}$ are indicated by solid line segments $A-B-C-D-E-F$ and $G-H-I-J$.

36 Vertical profile of areally-averaged diabatic heating rate (deg. K $\left.(6 \mathrm{hr} .)^{-1}\right)$ through MCC B for 002 to $06 Z$ 25 April 1975 time interval (see Figure 35 for location of grid points used in areal averaging).

37 Vertical cross section through jet streak and MCC B depicting observed wind isotachs (dashed, $\mathrm{m} \mathrm{s}^{-1}$ ) and isentropes (solid, deg. K) for (a) 00225 April 1975 and (b) $06 \mathrm{Z} 25$ April 1975. Vertical coordinate is pressure (mb) (see Figure 35 for location of cross sections).

38 Time-averaged total ageostrophic wind vectors and isotachs (dashed, $\mathrm{m} \mathrm{s}^{-1}$ ) for $330 \mathrm{~K}$ isentropic surface. Time period and format for jet streak and MCC B same as in Figure 32 . 
39 Time-averaged inertial advective wind vectors and isotachs (dashed, $\mathrm{m} \mathrm{s}^{-1}$ ) for $330 \mathrm{~K}$ isentropic surface. Time period and format for jet streak and MCC B same as in Figure 32.

40 Local wind tendency vectors and isotachs (dashed, $\mathrm{m} \mathrm{s}^{-1}$ ) for $330 \mathrm{~K}$ isentropic surface. Time period and format for jet streak and MCC B same as in Figure 32.

41 Inertial diabatic wind vectors and isotachs (dashed, $\mathrm{m} \mathrm{s}^{-1}$ ) for $320 \mathrm{~K}$ to $325 \mathrm{~K}$ isentropic layer. Time period and format for jet streak and MCC B same as in Figure 32 .

42 Residual ageostrophic wind vectors and isotachs (dashed, $\mathrm{m} \mathrm{s}^{-1}$ ) for $330 \mathrm{~K}$ isentropic surface. Time period and format for jet streak and MCC B same as in Figure 32.

43 Time-averaged semi-geostrophic inertial advective wind vectors and isotachs (dashed, $\mathrm{m} \mathrm{s}^{-1}$ ) for $330 \mathrm{~K}$ isentropic surface. Time period and format for jet streak and MCC B same as in Figure 32.

44 Semi-geostrophic inertial diabatic wind vectors and i sotachs (dashed, $\mathrm{m} \mathrm{s}^{-1}$ ) for $320 \mathrm{~K}$ to $325 \mathrm{~K}$ isentropic layer. Time period and format for jet streak and MCC B same as in Figure 32.

45 Isallobaric wind vectors and isotachs (dashed, $\mathrm{m} \mathrm{s}^{-1}$ ) for (a) $330 \mathrm{~K}$ isentropic surface and (b) $310 \mathrm{~K}$ isentropic surface. Time period and format for jet streak and MCC B same as in Figure 32.

46 Surface pressure tendency isallobaric component vectors and isotachs (dashed, $\mathrm{m} \mathrm{s}^{-1}$ ). Time period and format for jet streak and MCC $B$ same as in Figure 32.

47 Integrated pressure tendency isallobaric component vectors and isotachs (dashed, $\mathrm{m} \mathrm{s}^{-1}$ ) for (a) $330 \mathrm{~K}$ isentropic surface and (b) $310 \mathrm{~K}$ isentropic surface. Time period and format for jet streak and MCC B same as in Figure 32. 
48 Adiabatic isallobaric component vectors and isotachs

(b) $310 \mathrm{~K}$ isentropic surface. Time period and format for jet streak and MCC B same as in Figure 32.

49 Diabatic isallobaric component vectors and isotachs

(dashed, in $\mathrm{s}^{-1}$ ) for (a) $330 \mathrm{~K}$ isentropic surface and

(b) $310 \mathrm{~K}$ isentropic surface. Time period and format

for jet streak and MCC B same as in Figure 32.

50 Difference between actual and semi-geostrophic forms of ageostrophic motion vectors and isotachs (dashed, $m s^{-1}$ ) for $330 \mathrm{~K}$ isentropic surface. Time period and format for jet streak and MCC $B$ same as in Figure 32.

51 Difference between local wind tendency and isallobaric wind vectors and isotachs (dashed, $\mathrm{m} \mathrm{s}^{-1}$ ) for $330 \mathrm{~K}$ isentropic surface. Time period and format for jet streak and MCC B same as in Figure 32.

52 (a) schematic showing diabatically-induced ageostrophic motion $\left(\mathrm{U}_{\mathrm{ag}}\right)$ directed in same sense as pre-existing inertial advective wind $\left(U_{a g_{2}}\right)$. (b) schematic of jet streak with increased velocity due to inertial rotation of ageostrophic motion.

53 Vertical cross section schematic normal to jet streak (J) showing (a) location of developing MCC in relation to direct circulation in entrance region, (b) upper level isallobaric wind $\left[\left(U_{i s}\right)_{d}\right]$ forced by differential diabatic heating in mature MCC with resulting surface pressure tendencies and (c) resultant lower level adiabatically-induced isallobaric wind $\left[\left(U_{i s}\right)_{a}\right]$ convergence into MCC.

54 Vertical cross section schematic normal to jet streak (J) showing pre-existing direct circulation in entrance region and source of inertial diabatic wind $\left(U_{i n, d}\right)$ through combination of diabatic heating and vertical wind shear in MCC. Dashed lines indicate typical observed wind speeds $\left(\mathrm{m} \mathrm{s}^{-1}\right)$ in vicinity of jet core. 


\section{Introduction}

In recent years investigations of satellite images have documented the existence of large, organized convective storm systems called Mesoscale Convective Complexes (MCCs) (Maddox, 1980) which occur with regularity over the central United States between March and September. These weather systems, with length scales of $250 \mathrm{~km}$ to $2500 \mathrm{~km}$ and durations of at least six hours, generally produce large amounts of precipitation over wide geographical regions. Table I presents a complete definition of meso-a scale MCCs based on observations of enhanced infrared satellite imagery. Investigations have concluded that these convective storm systems can interact with and even modify the mass and momentum distribution of the synoptic scale environment.

Although the dynamics associated with scale interaction are not yet well understood, scientists have long recognized that thermodynamic and dynamic interaction between various scales of atmospheric circulation systems occurs with energy transferred up and down the spectrum of atmospheric motion. In their study of the dynamical interaction between sub-synoptic scale squall lines and the synoptic scale flow field, Newton and Newton (1959) found that in the presence of an environment with vertical wind shear, the nonhydrostatic pressure field created by relative motions at the boundary of the convective system can force vertical accelerations as large as normal buoyancy forces. They concluded that such a process alters the dynamic control exerted by the synoptic scale such that the squall line will self-propagate 
Table I

Physical Characteristics of Mesoscale Convective Complexes

(Maddox, 1980)

Size:

A-Contiguous cold cloud shield with infrared temperature $<-32{ }^{\circ} \mathrm{C}$ must have an area $>100,000 \mathrm{~km}^{2}$

B-Interior cold cloud region with temperature $<-52{ }^{\circ} \mathrm{C}$ must have an area $>50,000 \mathrm{~km}^{2}$

Initiate: $\quad$ Size definitions $A$ and $B$ are first satisfied

Duration: $\quad$ Size definitions $A$ and $B$ must be met for a period $>6$ hours

Maximum

Contiguous cold cloud shield (infrared $<-32{ }^{\circ} \mathrm{C}$ ) reaches maximum size

Shape: $\quad$ Eccentricity (minor axis/major axis) $\geqslant 0.7$ at time of maximum extent

Terminate: $\quad$ Size definitions $A$ and $B$ no longer satisfied 
through the environmental flow field. Normaliy, scale interaction between squall line systems, typically small in transverse scale, and the synoptic scale environment is difficult to diagnose with standard rawinsonde data because of the sub-grid nature of these storm systems. The size and time duration of the MCC with its relatively large radial scale, however, ensures that its mesoscale pressure and momentum field will be detected by several synoptic RAOB stations (Maddox, 1980). Consequently, rawinsonde data from the standard observing network may be used to study the MCC and its interaction with the larger scale. Convective storm systems act to vertically exchange properties between the lower and upper troposphere and are important in maintaining the large scale balance of angular momentum, energy and moisture in mid-latitudes (Palmen and Newton, 1969). Ninomiya (1971a, b) concluded that thunderstorm outflow aloft, associated with intense convection, was responsible for changing the pre-existing upper level flow in the vicinity of the storm development. He concluded that the release of latent heat in these convective systems was the primary factor in intensifying the upper level synoptic scale flow pattern through the strengthening of the horizontal temperature gradient.

Fritsch and Maddox (1980) studied the effects of MCCs on the synoptic scale flow and found that diabatic processes within these storm systems acted to intensify height gradients to the north of the convection and in turn suppress such gradients to the south. The end result was to substantially change the wind and height fields of the synoptic 
scale patterns by increasing the wind speeds to the north of the convective region and weakening them to the south.

In other studies, Maddox, et al. (1980) and Maddox (1979) also related the growth of a convective complex to the subsequent increase in the maximum winds in an upper tropospheric jet streak found north and downstream of the convective complex. They concluded that convective warming due to diabatic latent heating appeared to intensify mass circulations in the mid-troposphere. The result was an increase in pressure heights in the upper troposphere over the convection and the production of stronger winds at jet streak level through thermal wind effects.

In this case study of severe weather, the role of diabatic heating within the convective region in altering the ageostrophic mass circulation in the entrance region of the jet streak will be examined. The focus will be on the dynamical and thermodynamical interaction between an MCC and a synoptic scale upper tropospheric jet streak.

As parcels of air in the upper troposphere move through a propagating jet streak, they first accelerate into the core of maximurn winds through ageostrophic motion towards lower pressure and then decelerate upon exiting the core through ageostrophic motion towards higher pressure; thus, the momentum field is altered by the ageostrophic motion that is an important feature of propagating jet streaks. Studies by Cahir (1971) have shown that for a changing momentum field at the scale of upper tropospheric jet streaks, the mass field correspondingly ad- 
justs as the atmosphere attempts to maintain geostrophic and thermal wind balance. This mass adjustment leads to an intensification in atmospheric baroclinity in the exit region of the jet streak that is necessary to thermally support the core of maximum winds entering this region. The mass adjustment in the entrance region, on the other hand, relaxes the baroclinity as the jet streak propagates downstream.

Uccellini and Johnson (1979) have demonstrated that the adiabatic mass adjustment associated with the changing momentum field in an upper tropospheric jet streak prior to the development of deep convection is accomplished through transverse ageostrophic circulations in the entrance and exit regions of the jet streak. With a two layer model in the isentropic framework they point out that at the level of the jet streak, where wind speeds and the along-stream variation of the pressure gradient force are large, the inertial advective wind is the dominant component of ageostrophic motion primarily responsible for the mass transport. Within the confluent and diffluent pattern of the streamlines in the entrance and exit regions, the motion is in the direction of the pressure gradient force in the entrance region where winds are subgeostrophic and against the pressure gradient force in the exit region where winds are supergeostrophic (see figure 1). This ageostrophic circulation at jet streak level transports mass from the cyclonic side of the jet streak to the anticyclonic-side in the exit region and from the anticyclonic side to the cyclonic side in the entrance region. As a result of this mass transport by upper level ageo- 


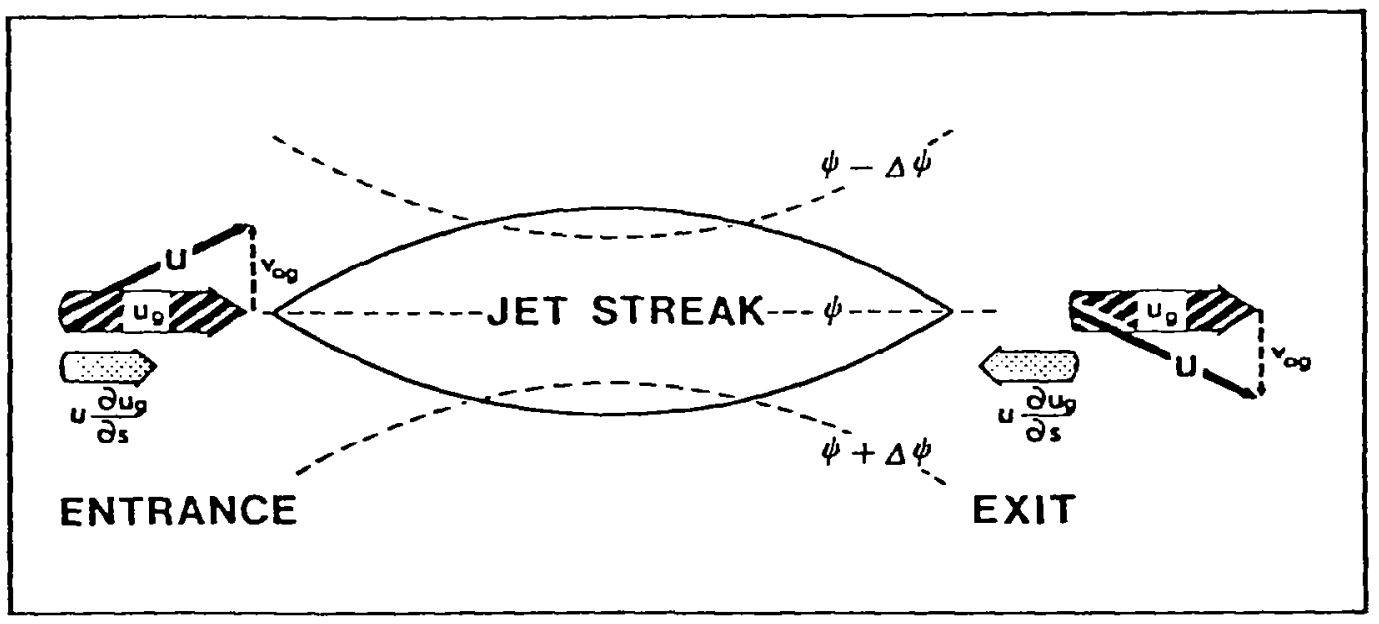

Figure 1: Schematic of acceleration ( $\left.u \partial u_{g} / \partial s\right)$ and transverse ageostrophic component $\left(\mathrm{v}_{\mathrm{ag}}\right)$ forced by along-stream variation of pressure gradient force at the jet streak level. $\psi$ is Montgomery stream function, $s$ is along-stream coordinate, $u$ is total wind and $u_{g}$ is geostrophic wind (from Uccellini and Johnson, 1979). 
strophic winds, the pressure gradient force intensifies locally in layers beneath the exit region and correspondingly weakens in layers beneath the entrance region of the jet streak. This temporal variation in the mass field in the upper layer simultaneously forces a dominant mode of ageostrophic motion at lower levels in the form of an isallobaric wind. In this lower branch of the transverse circulation mass is transported from the anticyclonic to the cyclonic side in the exit region and from the cyclonic to the anticyclonic side in the entrance region (Uccellini and Johnson, 1979). The effects of upper and lower mass circulations in the exit region of the jet streak are shown in Figure 2.

In their case study emphasizing primarily the mass-momentum adjustment during the twenty-four hours preceding the severe weather events, Uccellini and Johnson only evaluated the component of the isallobaric wind forced by horizontal mass flux divergence in the upper layer. They did not estimate the effect of diabatic heating on the vertical mass transport and the additional component of the isallobaric wind associated with this process. This diabatic component of the isallobaric wind may be important in regions of intense convection and may act to intensify the transverse mass circulations associated with the jet streak. Eliassen (1959) studied the role of diabatic heating on altering mass circulations and found that such heating can strengthen a pre-existing circulation.

Ageostrophic mass circulations within isentropic coordinates (Sechrist and Johnson, 1970) can be linked together with the tradition- 


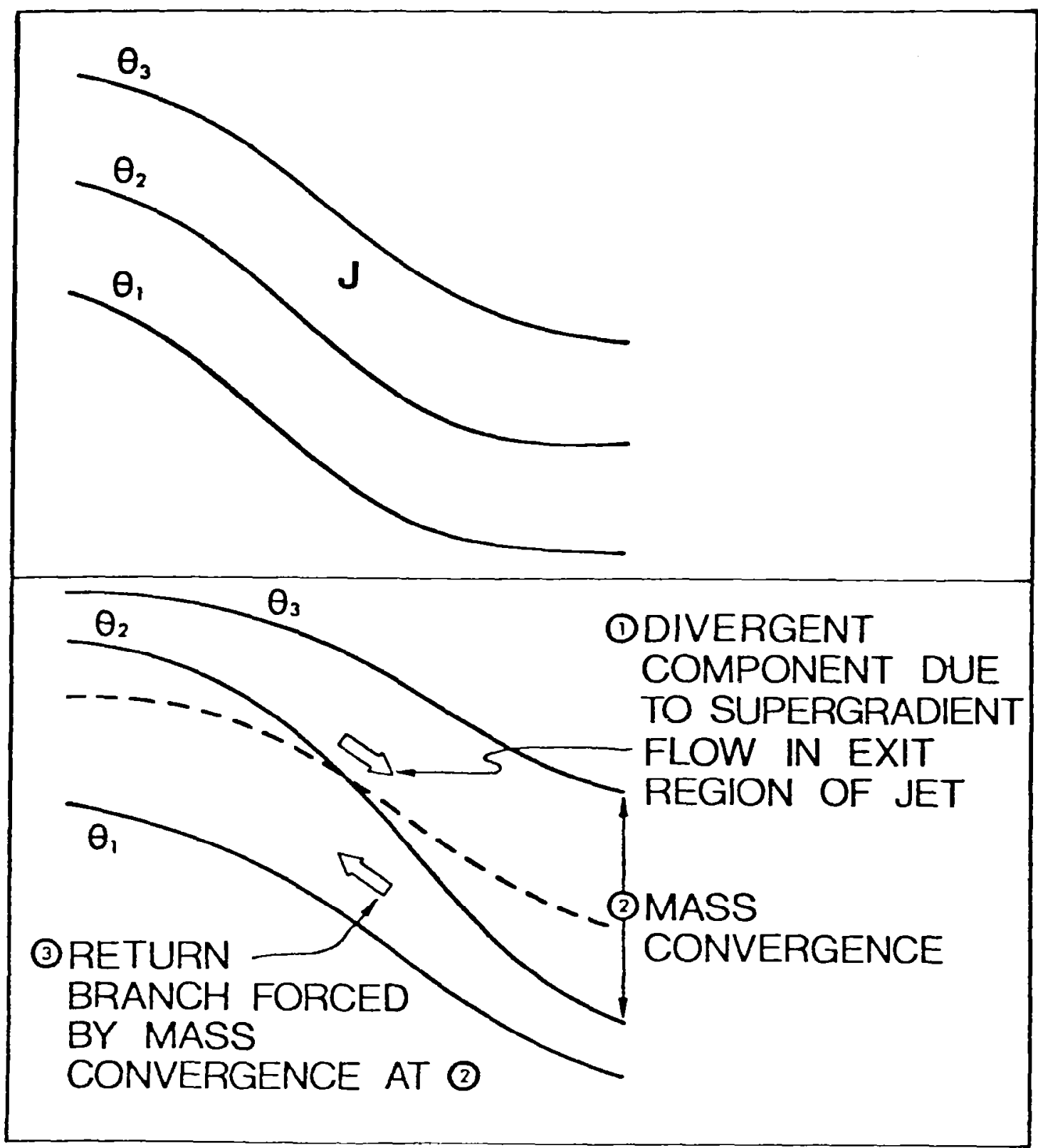

\section{MECHANISM FOR GENERATING THE BAROCLINIC SUPPORT FOR A PROPAGATING JET}

Figure 2: Upper panel: Cross section through exit region of approaching jet streak $(\mathrm{J})$. Lower panel: Mass divergence associated with transverse ageostrophic component with original position of $\theta_{2}$ represented by dashed surface (from Gall and Johnson, 1977). 
al "four cell" pattern that is observed with the jet streak (Riehl, et a1. 1952; Sechrist and Whittaker, 1979) (see Figure 3). In the exit region, mass convergence in the upper layer on the anticyclonic side of the jet streak implies descending motion in the right front quadrant and, from Dynes compensation rule, mass divergence in the lower layer. On the cyclonic side, mass convergence at low levels results in ascending motion and a compensating divergence of mass in upper layers. The result is a thermally-indirect circulation in the jet streak exit region which is linked to adiabatic mass transport in the isentropic framework. The thermally-direct circulation found in the entrance region of the jet streak is based on the same principles except that the location of rising and sinking air is reversed in this situation.

The case study examined by Uccellini and Johnson discovered a direct link between the upper tropospheric jet streak and a lower tropospheric jet streak embedded in the return branch of the indirect circulation in the entrance region. Severe weather in the form of an elongated squall line broke out in the vicinity of this low level jet streak due to the convective instability created in this region by strong differential advection of sensible and latent energies by the upper and lower level jet streaks.

In contrast, for the case study of this study, the MCC and severe weather were located southwest of the jet streak within the direct mass circulation of the entrance region. Since the severe weather activity was in different locations relative to the jet streak in these two 

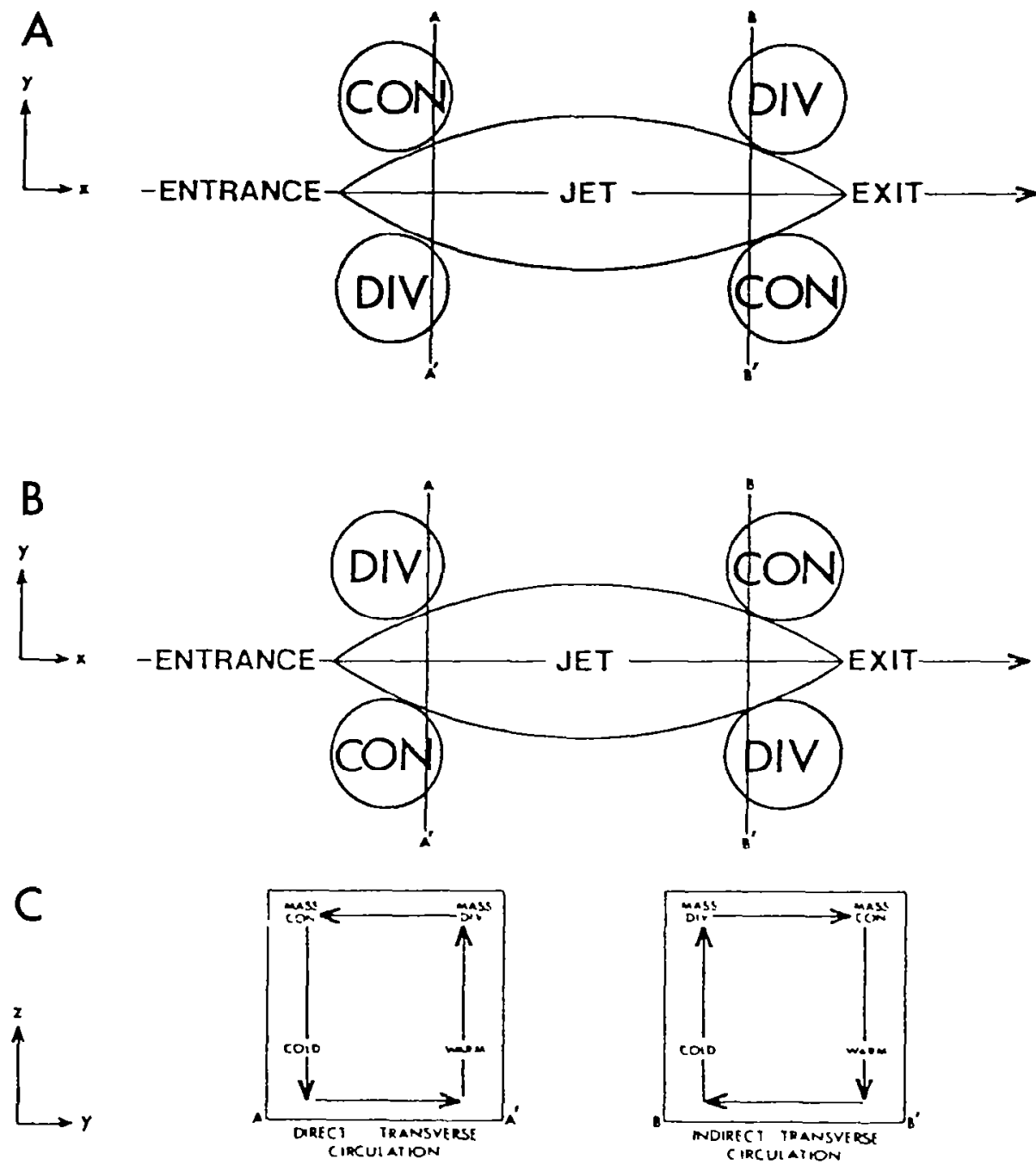

Figure 3: Mass convergence and divergence patterns (a) at the level of the upper tropospheric jet streak and (b) at a lower level beneath the upper tropospheric jet streak. Vertical cross section (c) through entrance and exit regions depicting direct and indirect transverse mass circulations. 
cases, it seems likely that the forcing of mass circulations acts in different ways in the development and maintenance of deep convection within larger scales.

Through the use of higher temporal resolution data from NASA's fourth Atmospheric Variability Experiment, this study addresses the scale interaction problem through a case study of the ageostrophic motion for two situations where maximum wind magnitudes in an upper tropospheric jet streak are significantly augmented some three to six hours after the onset of severe convection to the south and southwest of the jet core. The large precipitation totals from the two MCCs observed by the data network indicate the importance of diabatic latent heating within these storm systems. The primary purpose of this study is to investigate how diabatic heating in this mesoscale storm modifies the synoptic scale environmental flow through dynamical mechanisms which link the mass circulations of these two scales. The effect of diabatic heating on the mass circulation, and its alteration of the ageostrophic motion within the MCC as it relates to the thermallydirect circulation of the jet streak entrance region, is then examined. It is the ageostrophic motion that is primarily responsible for forcing the mass circulations around the jet streak and within the MCC. This component of motion links the mass-momentum adjustment of the jet streak and the MCC. A relative comparison of fields of the components of ageostrophic motion are examined with particular emphasis on those components forced by diabatic processes. A further goal of this study 
is to verify that this mode of ageostrophic motion can significantly contribute to the rapid acceleration of winds and thus ultimately intensify the upper tropospheric jet streak downstream. 
2. Dynamics of mass and ageostrophic motion fields

a. Mass circulations and diabatic heating rates

The interaction of ageostrophic mass circulations in the MCC, its environment and the entrance region of the jet streak is an important process to examine in this case study. In order to scrutinize the evolving mass structure within the atmosphere, the mass continuity equation in isentropic coordinates,

$$
\frac{\partial}{\partial \bar{t}_{\theta}}(\rho J)+\nabla_{\theta} \cdot(\rho J \underset{\sim}{U})+\frac{\partial}{\partial \theta}\left(\rho J \frac{d \theta}{d t}\right)=0,
$$

is employed. In (1) $\rho$ is density, $U$ is the horizontal velocity, $\theta$ is potential temperature, and $\mathrm{J}$ is a Jacobian transformation of the vertical coordinate from the Cartesian to the isentropic framework, $J=|\partial z / \partial \theta|$. With the hydrostatic assumption, the mass in an incremental volume element equals $\left|g^{-1} \partial p / \partial \theta\right|$ where $g$ is gravity and $p$ is pressure. Physically, (1) states that local mass changes in an isentropic volume element are due to horizontal mass flux divergence and/or vertical mass flux divergence. For example, an increase in the amount of mass in an atmospheric column must be the effect of either: (1) more mass transported horizontally into the column than out of the column or (2) more mass transported vertically into the bottom of the column than out of the top of the column. In the isentropic framework the vertical mass flux divergence is uniquely determined by diabatic processes in the atmosphere.

The vertical mass flux, $\rho J(d \theta / d t)$, determined at any isentropic level $\theta$ through the vertical integration of the mass continuity equa- 
tion (1), is given by

$$
\underset{d t}{\rho J_{--}^{d \theta}}=\underset{d t}{\rho J_{--}}\left({ }^{\theta} T\right)+\int_{\theta}^{\theta} \nabla_{\theta} \cdot(\rho J U \sim) d \theta-g^{-1}\left[\underset{\partial t_{\theta}}{\partial p}\left({ }^{\theta} T\right)-\frac{\partial p}{\partial t_{\theta}}\right],
$$

where ${ }^{\theta} T$ is the highest theta surface used in the calculations. In this case study an upper boundary condition that the vertical mass flux vanishes on the $385 \mathrm{~K}$ isentropic surface is employed. This assumption should be acceptable for a diagnostic study if the highest potential temperature surface is above the region of strong diabatic heating, yet below the layers of strong stratospheric heating within the ozone layer. The $385 \mathrm{~K}$ isentropic surface is near the $100 \mathrm{mb}$ level, the highest level of data available for this diagnostic study. The calculation of the vertical mass flux is a residual determination from a direct evaluation of the observed mass tendency and horizontal mass flux divergence. The diabatic heating rate on the level $\theta$ is obtained by dividing (2) by $\mathrm{oJ}$. Because of inaccuracies mainly due to truncation errors in the finite difference estimates of the horizontal mass flux divergence (Sechrist and Johnson, 1970; Peterson, 1981) and unavoidable rawinsonde recording errors in upper level winds, an adjustment factor must be applied. The adjustment factor is simply the residual between the local mass tendency and horizontal mass flux divergence in (1), from a vertical integration from the earth's surface to the highest isentropic level. The adjustment factor $\delta_{A}$ per unit mass is

$$
\delta_{A}=\left\{\int_{\theta_{S}}^{\theta} \nabla_{\theta} \cdot(\rho J U \sim \sim) d \theta-g^{-1}\left[\underset{\partial t_{\theta}}{\partial p}\left({ }^{\theta} T\right)-\underset{\partial t_{\theta}}{\partial-}\left(\theta_{S}\right)\right]\right\} / \int_{\theta_{S}}^{\theta} \rho J d \theta,
$$


where $\theta_{s}$ is the potential temperature at the surface of the earth. The adjustment factor is then multiplied by the mass for each isentropic layer and added onto the calculated horizontal mass flux divergence term to yield the adjusted horizontal mass flux divergence given by

$$
\left[\nabla_{\theta} \cdot(\rho \mathcal{\sim})\right]_{A}=\nabla_{\theta} \cdot(\rho J U)-\rho J \delta_{A} \cdot
$$

b. Ageostrophic motion

Ageostrophic motion is an important dynamical process linking the circulations associated with the jet streak and the MCC for two basic reasons. First of all within the mass transport, oJU, the ageostrophic component, $\rho \mathrm{JU}_{\mathrm{ag}}$, in the entrance and exit regions of the jet streak is important for transporting mass transverse to the jet streak in both the upper and lower branches of the direct and indirect circulations (see Uccellini and Johnson, 1979). Secondly, within its definition from the equation of motion, ageostrophic effects also force horizontal branches of the mass circulation within the MCC which become linked with the strong diabatic heating occurring within the region of severe convection.

A derivation of the expression for the ageostrophic motion begins with the complete horizontal equation of motion,

$$
\frac{d}{d t} \underset{\sim}{U}=-\nabla_{\theta} \psi_{m}-f \underset{\sim}{k} \times \underset{\sim}{U}+\underset{\sim}{F_{H}}
$$

where $\psi_{m}$ is the Montgomery stream function, $f$ the Coriolis parameter, and $F_{H}$ the horizontal frictional force. An expansion of the total acceleration within an isentropic coordinate system, 


$$
\frac{d}{d \bar{t}} \underline{U}=\left(\frac{\partial}{\partial \bar{t}_{\theta}}+\underline{U} \cdot \nabla_{\theta}+\frac{d \theta}{d \bar{t}} \frac{\partial}{\partial \bar{\theta}}\right) \underline{\sim},
$$

determines the three components of acceleration consisting of the local tendency and the horizontal and vertical advection of velocity. With the total horizontal wind vector on the right-hand side of (5) partitioned into geostrophic and ageostrophic components ${\underset{\sim}{g}}_{g}$ and $\underset{\sim}{U_{a g}}$ respectively, the substitution of (6) into (5), a rearrangement of terms and neglect of the horizontal frictional force gives the total ageostrophic motion

$$
\begin{aligned}
& U_{a g}=f^{-1} \underset{\sim}{k} \times\left(\frac{\partial}{\partial t_{\theta}}+U \cdot \nabla_{\theta}+\frac{d \theta}{d t} \frac{\partial}{\partial \bar{\theta}}\right) \underset{\sim}{U} . \\
& \text { A B } C
\end{aligned}
$$

The three major components of ageostrophic motion (Haltiner and Martin, 1957) are associated with local changes in the horizontal wind vector and with the horizontal and vertical advection of the velocity. Within the isentropic structure these three components of ageostrophic motion will be called the local wind tendency (term A), inertial advective (term B) and inertial diabatic (term C) components respectively. See portion A of Table II for a summary of their form of decomposition used in this diagnostic study within isentropic coordinates. The influence of both friction and convective momentum transport in mid-and upper levels of the atmosphere cannot be determined and thus the effect of these processes in forcing ageostrophic motion cannot be studied. 


\section{Table II}

\section{Expression for Components of Frictionless Ageostrophic Motion}

\section{In Isentropic Coordinates}

A. Total Form

$$
\underset{\sim}{U_{a g}}=f^{-1} \underset{\sim}{k} \times\left(\frac{\partial}{\partial \bar{t}_{\theta}}+\underset{\sim}{U} \cdot \nabla_{\theta}+\frac{d \theta}{d t} \frac{\partial}{\partial \bar{\theta}}\right) \underset{\sim}{U}
$$

$$
\text { A B C }
$$

Term A - Local wind tendency component:

$$
\left(\underline{\sim}_{a g}\right)_{A}=f^{-1} k \underset{\sim}{\partial t_{\theta}} \underset{U}{U}
$$

Term B - Inertial advective component:

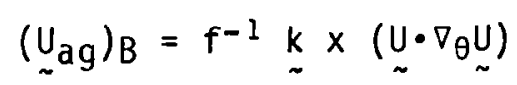

Term C - Inertial diabatic component:

$$
\left.\underset{\sim}{\left(U_{a g}\right.}\right)_{C}=f^{-1} \underset{\sim}{k} \times \frac{d \theta}{d t} \frac{\partial}{\partial \theta} \underset{\sim}{U}
$$

B. Semi-geostrophic Form

$$
\begin{aligned}
& \underset{\sim}{U_{a g}}=f^{-1} \underset{\sim}{k} \times\left(\frac{\partial}{\partial t_{\theta}}+\underset{\sim}{U} \cdot \nabla_{\theta}+\frac{d \theta}{d t} \frac{\partial}{\partial \theta}\right) \underset{\sim}{U_{g}} \\
& \text { or } \\
& \text { A B } C \\
& {\underset{\sim}{\mathrm{U}}}_{\mathrm{ag}}=-f^{-2}\left(\frac{\partial}{\partial \bar{t}_{\theta}}+\underset{\sim}{U} \cdot \nabla_{\theta}+\frac{d \theta}{d t} \frac{\partial}{\partial \theta}\right) \nabla_{\theta} \psi_{m} \\
& \text { A B } \quad \text { C }
\end{aligned}
$$


Table II, cont.

Term A - Isallobaric wind component

$$
\left.\underset{\sim}{\left(U_{a g}\right.}\right)_{A s}=f^{-1} \underset{\sim}{k} \times \frac{\partial}{\partial \bar{t}_{\theta} \underset{\sim}{U_{g}}=-f^{-2} \nabla_{\theta}-\overline{\psi_{m}}} \partial \bar{t}_{\theta}
$$

Term B - Inertial advective component:

$$
\left(\underline{\sim}_{a g}\right)_{B s}=f^{-1} \underset{\sim}{k} \times\left({\underset{\sim}{U}}^{U} \nabla_{\theta}{\underset{\sim}{g}}_{g}\right)
$$

Term C - Inertial diabatic component:

$$
\left(U_{a g}\right)_{S s}=f^{-1} \underset{\sim}{k} \times \frac{d \theta}{d t} \frac{\partial}{\partial \theta}{\underset{\sim}{U} g}^{U_{g}}
$$


With the assumption

$$
\frac{d}{d t} U \cong \frac{d}{d t} U_{\sigma} U^{\sigma}=\left(\frac{\partial}{\partial t_{\theta}}+U \cdot \nabla_{\theta}+\frac{d \theta}{d t} \bar{\partial} \bar{\theta}\right) U_{g}
$$

or equivalentiy,

$$
\left|\begin{array}{ll}
d & \\
-- & U_{a g} \\
d t & \sim
\end{array}\right| \ll\left|\begin{array}{ll}
d \\
-\overline{d t} & U_{g}
\end{array}\right|
$$

the geostrophic momentum approximation (Eliassen, 1949, 1962; Hoskins, 1975) provides for expressions for semi-geostrophic components (Hoskins, 1975) of the total and each of the components of ageostrophic motion (see portion B of Table II). From the geostrophic wind relationship,

$$
\underline{\sim}_{g}=f^{-1} \underset{\sim}{k} \times \nabla_{\theta} \psi_{m},
$$

alternative semi-geostrophic expressions for ageostrophic components are determined (see second form for II-2). In this form, the ageostrophic component of the tendency of the geostrophic velocity becomes an isallobaric component (II-2-A), while the inertial advective (II-2-B) and inertial diabatic $(I I-2-C)$ components become related to the hort $=$ zontal pressure gradient. The application of semi-geostrophic theory simplifies (II-2) through the elimination of higher order components associated with substantial derivatives of the ageostrophic motion field itself. Hoskins has successfully utilized the semi-geostrophic approximation to the total wind field in dynamical studies of fronts and jets with relatively large time and space scales. 
The isallobaric wind component (Brunt and Douglass, 1928) (II-2-A) is determined by temporal changes in the pressure gradient force. Its magnitude within the isentropic structure is proportional to the gradient of the $\psi_{m}$ tendency, while its direction is perpendicular to the isallobars and directed toward the center of falling $\psi_{m}$ values. The isallobaric wind can be influenced by diabatic as well as adiabatic processes in the atmosphere.

The inertial components of ageostrophic motion in both their total and semi-geostrophic forms within isentropic coordinates contain modes for both adiabatic and diabatic forcing. Inertial processes in the atmosphere are associated with the nonlinear advection of the horizontal wind field (or the geostrophic wind field in semi-geostrophic theory). The inertial advective component $((I I-1-B)$ and $(I I-2-B))$ is in a sense associated with the adiabatic component of motion since it instantaneously acts to advect momentum quasi-horizontally along isentropic surfaces. The inertial diabatic motion ((II-1-C) and II-2-C)) is related to the vertical advection of horizontal momentum through isentropic surfaces, and is uniquely associated with diabatic processes in the atmosphere. In regions of larger scale flow, the ageostrophic mass circulation in the entrance and exit regions of an upper tropospheric jet streak is dominated by the isallobaric terin and the inertial advective component, with the former being more important in the lower branch of the circulation while the latter is more important in the upper branch of the transverse circulation (Uccellini and Johnson, 1979). 
The focus in this study is to determine the relative importance of the inertial diabatic component in regions where diabatic heating and vertical wind shears are large, within the smaller scale of the MCC.

c) Components of isallobaric motion

The isallobaric wind component (II-2-A) is now expanded into components dealing with surface and integrated layer pressure tendencies which contain explicit modes associated with adiabatic and diabatic processes. The expansion of the isallobaric wind begins with the vertical integration of the isentropic form of the hydrostatic equation

$$
\overline{\partial \psi_{m}}=c_{p}\left(\frac{p}{p_{00}}\right)^{k},
$$

where $c_{p}$ is the specific heat capacity under constant pressure, $k$ is the ratio of the gas constant for dry air $R$ to $c_{p}$ while $p_{0 o}$ is the reference pressure of $1000 \mathrm{mb}$. With an integration of (10) from the earth's surface to some arbitrary isentropic level 9 , the Montgomery stream function is

$$
\psi_{T !}=\psi_{T n}\left(\theta_{s}\right)+\int_{\theta_{S}}^{\theta} c_{p}\left(\stackrel{p}{p_{0 O}}\right)^{\kappa} d \theta .
$$

The horizontal gradient of the Montgomery stream function is given by

$$
\nabla_{g} \psi_{m}=\nabla_{g} \psi_{n,}\left(\theta_{s}\right)+\nabla_{\theta} \int_{\sigma_{S}}^{\theta} c_{p}\left(\underset{p_{0 O}}{p}(--)^{\kappa} d \theta .\right.
$$

A local differentiation of (12) with respect to time along with several substitutions (see Uccellini and Johnson, 1979) yields an expanded form for the isallobaric wind 


$$
u_{a g_{i s}}=-f^{-2} R\left\{\nabla_{\theta}\left(-\frac{T_{s}}{p_{s}} \frac{\partial p_{s}}{\partial t}\right)+\nabla_{\theta} \int_{\theta_{s}}^{\theta} \underset{p_{00}}{(--)^{k}} \frac{1}{p} \frac{\partial p}{\partial t_{\theta}} d \theta\right\}
$$

A

B

In (13) $T_{s}$ and $p_{s}$ are temperature and pressure at the earth's surface. From its defining relation, the first term $A$ is uniquely related to the local derivative of the surface geostrophic wind while the second term $B$ is uniquely related to the local derivative of the thermal wind. In the form of $(13)$, surface geostrophic and thermal wind components of the isallobaric wind are now expressed in terms of the gradient of the surface pressure tendency (term A) and an indefinite integral of a pressure-weighted pressure tendency (term B) (Uccellini and Johnson, 1979). The first term $A$ is deternined by the vertically-integrated mass flux divergence while the second term $B$ is associated with an internal redistribution of mass through the time derivative of the gradient of the thickness field. The relationship of these processes to the local derivative of the defining geostrophic and thermal wind relations (12) and (13) should be kept in mind.

Individual modes for adiabatic and diabatic mass transport in the forcing of the isallobaric wind are linked through the local pressure tendencies in terms $A$ and $B$ of (13). An indefinite vertical integration of the mass continuity equation (1) from the highest isentropic boundary ${ }^{\theta} \mathrm{T}(385 \mathrm{~K})$ downward to the arbitrary level $\theta$ results in an expression for the local pressure tendency 


$$
\frac{\partial p}{\partial \bar{t}_{\theta}}=\frac{\partial p}{\partial \bar{t}_{\theta}}\left({ }^{\theta} T\right)-g \int_{\theta}^{\vartheta}\left[\nabla_{\theta} \cdot(\rho J U)+\frac{\partial}{\partial \theta} \underset{A}{-(\rho J--)] d t} d \theta\right. \text {. }
$$

Through (14), the tendency of pressure is related to the pressure change at the top of the layer and to adiabatic (term A) and diabatic (term B) forms of mass flux divergence within the layer. The adiabatic and diabatic components of the total pressure tendency are arbitrarily expressed by

$$
\left(\frac{\partial \underline{p}}{\partial t_{\theta}}\right)_{a}=\left[\frac{\partial \underline{p}}{\partial t_{\theta}}\left({ }^{\theta} T\right)\right]_{a}-g \int_{\theta}^{\theta^{T}} \nabla_{\theta} \cdot(\rho \underset{\sim}{U}) d \theta,
$$

and

$$
\begin{aligned}
\left(\frac{\partial p}{\partial t_{\theta}}\right)_{d} & =\left[\frac{\partial p}{\partial t_{\theta}}\left({ }^{\theta} T\right)\right]_{d}-g \int_{\theta}^{\theta} \frac{\partial}{\partial \theta}\left(\rho j-\frac{d \theta}{d t}\right) d \theta \\
& =\left[\frac{\partial p}{\partial t}\left({ }_{\theta} T\right)\right]_{d}-\left.g r \frac{\rho j}{d t}\right|_{\theta} ^{\theta} T
\end{aligned}
$$

respectively, where the subscripts a and $d$ indicate adiabatic and diabatic components of pressure tendency. The adiabatic component of the total pressure tendency is linked to the vertically-integrated horizontal mass flux divergence in the atmospheric column while the diabatic pressure tendency component is associated with the vertically-integrated vertical mass flux divergence.

With the boundary conditions that the local pressure tendency and the vertical mass flux vanish at the top of the atmosphere and the as- 
sumption that the vertical mass flux is zero at $385 \mathrm{~K}$, the diabatic component of the pressure tendency is zero at $385 \mathrm{~K}$. Thus, the vertical integration of the adiabatic pressure tendency (15) at the level $385 \mathrm{~K}$ must be equal to the vertically-integrated horizontal mass flux divergence from the atmosphere's top down to the $385 \mathrm{~K}$ surface. With the partitioning of the isentropic pressure tendency into adiabatic and diabatic components, the total isallobaric ageostrophic notion correspondingly divides into adiabatic and diabatic counterparts given by

$$
U_{\sim} g_{i s}=\left(U_{a} g_{i s}\right)_{a}+\left(U_{a} g_{i s}\right)_{d} \text {, }
$$

where the respective components are

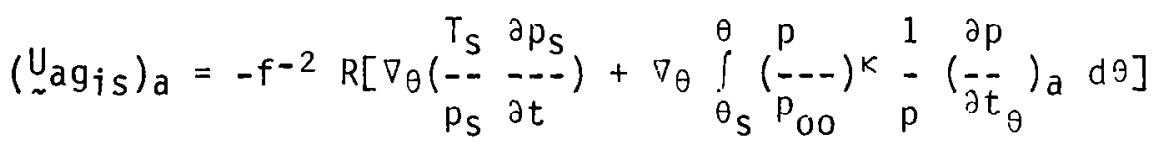

$$
\begin{aligned}
& =-f-2 R\left\{\nabla_{\theta}\left(\frac{T_{S}}{P_{S}} \frac{\partial p_{S}}{\partial t}\right)+\nabla_{\theta} \int_{\theta_{S}}^{\theta}\left(\frac{p}{p_{O O}}\right)^{k} \frac{1}{p}\left[\frac{\partial p}{\partial t_{\theta}}\left({ }^{\theta} T\right)\right.\right. \\
& \left.\left.\left.-g \int_{\theta}^{\theta} \nabla_{\theta} \cdot(\rho) \underset{\sim}{U}\right) d \theta\right] d \theta\right\}
\end{aligned}
$$

and

$$
\begin{aligned}
& \left.\left(U_{a g_{i s}}\right)_{d}=-f^{-2} R\left[\nabla_{\theta} \int_{\theta s}^{\theta} \underset{p_{o O}}{(---)^{k}} \frac{1}{p} \frac{\partial p}{\partial t_{\theta}}\right)_{d} d \theta\right] . \\
& =-f^{-2} g R\left[\nabla_{\theta} \int_{0}^{\theta}\left(\frac{p}{p_{0 O}}\right) \times \frac{1}{p} \rho j \frac{d \theta}{d t} d \theta\right]
\end{aligned}
$$




$$
\begin{aligned}
& =\frac{c_{p}}{f^{2}\left(p_{o o}\right)^{\kappa}} \nabla_{\theta} \int_{\theta_{s}}^{\theta} \frac{\partial p^{\kappa}}{\partial \theta} \frac{d \theta}{d t} d \theta \\
& =-\frac{k g}{f^{2}} \nabla_{\theta} \int_{\theta s}^{\theta} \rho J\left(\frac{Q_{m}}{p}\right) d \theta,
\end{aligned}
$$

where $Q_{\mathfrak{m}}$ is the rate of heat addition per unit mass.

The form of the adiabatic isallobaric ageostrophic component reveals that the adiabatic component of the isallobaric wind is determined from the gradient of the tendency of the surface geostrophic wind, the gradient of the adiabatic pressure tendency at $385 \mathrm{~K}$ and the gradient of the horizontal mass flux divergence between the isentropic level of interest and the $385 \mathrm{~K}$ surface. Recall that the first term is the tendency of the surface geostrophic wind. Thus, in this decomposition, the surface pressure tendency term in (13) is defined to be part of the adiabatic component for consistency and for physical reasons. The physical and mathematical relations require that diabatic heating result only in the vertical redistribution of mass within the atmospheric column. Such a process does not alter the surface pressure tendency since it is determined by the net horizontal mass flux divergence throughout the entire vertical extent of the atmosphere. Note in the decomposition that the evaluation of (20) and (22) to determine the total isallobaric component at the earth's surface retains this feature and reflects the independence of this process from the effects of diabatic heating. 
The second term of (19), the indefinite integral extending from the earth's surface to the level of interest, shows when expanded in (20) that the adiabatic tendency of the thermal wind component is determined through the gradient of the $10 \mathrm{cal}$ tendency of mass at $385 \mathrm{~K}$ and through the gradient of the horizontal mass flux divergence. Mass adjustment above $385 \mathrm{~K}$ changes the pressure distribution through the entire atmospheric column below $385 \mathrm{~K}$. The changing pressure distribution by this process is uniquely related to changes in the temperature within the atmospheric column from the earth's surface to the level of interest, the gradient of which is related to the changes of the thermal wind component. Likewise, the last term of (20) is the component of the thermal wind changes due to the gradient of the pressure tendency from the horizontal mass flux divergence within the layer over which the integral of the shear of the geostrophic wind is defined.

The contrast of the forms for the diabatic component of the isallobaric wind component in (21)-(24) reveals that its distribution is determined primarily by the gradient of heating within an atmospheric column weighted by the inverse of pressure. In general for a given gradient of the heat addition per unit mass, or for that matter, a given gradient of the vertical diabatic mass flux, the effect of heating in this ageostrophic component is enhanced at lower pressure. An offsetting factor is the condition that with the decrease of saturation mixing ratios with height, less heat is released with decreasing pressure. However, maximum latent heat release within deep convection with 
high equivalent potential temperatures is surprisingly high being above $600 \mathrm{mb}$. Thus, the effects of substantial release of latent heat at higher elevations and lower pressure in deep convection opens up the degree of freedom for this effect to be maximized in upper levels. It is also important to note that this diabatic component of the isallobaric wind will increase with height throughout the entire vertical extent of the diabatic heating within the atmosphere, which in deep convection must reach a maximum near the tropopause with occasional penetration into the stratosphere. 
3. Data source and synoptic events

a. AVE IV data set

In this case study of scale interaction between the MCC and its environment NASA's fourth Atmopsheric Variability Experiment (AVE IV) provided the primary data base. The purpose of the AVE program (Hill and Turner, 1977) is four-fold; 1) to evaluate the accuracy of satellite data in relation to mesoscale studies, 2) to investigate atmospheric variability on a smaller scale than can be detected through conventional twelve hour data, 3) to examine interrelationships of different atmospheric scales of motion with emphasis on severe weather development and 4) to provide information to improve numerical prediction models at the mesoscale. To date a total of seven AVE experiments and six AVE-SESAME studies have been conducted.

The primary advantage of the AVE IV data set over twelve hour conventional rawinsonde data is its higher three and six hour temporal resolution. Such data sets are necessary to capture meso-synoptic scale interactions over the several hour duration of a thunderstorm, squall line or convective complex event. In addition to its limitations for synoptic studies, information at twelve hour intervals fails to capture the degree of importance that thunderstorms and convective complexes play in modifying the synoptic scale flow field and cannot resolve the structure and dynamics of the severe weather event. An MCC could form, move through a region and dissipate in well under the twelve hour time interval of the standard RAOB data collection. 
The AVE IV experiment consists of soundings of the atmosphere taken at nine time periods: April 24 at 00Z, 06Z, 12Z, 15Z, $18 \mathrm{Z}$ and 21Z; and Apri1 25 at $00 Z, 06 Z$ and 12Z. The forty-two rawinsonde stations east of the Rocky Mountains which participated in the experiment are shown in Figure 4.

The AVE IV rawinsonde data is presented by Fucik and Turner (1975) in tabular form at $25 \mathrm{mb}$ intervals extending vertically from the surface to the $25 \mathrm{mb}$ level; surface data was provided by the National $\mathrm{Cli}$ matic Center. Wilson (1980) describes the methods of AVE IV data reduction and provides estimates of errors associated with the various parameters determined from the data.

For his AVE IV case study, Wilson utilized the Barnes (1973) objective analysis method to grid the data onto a conformal conic projection with a horizontal square grid increment of $158 \mathrm{~km}$ (see Figure 5). The Barnes method allows data from each rawinsonde station to influence grid points within a radius of three grid distances and employs four successive corrections to a first-guess field. A nine-point filter, applied to the analyzed fields, retains approximately $90 \%$ of the amplitudes of wavelengths of $1400 \mathrm{~km}$. Wilson's gridded isobaric analyses provided the information base that was vertically interpolated at each grid point into isentropic coordinates for the diagnostic study summarized in this study.

The AVE IV case was chosen for diagnostic studies in this investigation for three reasons; 1) no intense cyclone activity was present to 


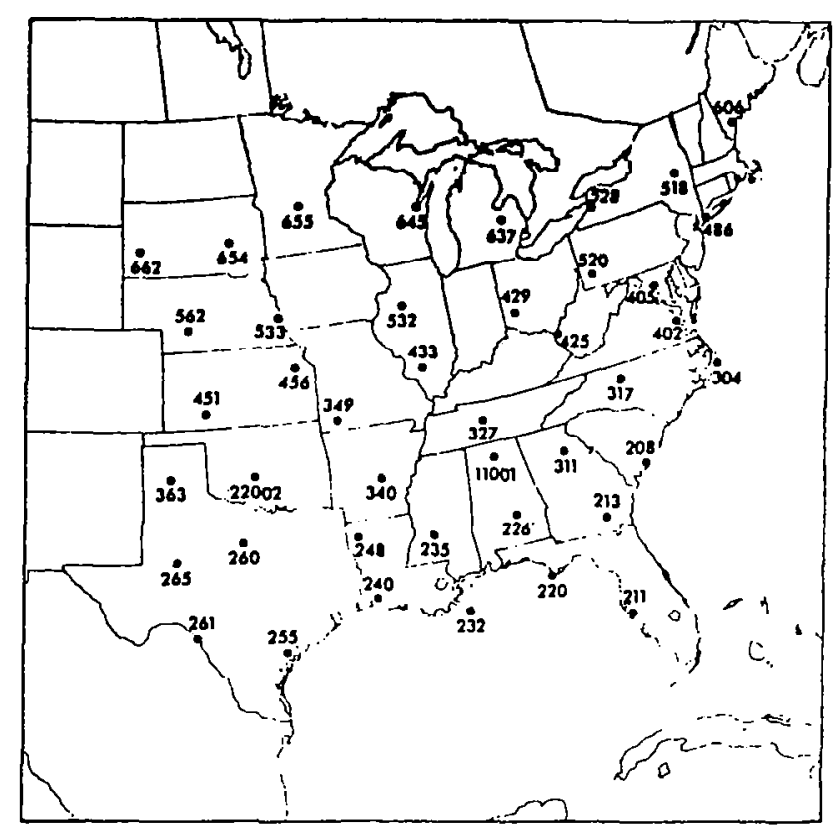

Figure 4: Rawinsonde stations participating in the AVE IV experiment.

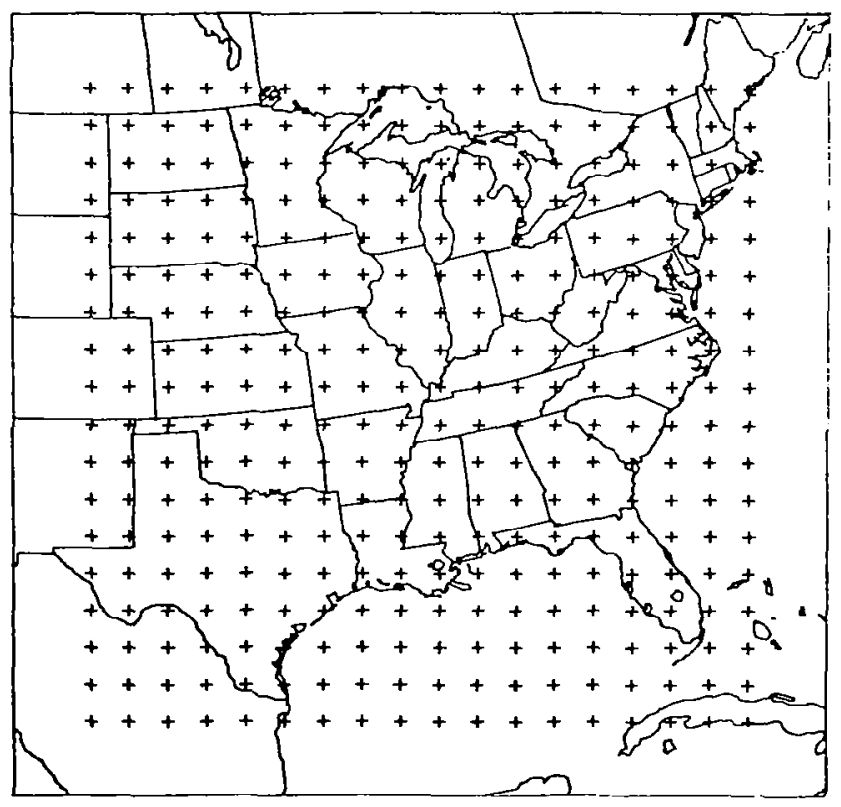

Figure 5: AVE IV grid network used in diagnostic studies. 
influence ageostrophic circulations, 2) the data had supposedly been carefully checked and only five stations were listed as having unusual or erroneous soundings (see Fucik and Turner, 1975) and 3) the appearance of two polar jet streaks, both of which intensified dramatically over a six hour time period, appeared to be directly linked to the strong convective activity and severe weather which occurred from $00 z$ 24 April to 12225 April. Unfortunately, some drawbacks are also apparent with this case. The most important problem is the limited area covered by the network. The three hour data does not extend into southeastern Canada where a fairly deep trough moves through at the end of the experiment as the jet streak over the northeastern United States intensifies so rapidly. An additional problem is that both the first and last three time periods were separated by intervals of six hours. A three hour interval would have provided more insight into the adjustment process associated with the intensifying jet streak over the northeast.

Theoretically, data with a high temporal resolution, such as the AVE IV information, should improve the accuracy in the diagnostic analyses of mesoscale processes in the atmosphere. However, problems can occur with an increase of the temporal resolution. Since data observations are discrete and undoubtedly contain bias and random errors, the variance of the smaller scale fields estimated from discrete information will increase unboundedly and result in spatially- and temporally-inconsistent mass and momentum fields unless the accuracy of 
the observations is increased accordingly. Such a problem was initially encountered in the research endeavor and was corrected only by ensuring that the AVE IV information display temporal and spatial integrity.

\section{b. Synoptic situation}

The severe weather outbreak for the AVE IV case occurred on 24-25 April 1975. During this time two separate MCCs moved through the AVE IV region spawning some 23 tornadoes or funnel clouds and producing heavy precipitation, strong winds and extensive hail. A composite map showing the location of severe weather activity is presented in Figure 6, while Table III identifies the severe weather events related to the AVE IV case.

Figures $7 \mathrm{a}-\mathrm{g}$ depict the surface low pressure regions and attending frontal systems in addition to radar-observed convection and squall line location over each six hour period from 00224 April to 12225 April. Figures $8 a-d$ show the isotach and Montgomery stream function fields on the $330 \mathrm{~K}$ isentropic surface at twelve hour time intervals from 00224 April to 12225 April. Wind speeds greater than $40 \mathrm{~m} \mathrm{~s}^{-1}$ are hatched in these figures and the radar-observed convection is also portrayed. Throughout this case study, the polar jet streak was found to be best represented on the $330 \mathrm{~K}$ isentropic surface. The two MCCs under investigation in this study are labelled $A$ and $B$ in both the surface and upper air figures.

At 00224 April, the initial time period of AVE IV, a quasistationary frontal zone extended southwest from a low pressure region 


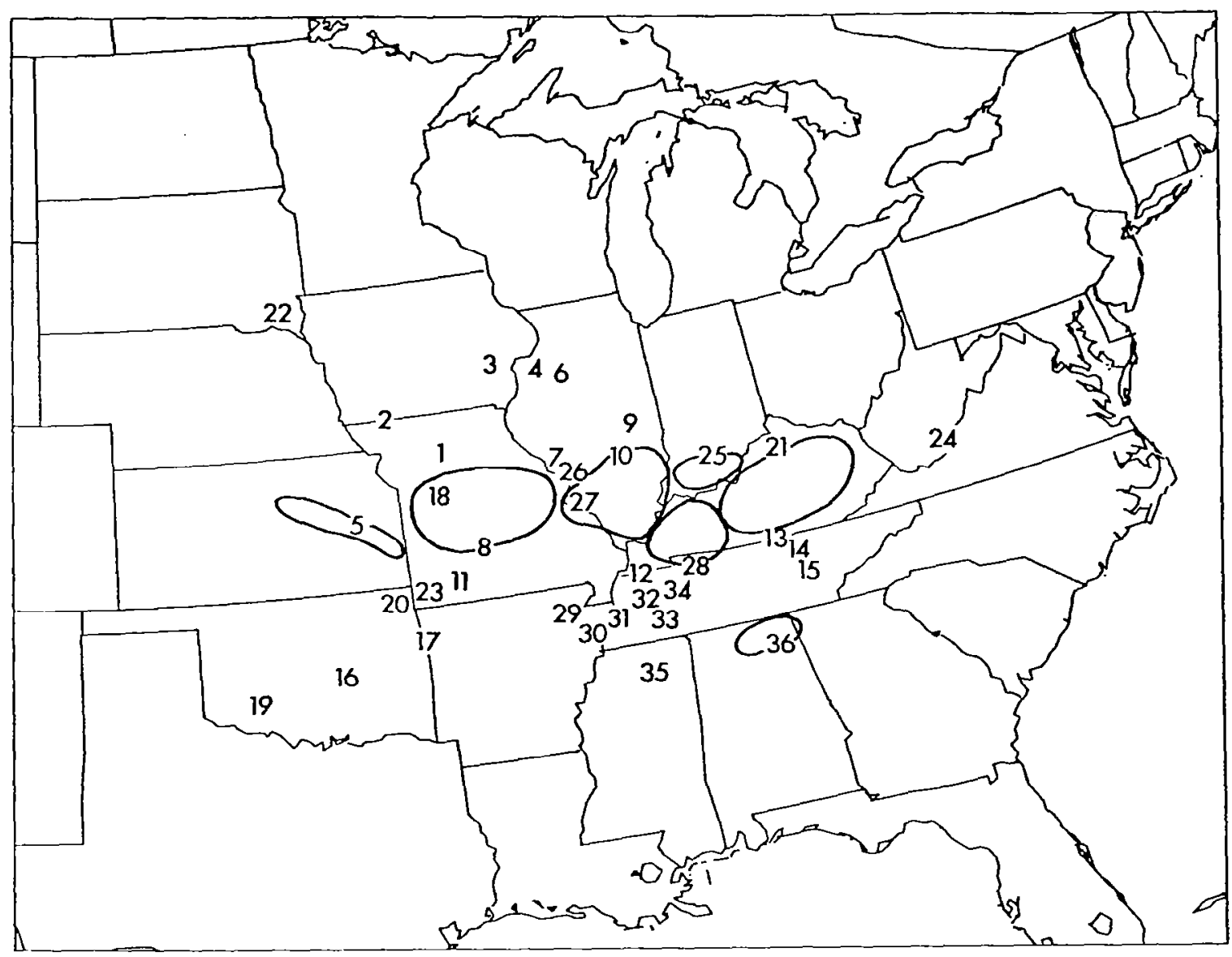

Figure 6: Locations of severe weather reports for 24-25 April 1975 (from Maddox, 1979). See Table II I for details. 
Table III

Severe Storm Reports

(Maddox, 1979)

\begin{tabular}{|c|c|c|c|c|}
\hline Eo. & Dare/T1Ee & (ar) & Event & Detalls \\
\hline 1 & $\begin{array}{l}23 / 2040 \\
24 / 0000\end{array}$ & to & $\begin{array}{l}\text { Torasdo, Ulnd, } \\
\text { and Buil }\end{array}$ & 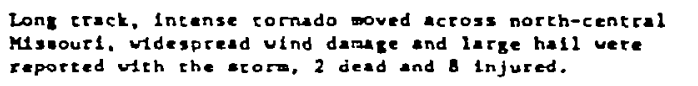 \\
\hline 2 & $23 / 2155$ & & Torando & Small torado viclnity Vew Market. Ious. \\
\hline $\mathbf{3}$ & $23 / 2230$ & & Torando & Sell comedo viclatey lowe Cley. Lowa. \\
\hline 4 & $23 / 2325$ & & Hall & Hati to $3 / 4^{n}$ at Orion. Illinols. \\
\hline $\mathbf{s}$ & $\begin{array}{l}26 / 0000 \\
24 / 0200\end{array}$ & to & Niod and Ral1 & 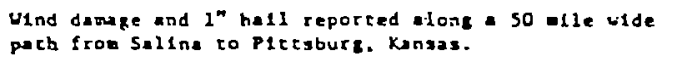 \\
\hline 6 & $24 / 0040$ & & vind & Wind demge dear oradford, ilitinots. \\
\hline 7 & 26/015s & & vind & Wiod susts to 60 oph at Jerseyulile. I11lnols. \\
\hline • & $\begin{array}{l}24 / 0200 \\
24 / 1000\end{array}$ & ro & $\operatorname{men}$ & 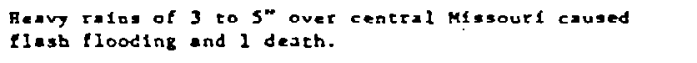 \\
\hline s & $24 / 0330$ & & wiad & Wiad dumge at Archur, IL11nots. \\
\hline 10 & $\begin{array}{l}24 / 0600 \\
24 / 1200\end{array}$ & to & Re10 & $\begin{array}{l}\text { Torrenclel rainof up to } 7 " \text { over southeast Illinols } \\
\text { crused flash flooding. }\end{array}$ \\
\hline $\mathbf{1 1}$ & $\begin{array}{l}24 / 1100 \\
24 / 1200\end{array}$ & to & Tornedo & Tho sell tomadoes repotted vicinity of six. Missourl. \\
\hline 12 & $24 / 2 \in 45$ & & Ioroedo & Sall tornado near Marein. Tennessee. \\
\hline 13 & $24 / 2000$ & & vind & Wlod dasege at Lafayetre. Tennesser. \\
\hline 14 & $24 / 2000$ & & Wiad & Ulad darage at Red Bolling Springs. Tennessee. \\
\hline is & $24 / 2230$ & & Tornedo & $\begin{array}{l}\text { Moderte comedo vilinity of crossville. Tennessec, } \\
1 \text { killed and } 4 \text { injured in noblle homes. }\end{array}$ \\
\hline 16 & $24 / 2315$ & & Fe11 & $\begin{array}{l}\text { Qull as large as bateballs reported in anc near } \\
\text { Wewolu. Oklahoms. }\end{array}$ \\
\hline 17 & $24 / 2325$ & & Ba11 & Ball demge at Sc1lluell, Oklahous. \\
\hline 18 & $25 / 0000$ & & $\ln 11$ & $\begin{array}{l}\text { Hall as large as rolfballs reported in the vicinity of } \\
\text { Sedalia. Missourt. }\end{array}$ \\
\hline 19 & $25 / 0000$ & & B.11 & Hall to $1^{n}$ reported over Cotcon County, Oklahome. \\
\hline 20 & 2510000 & & Tornado & roderate cornado near Mlami, Oklahoma. 3 Injurtes. \\
\hline 21 & $\begin{array}{l}25 / 0000 \\
25 / 0700\end{array}$ & ro & Reto & 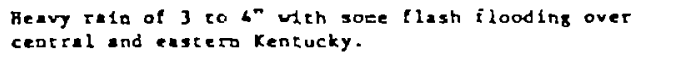 \\
\hline 22 & $25 / 0030$ & & $\mathrm{~B}=11$ & $\begin{array}{l}\text { Ball a latge as golfballs reported frow Freedan to } \\
\text { Devis, South Dakoca. }\end{array}$ \\
\hline 23 & $\begin{array}{l}23 / 0040 \\
25 / 0110\end{array}$ & ro & Tornado & $\begin{array}{l}\text { Intense tornado etruck Senecs and then seosho. Migsourl } \\
\text { with } 3 \text { deaths and } 22 \text { injuries. }\end{array}$ \\
\hline 24 & $25 / 0045$ & & Tornado & $\begin{array}{l}\text { Sandi ec thedo reported vicinity of leviaburg, thest } \\
\text { virginla. }\end{array}$ \\
\hline 23 & $\begin{array}{l}2510200 \\
25 / 0700\end{array}$ & co & $\ln 20$ & $\begin{array}{l}\text { Hest refine co } 3 \text { " and llach flooding over extrede } \\
\text { gouchern Indina. }\end{array}$ \\
\hline 26 & $\begin{array}{l}25 / 0200 \\
23 / 0300\end{array}$ & to & Fa1] and WInd & 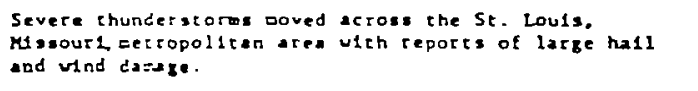 \\
\hline 27 & $25 / 0400$ & & Wind & Wind darage reported at Sparta, Il11nols. \\
\hline 22 & $\begin{array}{l}23 / 0400 \\
25 / 0700\end{array}$ & co & Wlad & $\begin{array}{l}\text { Numerouk teports of wind darage over destern and south- } \\
\text { central kentucky. }\end{array}$ \\
\hline 29 & $23 / 0620$ & & wiad & U1nd dearge reported in Cralghead Councy, Arkansas. \\
\hline 30 & $23 / 0665$ & & Ternado & Smil tornado at Tutrell, Arkansas. \\
\hline $\mathbf{3 1}$ & $25 / 0700$ & & Tornado & 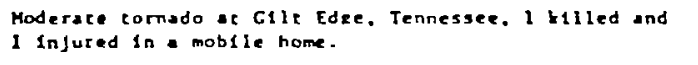 \\
\hline 32 & $25 / 0720$ & & Tormedo & $\begin{array}{l}\text { Moderace cornado reported vicintigy of haty Cley. } \\
\text { Tennessee. } 6 \text { injured in moblle homeg. }\end{array}$ \\
\hline 33 & $25 / 0740$ & & Yind & Vind dewge ar Murboldx. Tennessee with 1 ingury. \\
\hline $\mathbf{3 6}$ & 2510800 & & Uind & $\begin{array}{l}\text { Wind danage as Huntingdon. Tennessee. S injured in mo- } \\
\text { bile howes. }\end{array}$ \\
\hline נ9 & $25 / 1030$ & & vind & Wind demege reported et Uorer Voliag. Mussingippl. \\
\hline 36 & $\begin{array}{l}25 / 1130 \\
25 / 1300\end{array}$ & to & wind & 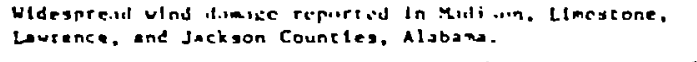 \\
\hline
\end{tabular}



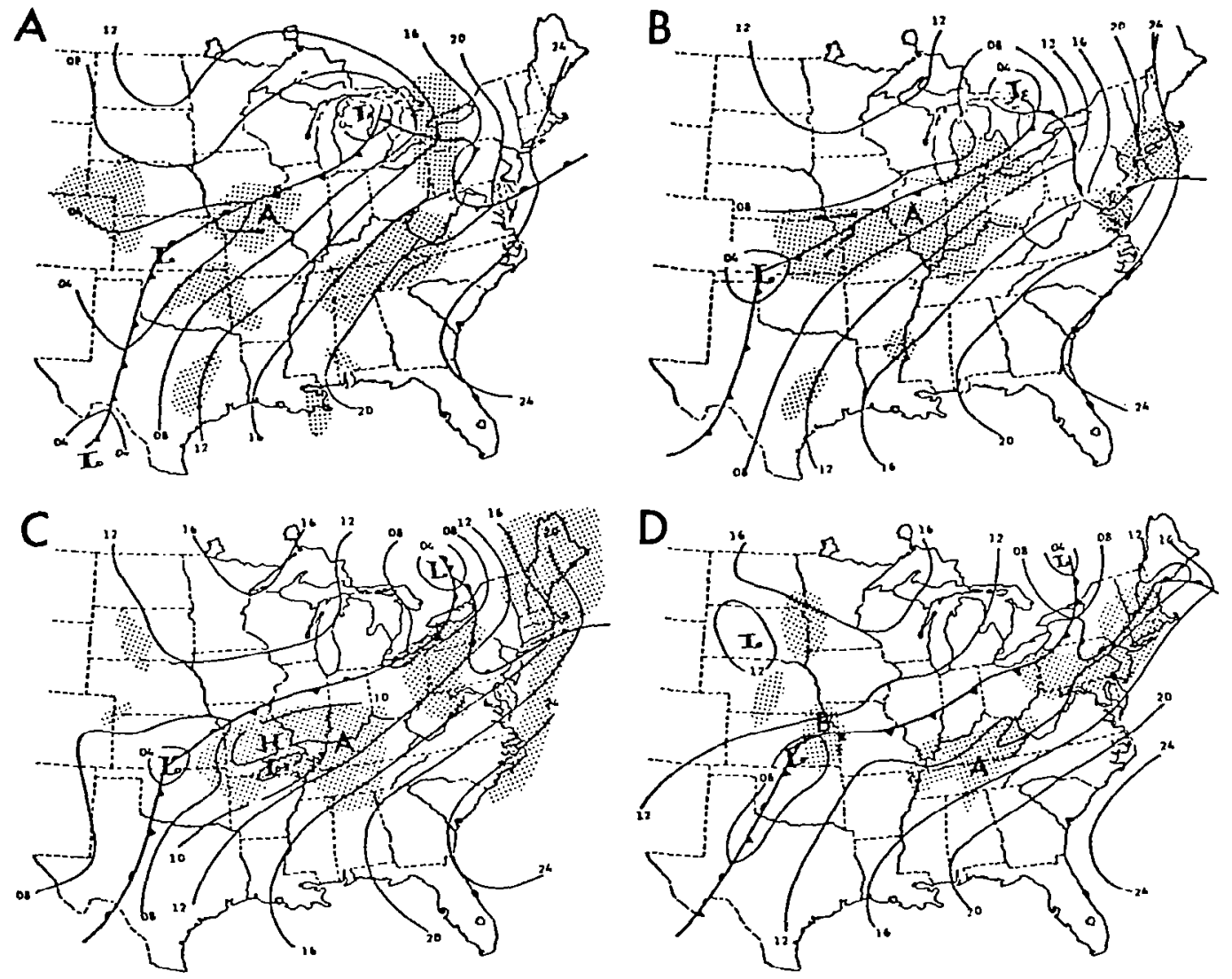

Figure 7: Surface synoptic analyses (from Fucik and Turner, 1975) for (a) $00 Z 24$ April 1975, (b) $06 Z 24$ April 1975, (c) $12 Z 24$ Apri1 1975, (d) $18 Z 24$ April 1975, (e) $00 Z 25$ Apri1 1975, (f) $06 Z 25$ April 1975 and (g) 12225 April 1975. Radar-observed convection is stippled and squall lines are indicated. A and B denote MCCs under study. 

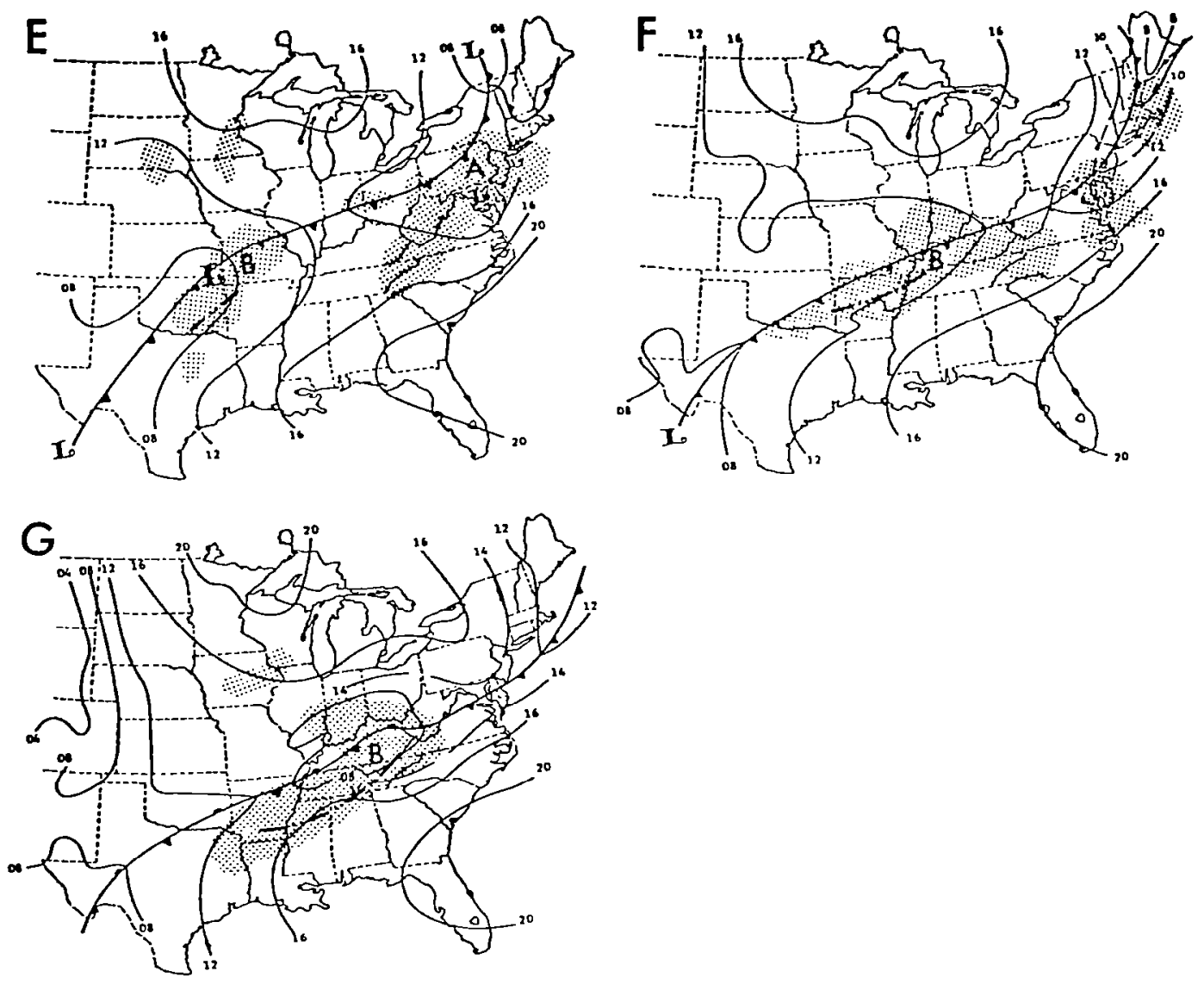

Figure 7 (continued) 
centered over northern Michigan to another low pressure center over Kansas. The sharp temperature contrast across this front played a role in the larger scale dynamical adjustment through which the severe weather activity developed. The surface synoptic picture remained relatively stationary throughout the AVE IV experiment, however the northern portion of the cold front did gradually move southeastward in conjunction with the northeastward movement of the low pressure center over Canada. The low pressure wave over Kansas began to intensify during the first six hours of the experiment but exhibited little change in position. After 12224 April, this low pressure wave weakened and inoved northeastward along the cold front. Throughout the AVE IV experiment the polar front was linked with a band of strong winds aloft, which are clearly distinguishable on the $330 \mathrm{~K}$ isentropic surface. The strong winds along with a hyperbaroclinic zone beneath extended northeastward from Kansas through Michigan and New York to Maine.

During the first twenty-four hours of the AVE IV experiment, the upper level flow field remained basically zonal over the AVE IV region. Several short waves moved through this area, as evidenced by the $330 \mathrm{~K}$ flow pattern. One short wave at 00224 April over Wisconsin and Iowa was associated with a rapidly developing convective region over Missouri and Iowa in advance of the frontal zone. This region of convection, which contained strong winds, hail, tornadoes, and very intense thunderstorms embedded in a squall line, is labelled $A$ in the synoptic 

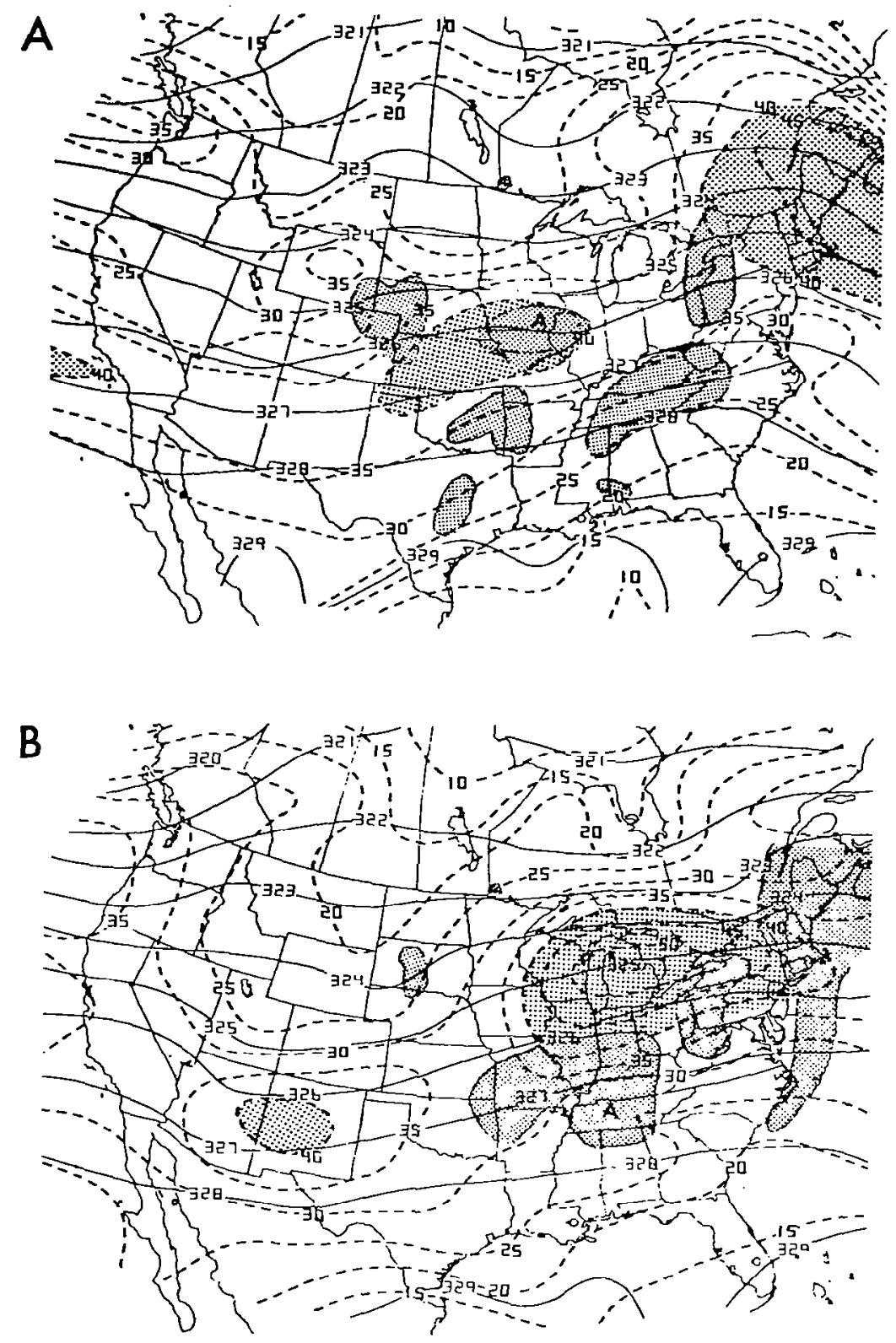

Figure 8: Observed wind isotachs (dashed, $\mathrm{m} \mathrm{s}^{-1}$ ) and Montgomery stream function field ( $\mathrm{solid}, \times 10^{3} \mathrm{~m}^{2} \mathrm{~s}^{-2}$ ) on $330 \mathrm{~K}$ isentropic surface for (a) $00 Z 24$ April 1975, (b) 12224 April 1975, (c) $00 Z 25$ April 1975 and (d) $12 Z 25$ Aprii 1975. Radar-observed convection and observed wind speeds greater than $40 \mathrm{~m} \mathrm{~s}^{-1}$ are stippled. A and B denote MCCs under study. 

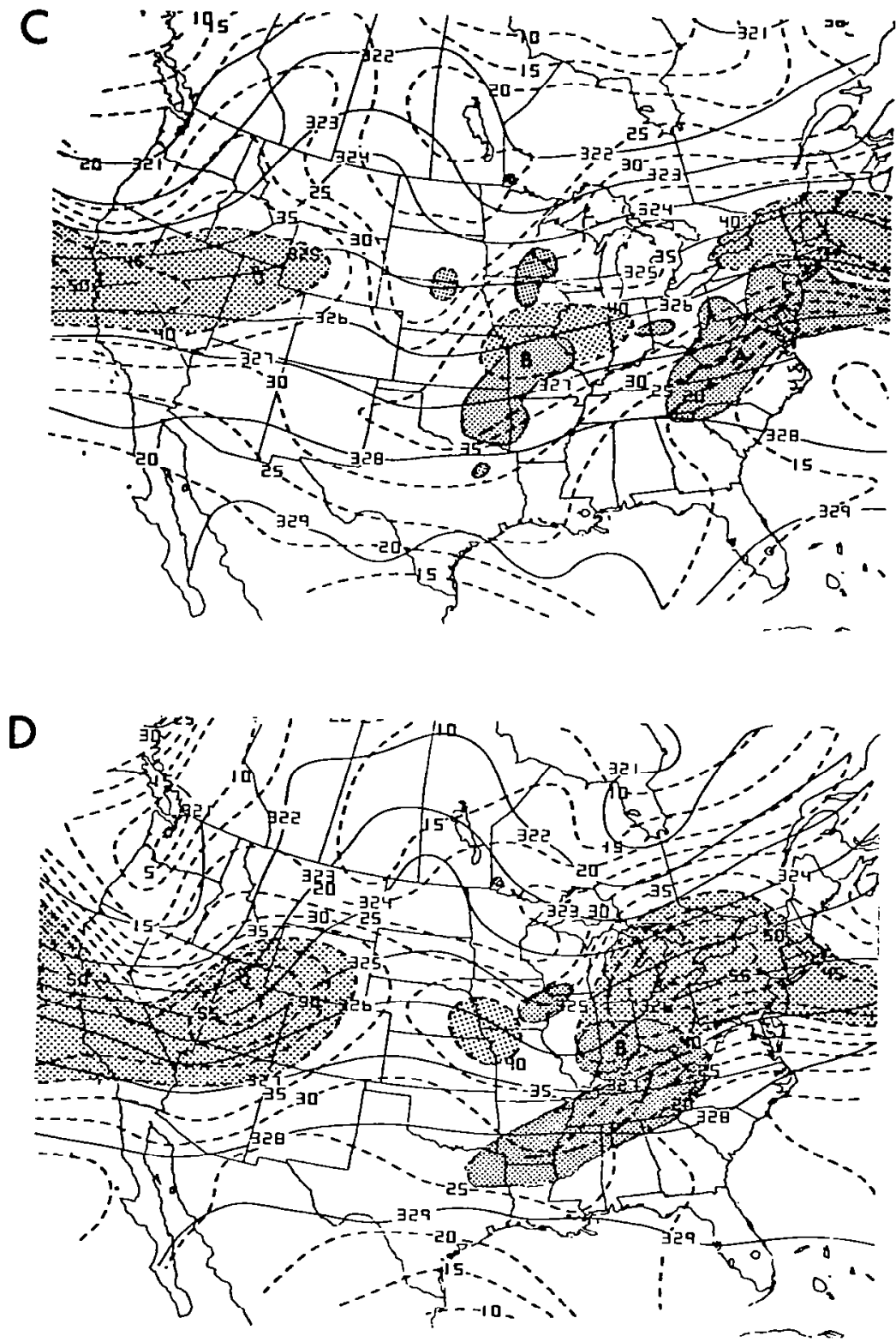

Figure 8 (continued) 
figures. The convection was located in the entrance region of a poorly defined upper tropospheric jet streak with winds exceeding $40 \mathrm{~m} \mathrm{~s}^{-1}$ in its extension from Kansas to Illinois.

Convective region $A$ developed into an MCC during its eastward movement and increased both in areal extent and in intensity during the tweive hour interval from 002 to 12224 April. The MCC grew most rapidly during the first six hours of this time interval, during which time it produced heavy amounts of precipitation over Missouri and southern Illinois. The Neosho, Missouri tornado evolved from this MCC and was responsible for three fatalities. The structure of the upper tropospheric jet streak was also significantly altered over this twelve hour period from $00 Z$ to 12224 April. During the jet streak's eastward movement, increases occurred both in wind speeds within the core (from $40 \mathrm{~m} \mathrm{~s}^{-1}$ to $50 \mathrm{~m} \mathrm{~s}^{-1}$ ) and in the variation in along-stream horizontal wind speed in the entrance and exit regions. This sudden intensification of the jet streak is impressive by the fact that most of the change occurred over the first six hours of this time interval (the $330 \mathrm{~K}$ figure for $06 \mathrm{Z} 24$ April is not shown). Throughout most of this time period, the large MCC was located on the anticyclonic side of the entrance region of the jet streak.

The rapid development of MCC A from $00 Z$ to $06 Z 24$ Apri1 is best depicted in the infrared satellite images for the eastern half of the United States (Figures 9a-e). From 002 to $04 z$ the cirrus shield above the MCC grew rapidly eastward with an increase in the size of the con- 

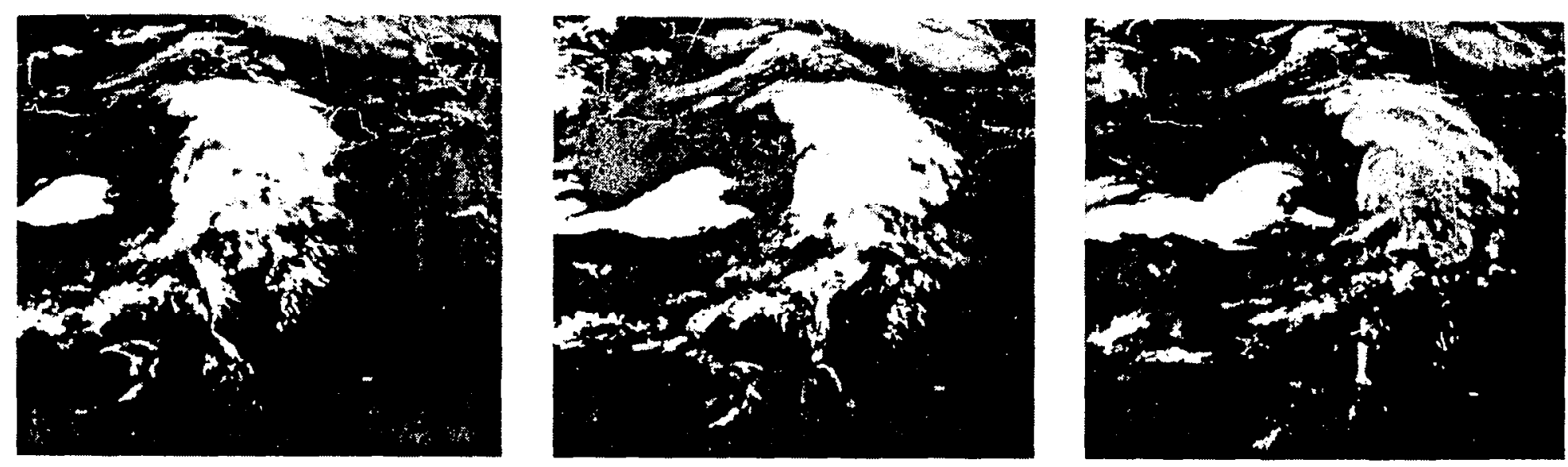

Figure 9: Infrared satellite images over eastern half of U.S. for (a) 00224 April 1975, (b) 02224 April 1975, (c) 04224 April 1975, (d) 06224 April 1975 and (e) 10224 April 1975. 

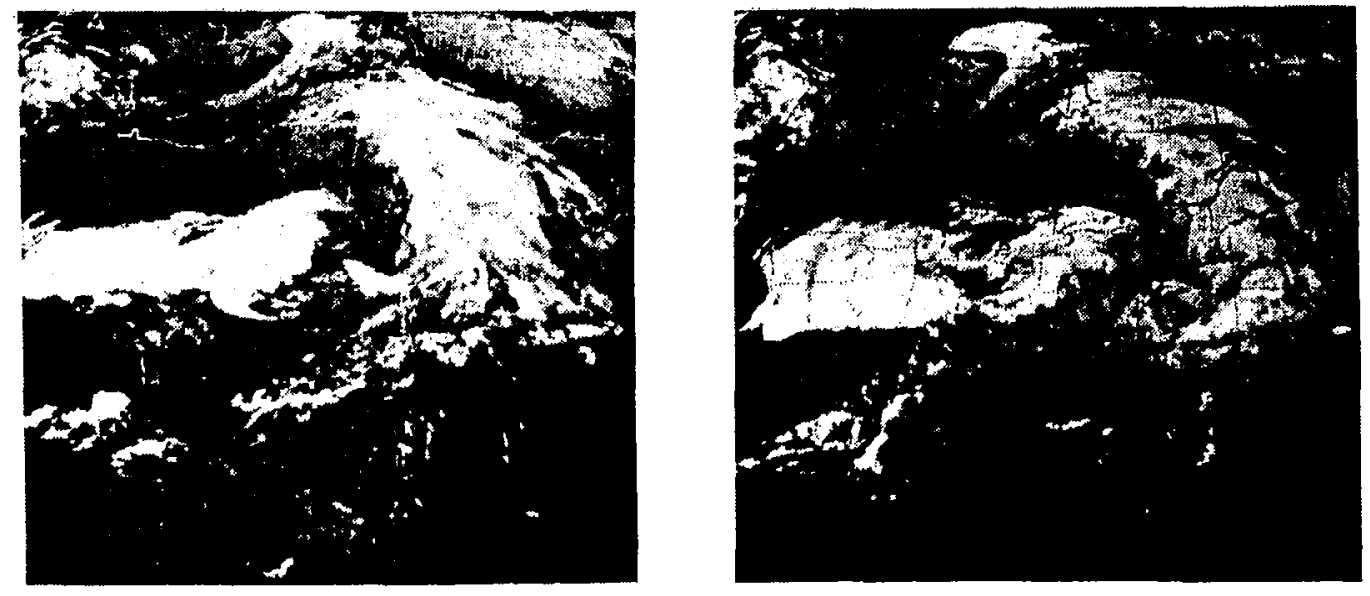

Figure 9 (cont inued) 
vective region. The orientation and areal extent of the cirrus shield changed very little from 062 to 102 , however some northward and eastward movernent occurred. By $10 Z$ the intensity of MCC A appeared to have decreased as evidenced by the darker color of the clouds in the 102 satellite picture.

The jet streak continued to move east from 122 to 002 24-25 April while the MCC, which intensified due to daytime heating, remained to the southwest of the core of maximum winds. A squall line redeveloped in the MCC at this time and caused heavy precipitation, tornadoes and severe thunderstorms to break out over West Virginia, eastern Kentucky and Tennessee. An upper air short wave moved through the Great Plains during this time period and generated a new region of convective activity over eastern Kansas by $18 Z 24$ Apri1. This second convective region, which eventually developed into an MCC, is labelled $B$ in the synoptic figures. Also at this time a new jet streak, with winds greater than $40 \mathrm{~m} \mathrm{~s}^{-1}$, entered the AVE IV region over Kansas. By 00225 April the convection over Kansas developed into an MCC which was centered over Missouri and eastern Oklahoma. Hail, strong winds and heavy precipitation occurred throughout the region of the MCC. In addition, a squall line extending from northwestern Arkansas to south-central Oklahoma produced tornadoes in Oklahoma and Missouri. As was the case with the earlier MCC, the convective complex remained southwest of the polar jet core and moved eastward with the jet streak.

Over the twelve hour period from $00 Z$ to 12225 April, the MCC grew both in areal extent and in intensity with a squall line occurring 
within the convective system at the middle of this time period. The squall line extended from western Tennessee to west-central Arkansas. As with the case of the first MCC to move through the region, most of the development in the MCC occurred over the first six hours of this time interval. Several tornadoes were produced in the vicinity of the squall line in addition to heavy precipitation in the Ohio River val1ey. Intensification of the polar jet streak over this twelve hour period was evident with its eastward movement from central Illinois to the eastern Great Lakes region. The short wave supporting the jet streak moved into a long wave trough located over Hudson Bay. Maximum winds within the core increased from $40 \mathrm{~m} \mathrm{~s}^{-1}$ to $55 \mathrm{~m} \mathrm{~s}^{-1}$; in addition, the along-stream variation in horizontal wind speed increased in the entrance and exit regions of the jet streak. The strengthening of the jet streak, which occurred primarily from $00 Z$ to $06 Z 25$ Apri1, appeared to coincide with the explosive development of convective activity to its southwest--an event quite similar to the jet streak-MCC interaction twenty-four hours previous (the $330 \mathrm{~K}$ figure for $06 \mathrm{Z} 25$ April is not shown).

Figures 10a-e are infrared satel1ite images over the eastern United States covering $00 Z$ to 10225 April. By OOZ MCC A had weakened considerably and moved eastward to a position over the middle Atlantic states. Individual thunderstorm cells over Illinois, Missouri and Arkansas at $00 Z$ merged into MCC B by $02 Z$. During the period $02 Z$ to $06 Z$ MCC $B$ continued to grow in size and intensify as indicated in the 

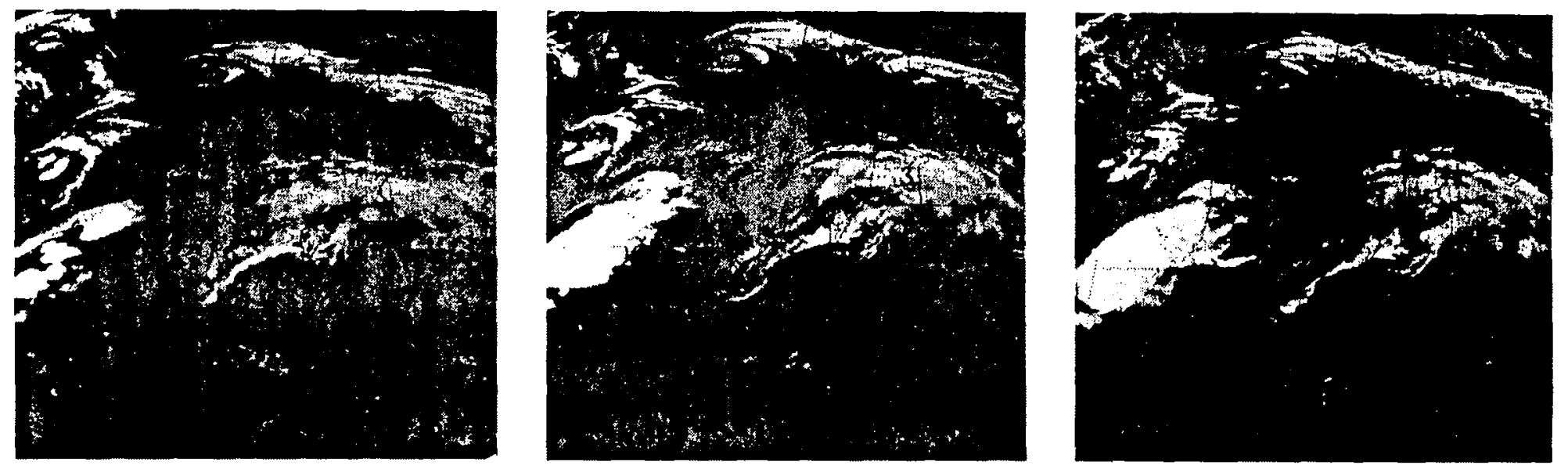

Figure 10: Infrared satellite images over eastern half of U.S. for (a) 00225 April 1975, (b) $02225 \mathrm{April} 1975$, (c) 04225 April 1975, (d) 06225 April 1975 and (e) $10 Z 25$ April 1975. 

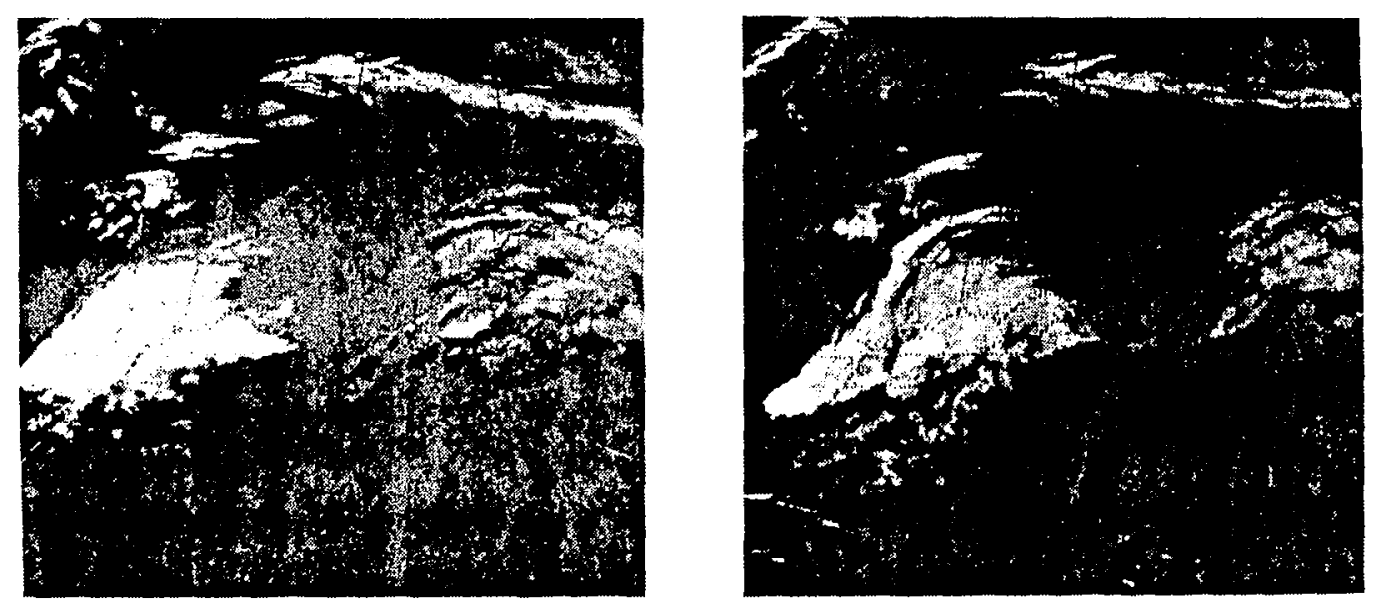

Figure 10 (continued) 
satellite pictures. By $10 Z$ the system slowly moved eastward and weakened.

The distribution of precipitation for the period from 06223 April to 06225 April, presented in Figure 11, shows rainfall exceeding one inch from Missouri to Ohio. Rainfall exceeding three inches occurred in a band from Kansas City, Missouri to Louisville, Kentucky; over four inches of precipitation fell near Kansas City during this forty-eight hour period. These rainfall amounts reflect the intensity and the large areal extent of the two MCCs which moved through this area. The large precipitation amounts are also indicative of the strong diabatic latent heating which must have occurred within the convective complexes. 


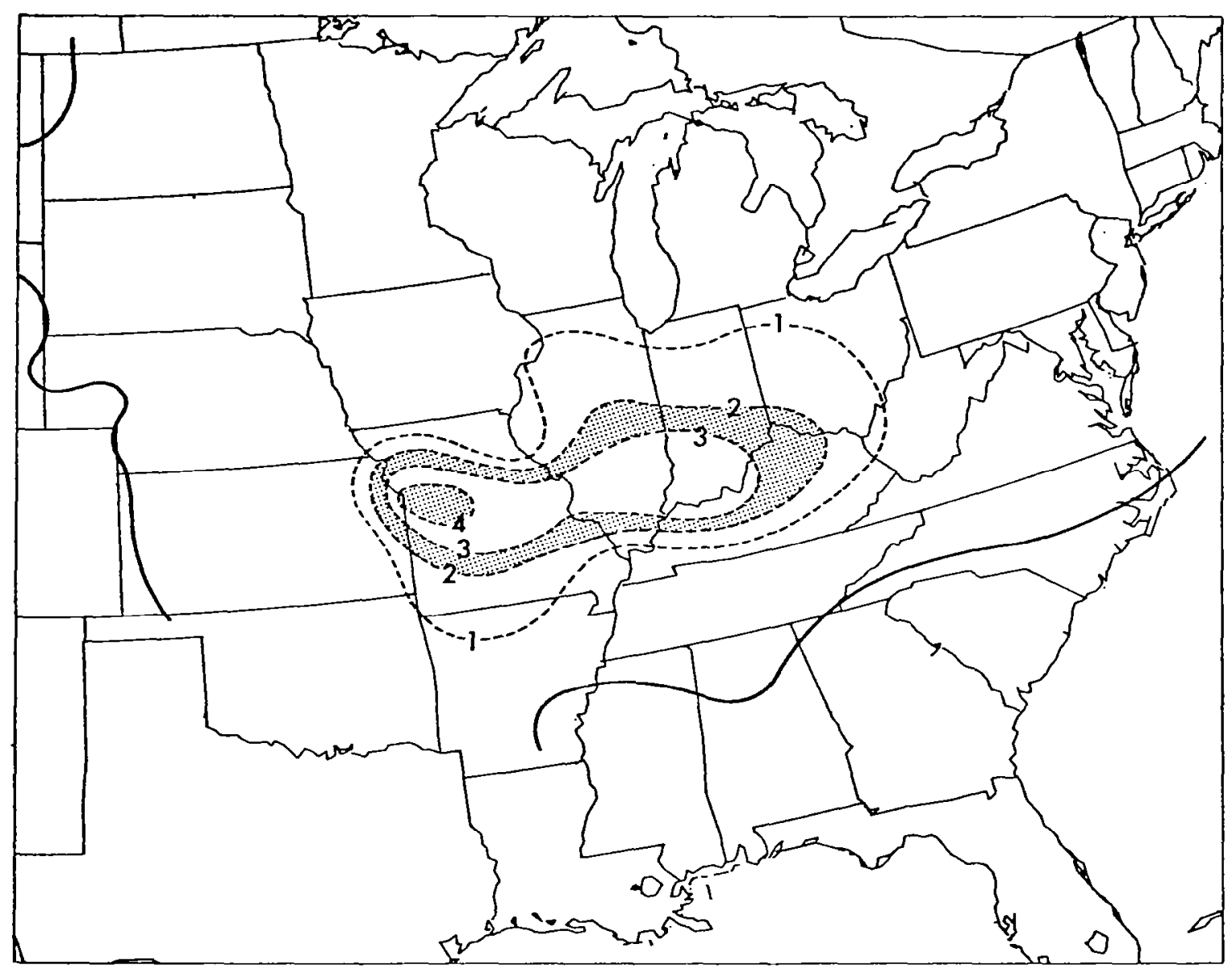

Figure 11: Precipitation totals (inches) for 06Z 23 April 1975 to $06 Z 25$ April 1975 (from Daily Weather Maps, U.S. Dept. of Commerce). 


\section{Results of diagnostic analyses}

In this chapter, two cases of jet streak-MCC interaction for AVE IV are studied in order to examine the dynamical processes involved in linking these two scales of motion. The diagnostic emphasis is focused on ascertaining the balance of the ageostrophic motion and the isentropic mass circulation within the MCC and the entrance region of the upper tropospheric jet streak.

Diagnostics of the isentropic mass circulation are first examined to determine the distributions of the mass tendency, the horizontal mass flux divergence and the diabatic heating determined from a vertical integration of the isentropic mass continuity equation (1). The structure of various components of ageostrophic motion are next examined and a relative comparison of their importance during the lifetime of the MCCS of the AVE IV data period is made. A key feature of the study is the determination of the inertial diabatic component of ageostrophic motion in the entrance region and the role of differential heating in forcing a diabatic component of the isallobaric ageostrophic motion. Next, diagnostics of ageostrophic motion defined through semigeostrophic theory are studied to determine the relative accuracy of this simplified form for ageostrophic motion. Finally, a physical explanation of the structure of diabatically-induced ageostrophic motion within the convective complex is presented. The results establish in a more direct way the mechanisms which intensify the direct circulation in the entrance region of the jet streak and generate kinetic energy that ultimately strengthens winds in the jet streak downstream. 
a. Jet streak-MCC interaction case of 002 to 062 24. April 1975

1) Structure of the isentropic mass circulation

The time-averaged horizontal mass flux divergence component of the isentropic mass continuity equation (1) is shown for the $330 \mathrm{~K}$ isentropic surface in Figure $12 \mathrm{a}$ and the $305 \mathrm{~K}$ surface in Figure 12b. The mesoscale mass circulation associated with MCC A is clearly depicted. Strong low level mass flux convergence into the MCC tends to be balanced by upper level divergence from the convective complex. Further evidence of the strong mass circulation within the MCC is displayed in the vertical profile of the time-areally-averaged horizontal mass flux divergence for MCC A (see Figure 13). The area average of horizontal mass flux divergence values within the MCC is calculated for the region of the twenty-six grid points outlined in Figure 12a. Note that mass inflow is maximized near $305 \mathrm{~K}$ while mass outflow is strongest in the $325 \mathrm{~K}$ to $330 \mathrm{~K}$ isentropic layer. This agrees well with the evidence that $305 \mathrm{~K}$ and $325 \mathrm{~K}$ are characteristic potential and equivalent potential temperatures within the low tropospheric region from which the convection originates. The oscillation in the profile between $310 \mathrm{~K}$ and $320 \mathrm{~K}$ may be due to truncation errors that occur in estimates of the mass divergence for smaller scale structure.

Average mass tendencies for the six hour time interval are represented in lower and upper layers of the atmosphere by Figures 14a and $14 \mathrm{~b}$ respectively. Within the MCC large positive changes in the surface to the $305 \mathrm{~K}$ layer are attributed to strong horizontal mass flux con- 

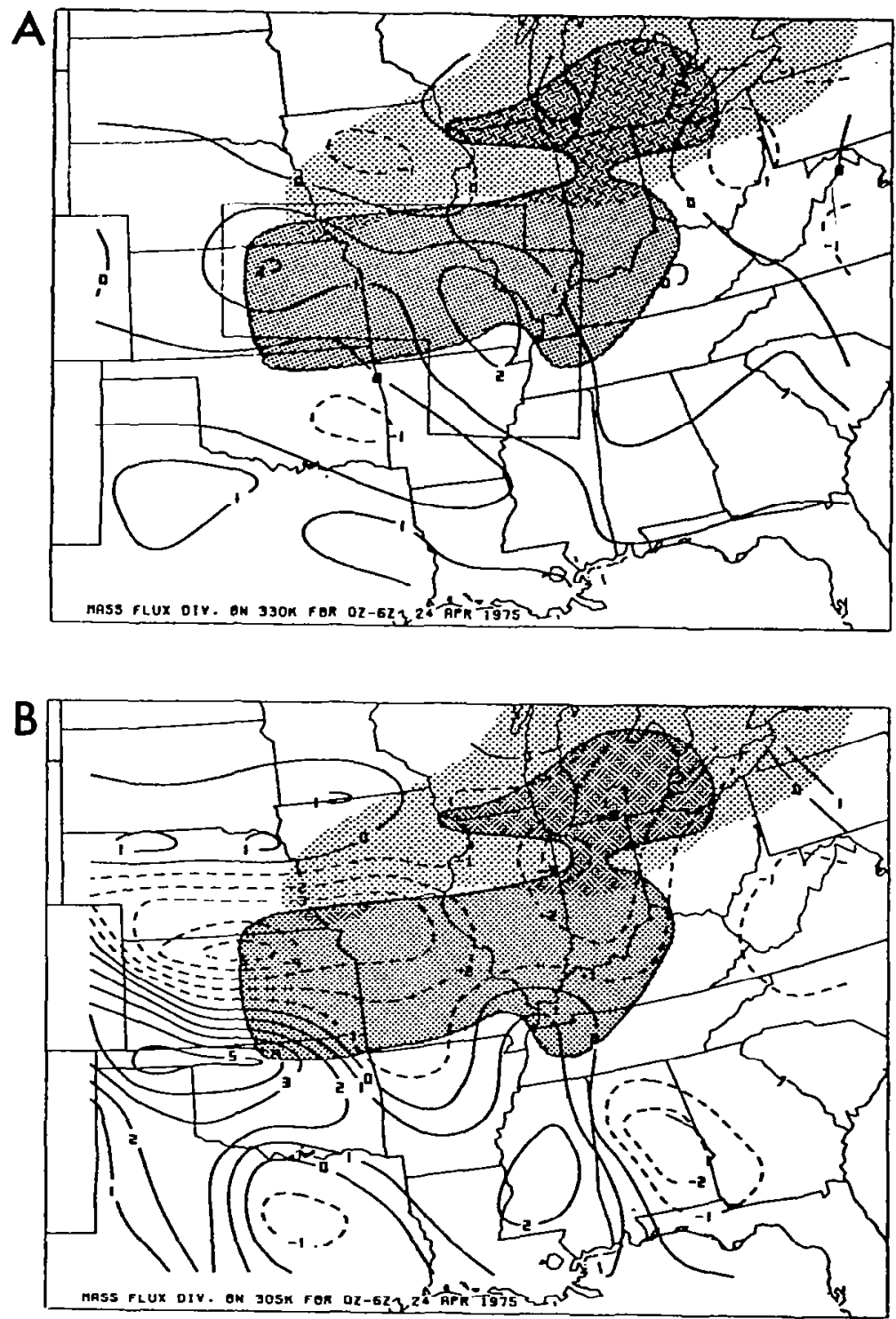

Figure 12: Time-averaged horizontal mass flux divergence for (a) $330 \mathrm{~K}$ isentropic surface and (b) $305 \mathrm{~K}$ isentropic surface (positivesolid, negative-dashed, $\times 10^{1} \mathrm{~g} \mathrm{~m}^{-2} \mathrm{~s}^{-1}$ ) computed for $00 \mathrm{z}$ to $06 \mathrm{Z} 24$ April 1975. Grid points used in areal averaging for Figure 13 are enclosed with solid line in (a). Mesoscale convective complex $A$ and observed wind speeds greater than $40 \mathrm{~m} \mathrm{~s}^{-1}$ on $330 \mathrm{~K}$ at 06224 April 1975 are stippled. 


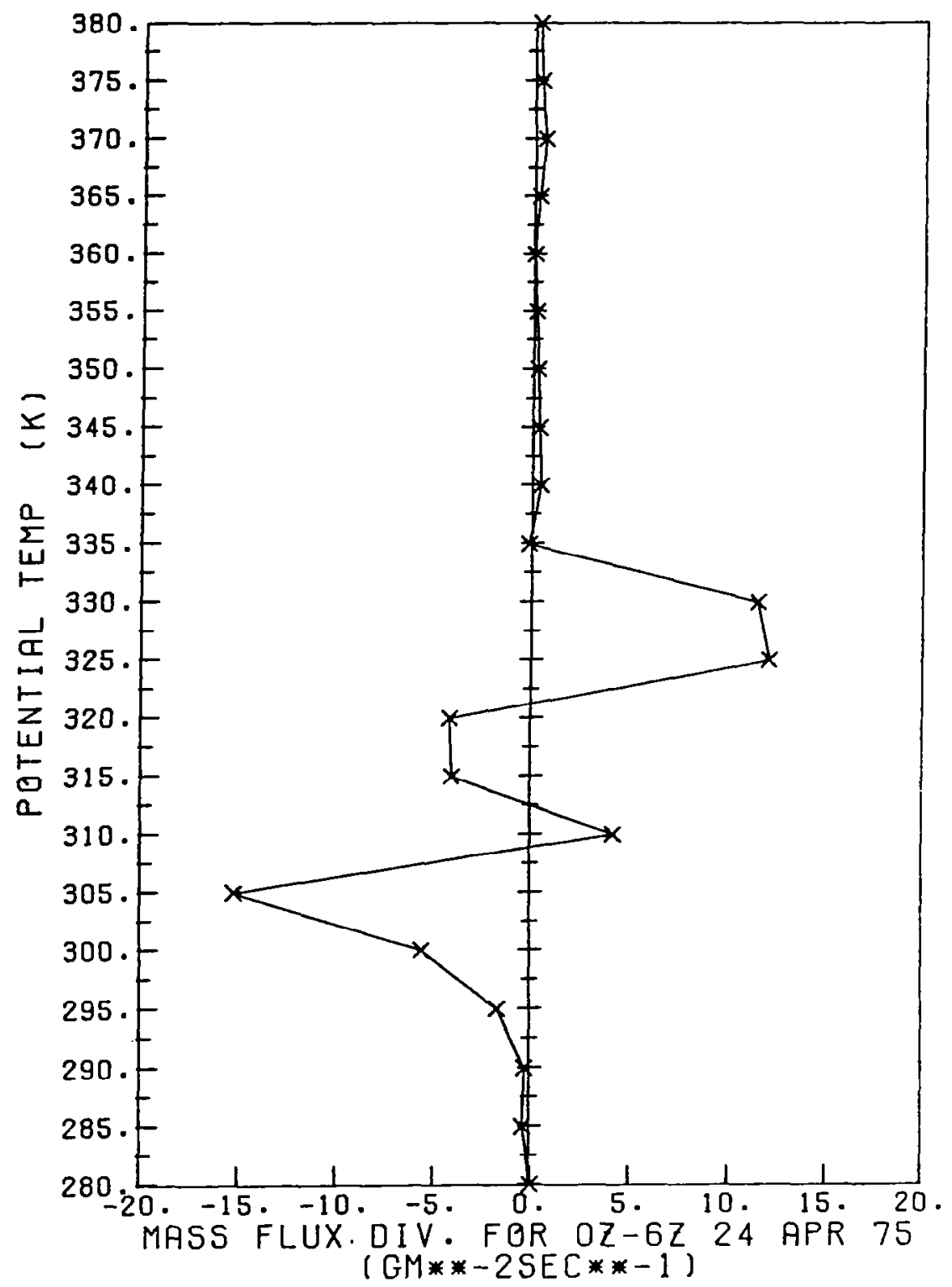

Figure 13: Vertical profile of time-areally-averaged horizontal mass flux divergence $\left(\mathrm{g} \mathrm{m}^{-2} \mathrm{~s}^{-1}\right)$ through MCC A for $00 \mathrm{Z}$ to 06224 April 1975 time interval (see Figure 12a for location of grid points used in areal averaging). 

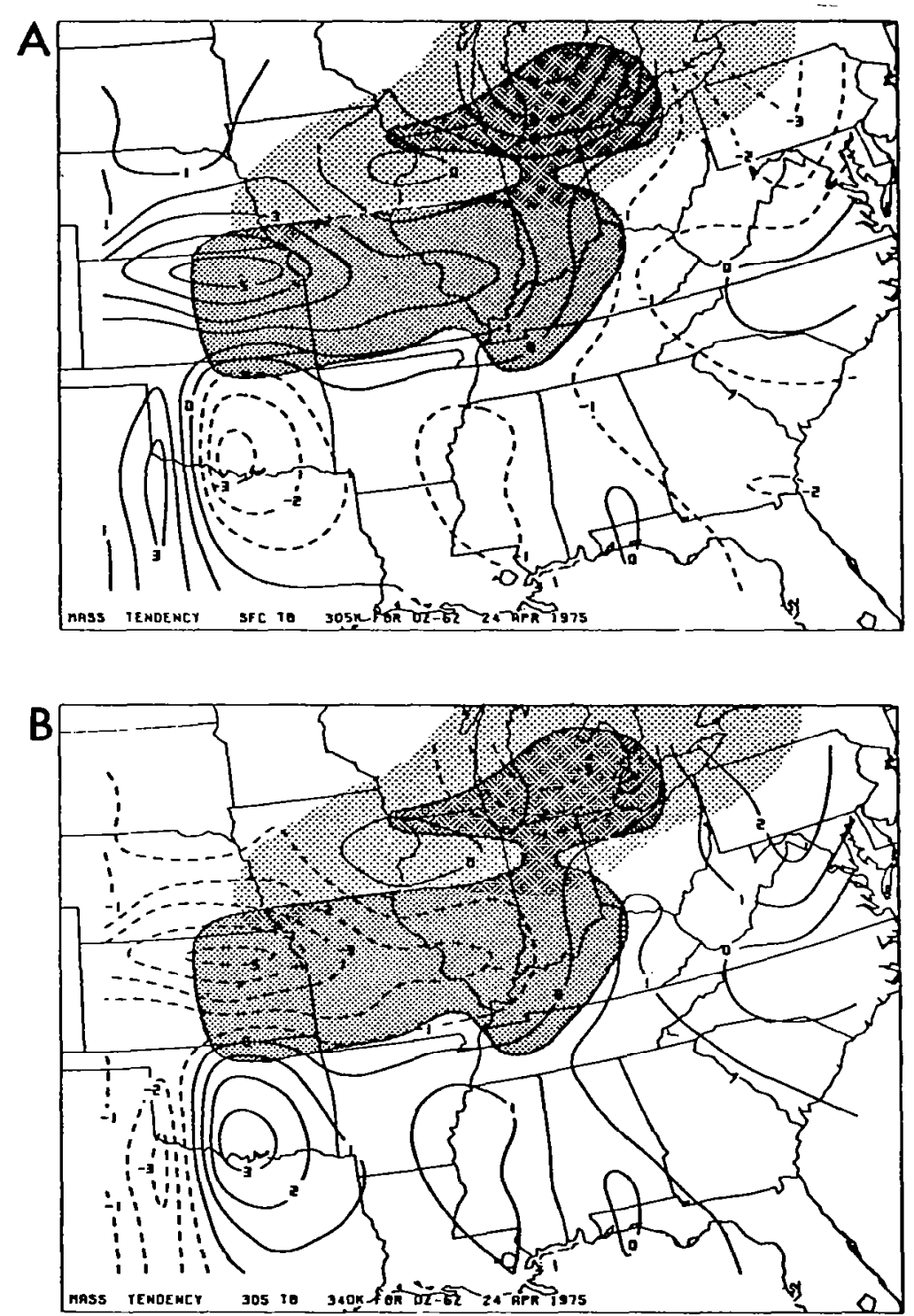

Figure 14: Mass tendency (positive-solid, negative-dashed, $\times 10^{1} \mathrm{~g} \mathrm{~m}^{-2} \mathrm{~s}^{-1}$ ) for (a) surface to $305 \mathrm{~K}$ isentropic 1 ayer and (b) $305 \mathrm{~K}$ to $340 \mathrm{~K}$ isentropic layer. Time period and format for jet streak and MCC $A$ same as in Figure 12. 
vergence while the negative mass tendencies in the $305 \mathrm{~K}$ to $340 \mathrm{~K}$ isentropic layer are due to horizontal mass flux divergence.

Diabatic heating rates are calculated through a vertical integration of the mass tendency and horizontal mass flux divergence. Figure 15 displays diabatic heating rates over six hours on the $320 \mathrm{~K}$ isentropic surface. Several important features are apparent from this figure. Note the excellent correspondence between the location of MCC $A$ and regions of strongest diabatic heating rates. The western maximum of heating over Kansas and Nebraska, with values exceeding $8 \mathrm{~K}(6 \mathrm{hr}$.)${ }^{1}$, is located near two intense squall lines (see Figure 7b). Also, heavy rains were reported over southern Illinois and Indiana near the location of the eastern heating maximum. Diabatic heating rates in this region are greater than $12 \times(6 \mathrm{hr} .)^{-1}$. The vertical profile of areally-averaged heating through MCC $A$ in Figure 16 shows that the average diabatic heating rates are strongest in the $315 \mathrm{~K}$ to $330 \mathrm{~K}$ isentropic layer. Diabatic cooling rates as large as $4 \mathrm{~K}(6 \mathrm{hr} .)^{-1}$, found in the $290 \mathrm{~K}$ to $305 \mathrm{~K}$ layer, are probably caused by evaporation of falling precipitation. The location of the twenty-five grid points utilized in determining the areally-averaged diabatic heating rates is shown in Figure 15.

Although diabatic heating rates within the convective complex may not be as substantial as what might be expected considering the intensity of the storm and the large precipitation totals, it is important to realize that the AVE data does not adequately resolve the smaller 


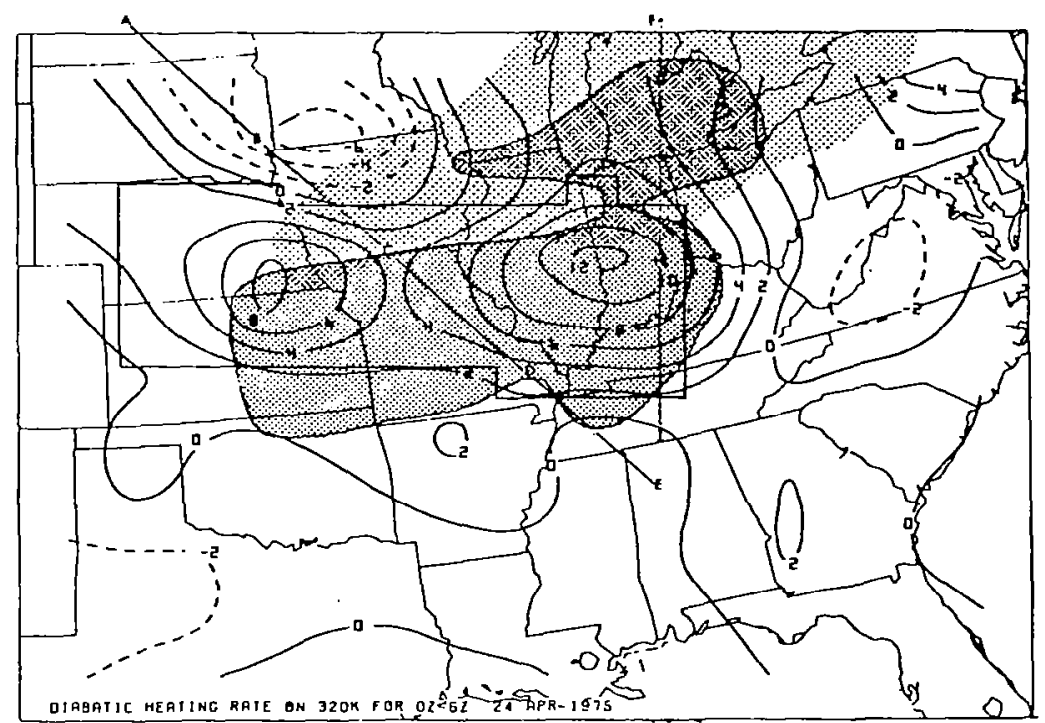

Figure 15: Diabatic heating rate $(\mathrm{d} \theta / \mathrm{dt}$ ) (positive-solid, negativedashed, deg. $\left.K(6 \mathrm{hr} .)^{-1}\right)$ for $320 \mathrm{~K}$ isentropic surface. Time period and format for jet streak and MCC A same as in Figure 12. Grid points used in areal averaging for Figure 16 are enclosed with solid ine and location of vertical cross sections in Figures 17a, b are indicated by solid 1 ine segments $A-B-C-D-E$ and $F-G-H-I$.

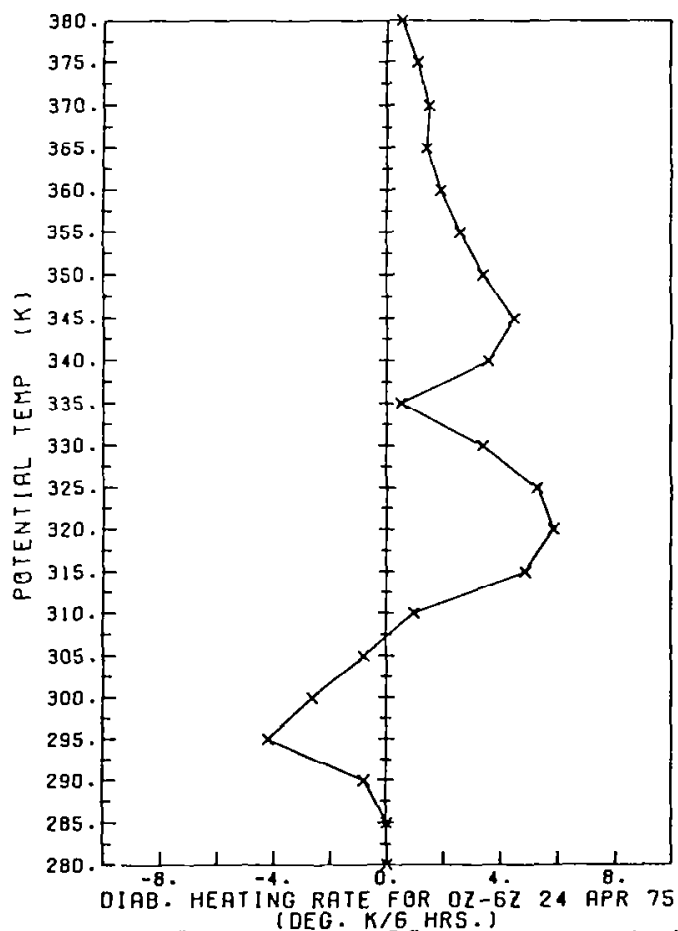

Figure 16: Vertical profile of areally-averaged diabatic heating rate (deg. K (6 hr. $\left.)^{-1}\right)$ through MCC A for 002 to $06 Z 24$ April 1975 time interval (see Figure 15 for location of grid points used in areal averaging). 
scale processes occurring within squall lines and individual thunderstorm cells embedded in the MCC. Data with higher temporal and spatial resolution would likely isolate such processes and result in larger estimates of diabatic heating rates within MCC $A$.

One drawback of using real data in diagnostic analyses is exemplified by the unrealistically large diabatic cooling rates which are present over southern Minnesota in Figure 15. This problem likely occurs because of the increased difficulty of accurately estimating the horizontal mass flux divergence near the boundaries of grids and the calculation of the instantaneous mass tendency over a sampling interval of six hours. The end result is bias error which limits the accuracy of calculations of this mass circulation near the boundaries of the AVE IV rawinsonde network.

The three-dimensional structure of the changing mass field in the vicinity of the jet streak and convective complex is best illustrated by means of vertical isentropic cross sections through these features. Figure $17 \mathrm{a}$ is a cross section through the developing jet streak at $00 \mathrm{z}$; Figure $17 b$ is a cross section through the center of the jet streak at 062 (see Figure 15 for location of cross sections). Note the $15 \mathrm{~m} \mathrm{~s}^{-1}$ increase in wind speeds in the jet core and the strengthening of the vertical wind shear above and beneath the jet over this six hour time period. Examination of Figure $17 \mathrm{~b}$ reveals that the jet has stretched horizontally, a feature common in evolving jet cores. Inspection of Figure 17a points out a localized lowering of isentropic surfaces be- 

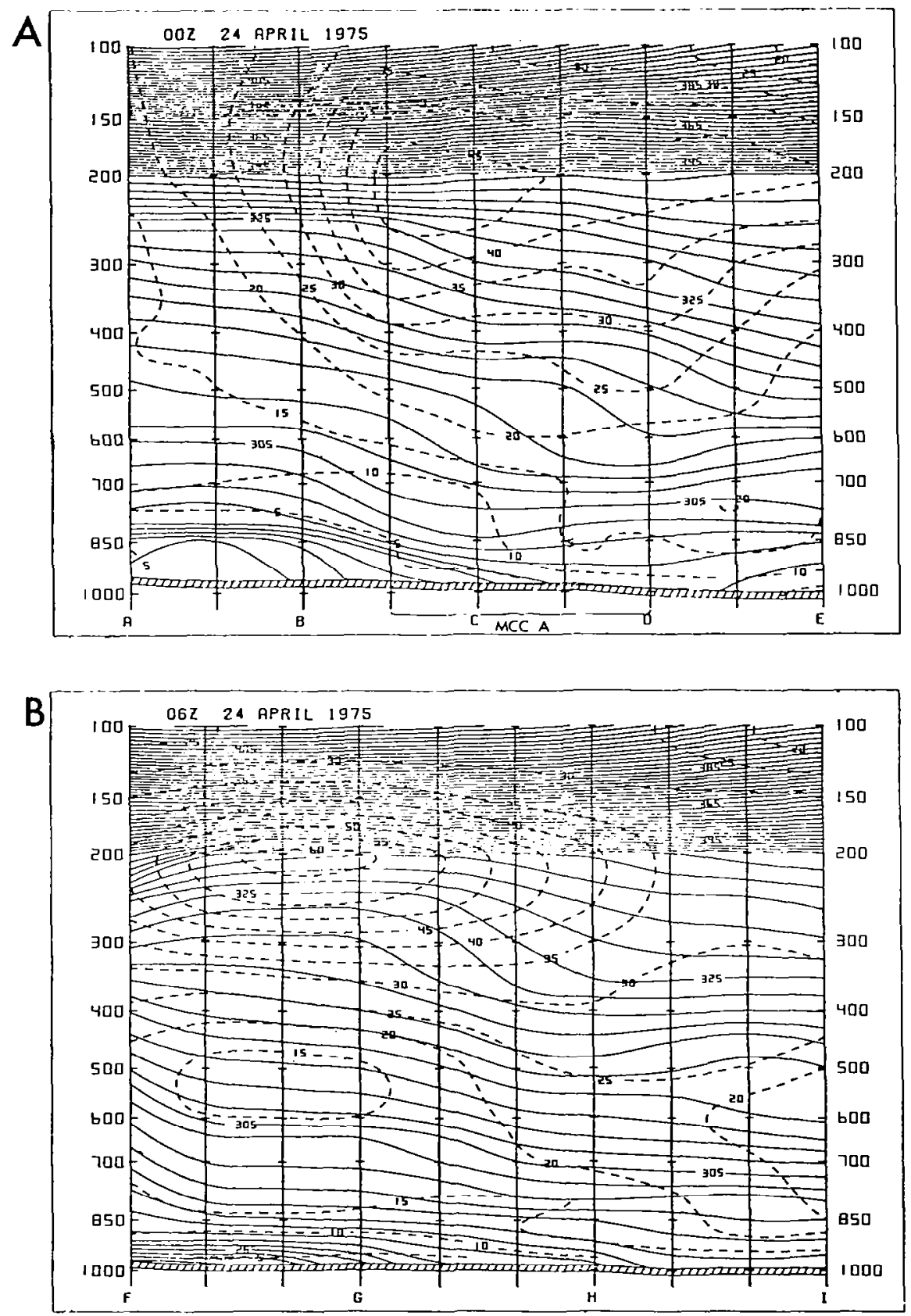

Figure 17: Vertical cross section through jet streak and MCC A depicting observed wind isotachs (dashed, $\mathrm{m} \mathrm{s}^{-1}$ ) and isentropes (solid, deg. K) for (a) $00 Z 24$ April 1975 and (b) 06Z 24 April 1975. Vertical coordinate is pressure (mb) (see Figure 15 for location of cross sections). 
tween $850 \mathrm{mb}$ and $600 \mathrm{mb}$ in the vicinity of the rapidly developing convective complex and suggests that warming due to the effect of diabatic latent heating is readily observed in this cross section. However, one should realize that this effect may be due to energy advection associated with adiabatic mass convergence.

In summary, the isentropic mass circulation within MCC A is characterized by strong upward vertical mass transport forced by diabatic latent heating within the convective region. The results verify through mass continuity requirements that low level horizontal mass transport into the convective region tends to be balanced by upper level horizontal mass transport away from the MCC. The horizontal branches of this mass circulation act in the same sense as the thermally-direct mass circulation in the entrance region of the upper tropospheric jet streak and thus have the potential, through interaction, to intensify the direct circulation.

2) Structure of the ageostrophic motion field

The diagnosis of ageostrophic motion from real data sources, like diabatic heating rate calculations, presents several problems. First, a reliable calculation of ageostrophic wind structure requires consistency and accuracy in the observation and analysis of both wind and mass fields. In this study, where the evolution of ageostrophic motion is examined, such accuracy must be present at each time period. In addition, the structure and evolution of the atmosphere within the six hour period between observations must be consistent with the events oc- 
curring at the time of observations. Otherwise, spatially-and temporally-inconsistent ageostrophic wind fields will result in the analyses. Such problems are encountered to some extent in analyses presented in this section. Another problem, previously discussed in Chapter 3 , is related to the increased temporal resolution of the AVE IV data set. With the limited accuracy of observations, the random error variance of estimates of structure and processes for shorter time scales may actually increase to the point where the structure of ageostrophic motion becomes inconsistent in both space and time.

The six hour time-averaged $330 \mathrm{~K}$ ageostrophic wind field from $00 \mathrm{Z}$ through 06224 April 1975 is depicted for the jet streak level in Figure 18. While weak divergence is observed over MCC $A$, the significant feature to note is the strong $15 \mathrm{~m} \mathrm{~s}^{-1}$ southerly wind over Iowa. This strong ageostrophic wind flows northward out of the MCC and extends through the entrance region of the jet streak. The pattern here agrees with the concept of motion in the confluent flow field of the entrance region with subgeostrophic motion being deflected ageostrophically in the direction of the pressure gradient force.

Figure 19 represents the time-averaged inertial advective component of ageostrophic motion (II-1-B) on the $330 \mathrm{~K}$ isentropic level. Although Uccellini and Johnson (1979) found this component to be the primary contributor to ageostrophic motion in the entrance region at jet streak level in their case study, the circumstances are different in this study. Southerly inertial advective wind speeds exceeding 


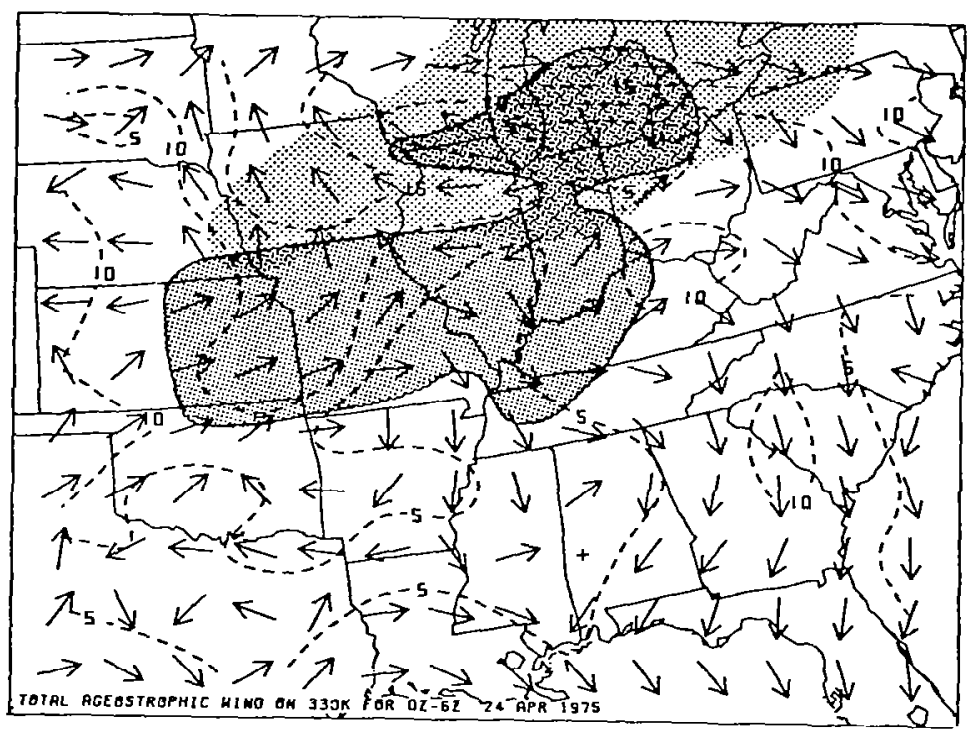

Figure 18: Time-averaged total ageostrophic wind vectors and isotachs (dashed, $\mathrm{m} \mathrm{s}^{-1}$ ) for $330 \mathrm{~K}$ isentropic surface. Time period and format for jet streak and MCC $A$ same as in Figure 12.

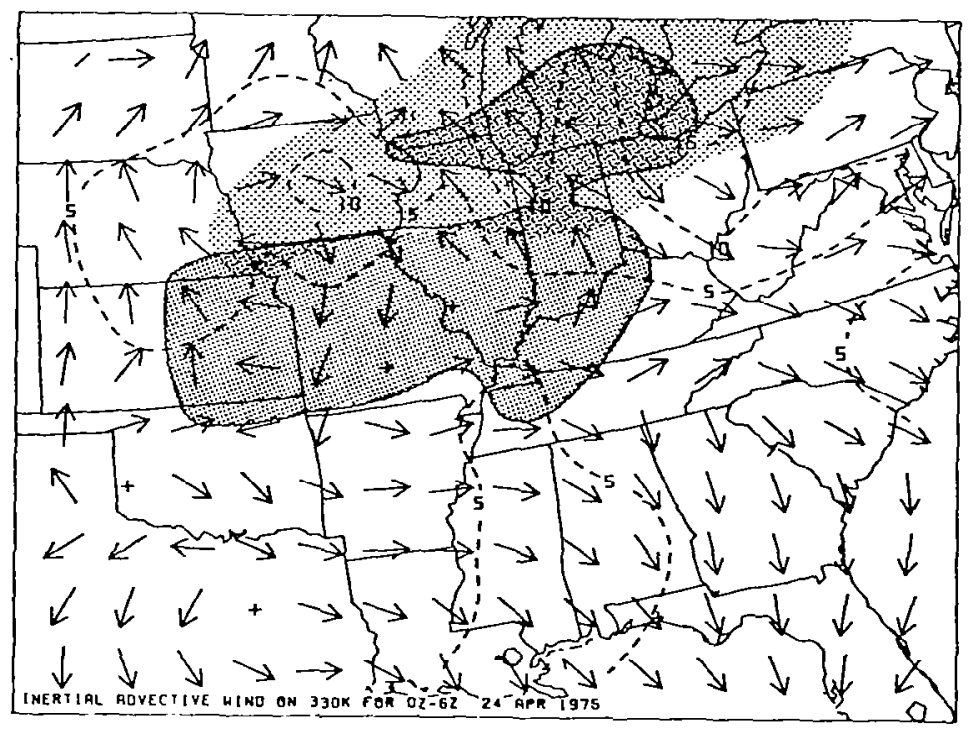

Figure 19: Time-averaged inertial advective wind vectors and isotachs (dashed, $\mathrm{m} \mathrm{s}^{-1}$ ) for $330 \mathrm{~K}$ isentropic surface. Time period and format for jet streak and MCC A same as in Figure 12. 
$10 \mathrm{~m} \mathrm{~s}^{-1}$ are present over southern Lake Michigan in the entrance region, however, weak westerly and northwesterly inertial advective motion over Iowa suggests that this term is not the primary contributor to the total ageostrophic wind here. Inertial advective wind speeds over Iowa at this time barely exceed $10 \mathrm{~m} \mathrm{~s}^{-1}$. Note that the flow pattern of the time-averaged inertial advective wind for this case exhibits slight diffluence over the MCC position.

The structure of the local wind tendency component of ageostrophic motion (II-1-A) for the $330 \mathrm{~K}$ isentropic surface is displayed in Figure '0. At this time northeasterly ageostrophic winds exceeding $12 \mathrm{~m} \mathrm{s-1}$ over Iowa tend to be orthogonal to the total ageostrophic wind in the entrance region and generally oppose the direction of the inertial component here. A comparison of Figures 19 and 20 points out that the magnitude of the local wind tendency term actually dominates the inertial advective wind speed in the entrance region of the jet streak and over the MCC. The local wind tendency component is also quite strong within the left-hand quadrant of the downstream jet streak where the speed of its core is locally increasing with time.

The inertial diabatic wind $(I I-1-C)$ can be directly calculated from the diabatic heating rate and vertical wind shear information derived from the AVE IV data set. Analysis of this term in the $325 \mathrm{~K}$ to $330 \mathrm{~K}$ isentropic layer (Figure $21 \mathrm{a}$ ) and in the $320 \mathrm{~K}$ to $325 \mathrm{~K}$ layer (Figure 21b) shows that it is strongest in magnitude over southeastern Nebraska and northeastern Kansas, where maximum wind speeds are as 


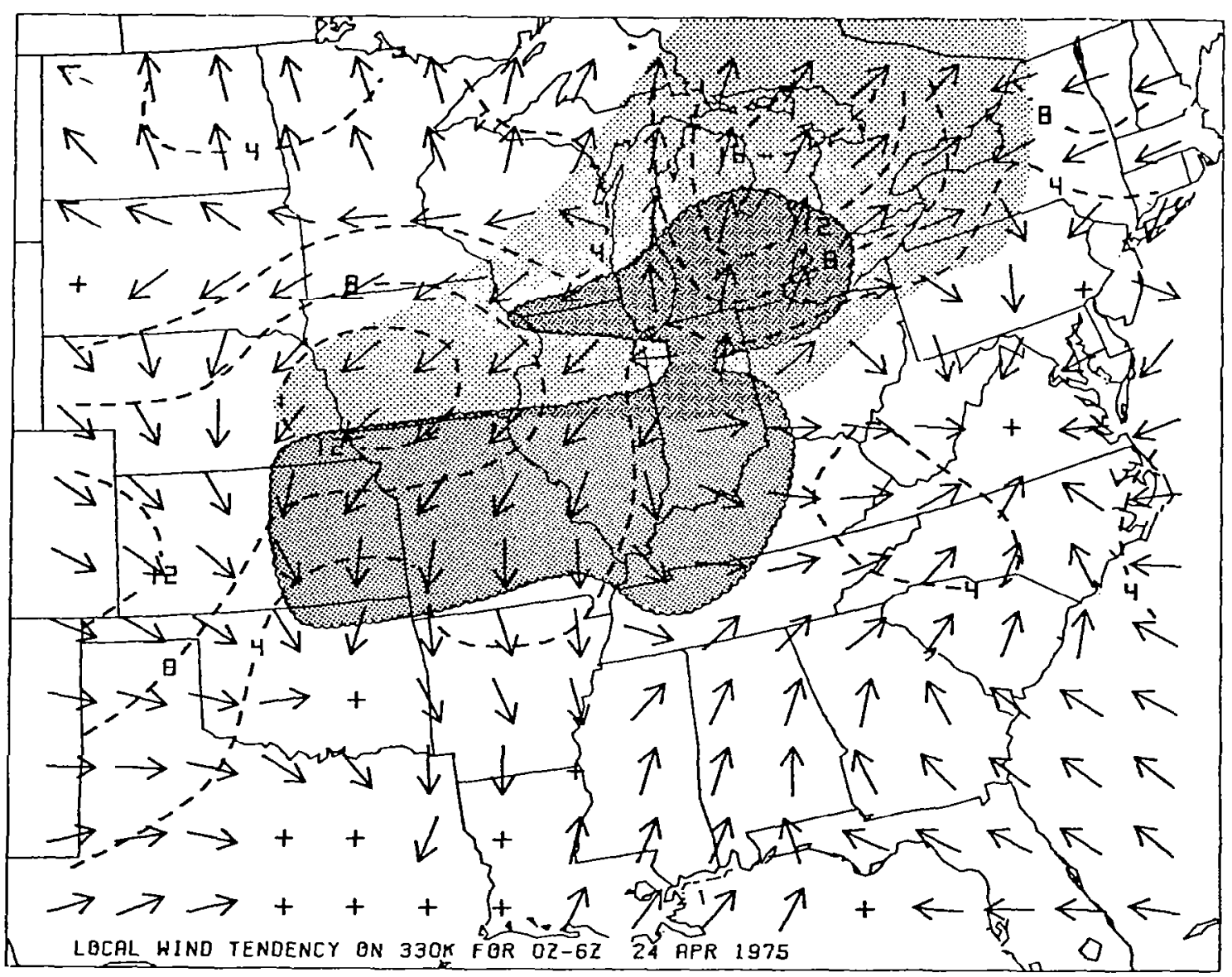

Figure 20: Local wind tendency vectors and isotachs (dashed, $m s^{-1}$ ) for $330 \mathrm{~K}$ isentropic surface. Time period and format for jet streak and MCC $A$ same as in Figure 12. 

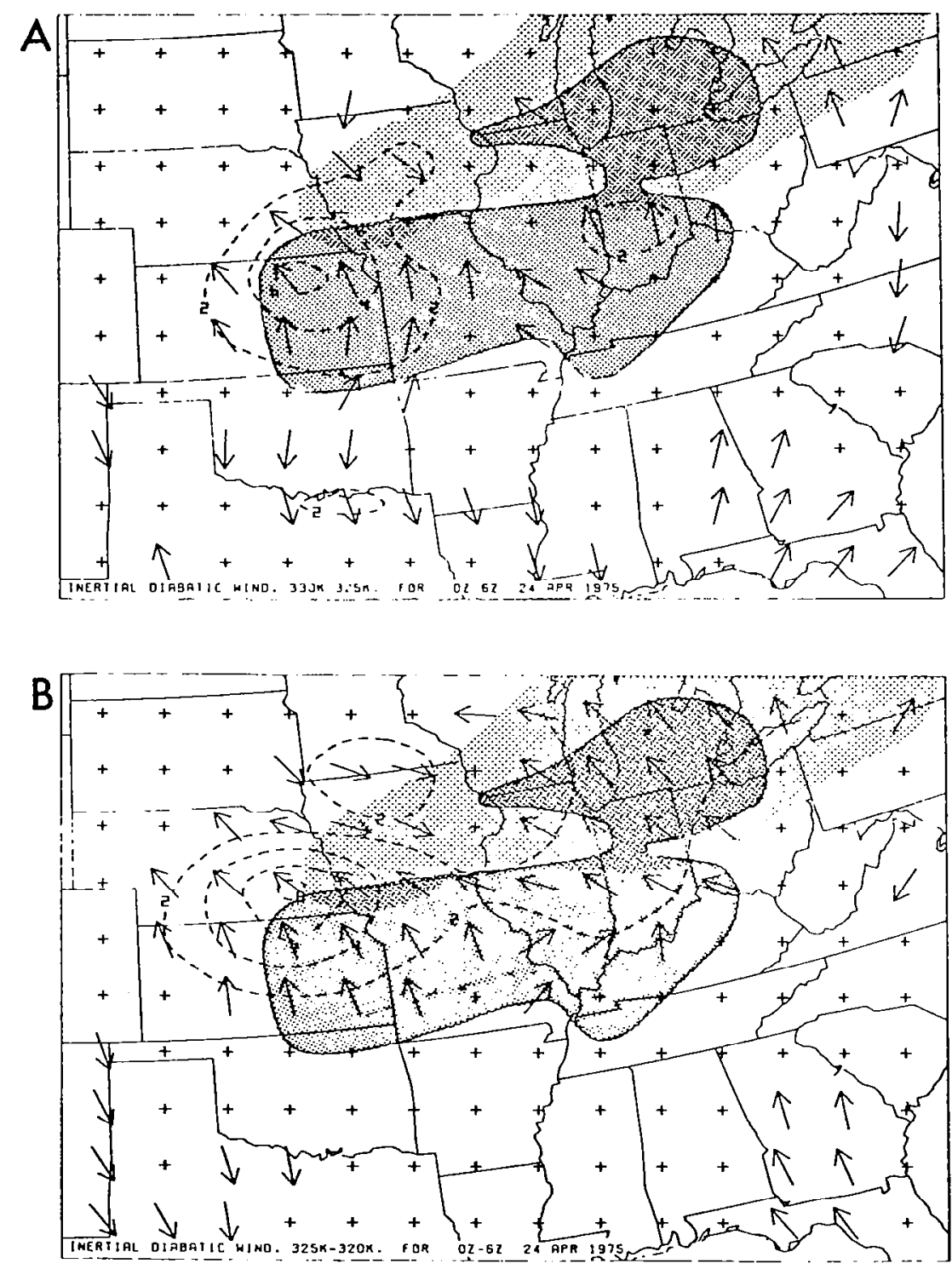

Figure 21: Inertial diabatic wind vectors and isotachs (dashed; $\mathrm{m} \mathrm{s}^{-1}$ ) for (a) $325 \mathrm{~K}$ to $330 \mathrm{~K}$ isentropic layer and (b) $320 \mathrm{~K}$ to $325 \mathrm{~K}$ isentropic layer. Time period and format for jet streak and MCC A same as in Figure 12 . 
strong as $8 \mathrm{~m} \mathrm{~s}^{-1}$ from the southeast. In a vertically-sheared environment, the effect of heating is to force a systematic ageostrophic component to the left of the flow in the general direction of the mass transport in the upper branch of the direct circulation transverse to the jet.

A residual ageostrophic component of motion can be determined through the subtraction of the time-averaged form of (II-1-A) and (II-1-B) from the total ageostrophic wind vector. Ideally the residual should consist of the sum of the inertial diabatic component and the frictional component of ageostrophic motion. Problems arise in analyses based on such an assumption, however, since errors associated with actual wind observations, grid point interpolation and finite differencing processes in space and time may constitute a significant portion of the total residual term. However, if error effects are sinall enough so as to not mask actual dynamical processes then the residual term would be a reasonable estimate of the sum of the inertial diabatic and frictional components of ageostrophic motion. If the frictional component is small, the residual should be directly linked to the inertial diabatic component of ageostrophic motion. The magnitude of this timeaveraged residual, calculated over the six hour time interval, is strong on $330 \mathrm{~K}$ over Iowa and northern Missouri; southerly wind speeds here exceed $30 \mathrm{~m} \mathrm{~s}^{-1}$ (see Figure 22). A comparison of Figures 18-22 illustrates that this residual reaches a maximum over the region of convection in Iowa and is actually the dominant component of ageostro- 


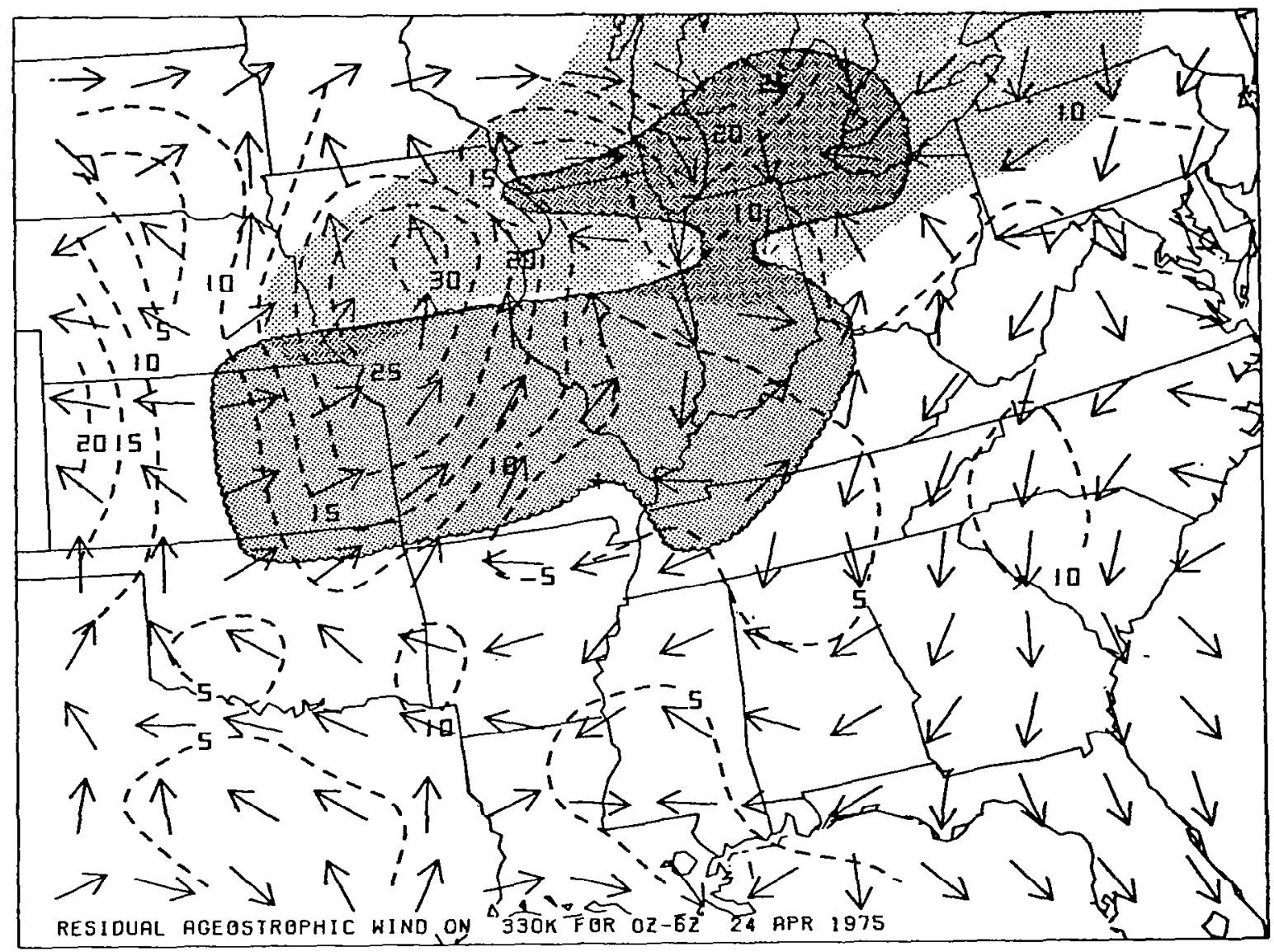

Figure 22: Residual ageostrophic wind vectors and isotachs (dashed, $\mathrm{m} \mathrm{s}^{-1}$ ) for $330 \mathrm{~K}$ isentropic surface. Time period and format for jet streak and MCC A same as in Figure 12 . 
phic motion in the jet streak entrance region over Iowa. The comparison also shows that the general location of the speed maxima is in the region of the MCC where the direction of the inertial diabatic component and the residual term compare favorably. However, a detailed comparison also illustrates several problems. The location of strongest inertial diabatic wind speeds is somewhat west of the region where the residual magnitude is largest in the entrance region (see Figure 22). Also, note that inertial diabatic wind speeds are much weaker than residuat wind speeds throughout the jet streak-MCC neighborhood. Two basic factors may explain the large inconsistency between these two terms. First, recall that the residual includes data and computational errors as well as frictional effects; it is possible, therefore, that this residual overestimates inertial diabatic motion. A second uncertainty lies with the method of calculation of the inertial diabatic term. The vertical wind shear employed in this computation is time averaged while diabatic heating rates are determined over intervals of six hours: Instantaneous values for these two quantities would certainly yield larger magnitudes of wind shear and heating at the time and position of most intense convective activity and strongest vertical wind shear that occur in and near the position of the MCC. Higher temporal and spatial resolution data is needed in order to more accurately ascertain the structure of this component of ageostrophic motion. The true magnitude of the inertial diabatic term for this case probably lies somewhere between the two extremes of $8 \mathrm{~m} \mathrm{~s}^{-1}$ and $30 \mathrm{~m} \mathrm{~s}^{-1}$ since 
the former is a conservative estimate due to averaging while the latter may be inflated due to errors in residual calculations. Speeds in this range certainly indicate that in the entrance region inertial diabatic motion is an important contributor to the total ageostrophic wind field. Also, note from Figure 21 b that southeasterly inertial diabatic winds greater than $2 \mathrm{~m} \mathrm{~s}^{-1}$ extend from Nebraska eastward to the eastern Great Lakes region in conjunction with the jet streak entrance region. 3) Ageostrophic motion estimated through the semi-geostrophic momentum approximation

The time-averaged semi-geostrophic form for the inertial advective component of ageostrophic motion is shown on $330 \mathrm{~K}$ in Figure 23 . Note that although the magnitude of this component does exceed $20 \mathrm{~m} \mathrm{~s}^{-1}$ north of MCC A in western Iowa, its southeastward direction in the entrance region does not conform with concepts based on adiabatic propagation of jet streaks. Evidence of southerly flow is present in the entrance region east and north over Wisconsin and Michigan; in this region the semi-geostrophic form for inertial advective motion does correspond with concepts. A comparison of Figure 19 and Figure 23 points out the generally large disagreement between the actual and semigeostrophic forms for the inertial advective wind. The disagreement is especially large near the western flank of MCC A and the jet streak over eastern Nebraska and western Iowa and farther east over northern Illinois. This large difference must be attributed to differences be- 


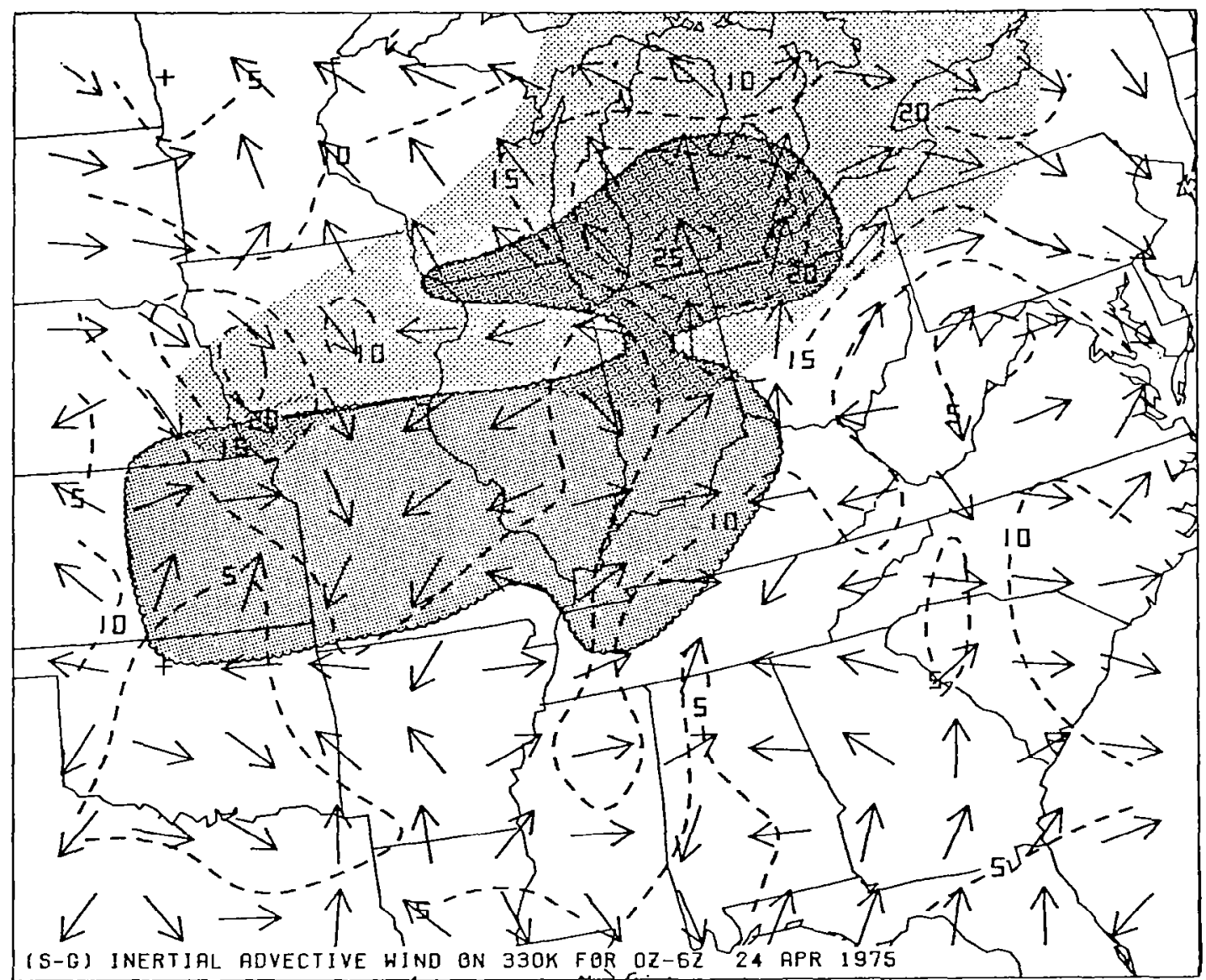

Figure 23: Time-averaged semi-geostrophic inertial advective wind vectors and isotachs (dashed, $\mathrm{m} \mathrm{s}^{-1}$ ) for $330 \mathrm{~K}$ isentropic surface. Time period and format for jet streak and MCC A same as in Figure 12. 
tween the horizontal distribution of the actual and geostrophic velocities, since in the calculation of this component the advective velocity $\mathrm{U}$ is common to both expressions.

Figures $24 a$ and 24b depict the semi-geostrophic inertial diabatic component of ageostrophic motion in the $325 \mathrm{~K}$ to $330 \mathrm{~K}$ and $320 \mathrm{~K}$ to $325 \mathrm{~K}$ isentropic layers respectively. In both figures, a general southeasterly motion exists in the entrance region stretching from Nebraska eastward to Indiana. The difference between the direction of the observed and semi-geostrophic forms of this ageostrophic component is small as illustrated by a comparison of Figure 21 and Figure 24, however, the semi-geostrophic form is somewhat weaker in the entrance region. Such a result would indicate that the vertical shear in the ageostrophic wind is smaller than the actual wind shear in these isentropic layers.

Apart from semi-geostrophic theory, the isallobaric wind component is important to examine from fundamental considerations since it displays the evolution of the forcing by the pressure distribution, which for hydrostatic structures is determined through the redistribution of mass. The total isallobaric wind field over the six hour time interval is depicted at $330 \mathrm{~K}$ and at $310 \mathrm{~K}$ in Figures $25 \mathrm{a}$ and $25 \mathrm{~b}$ respectively. Upper level isallobaric wind divergence is observed within MCC A in Figure $25 \mathrm{a}$ in association with speeds exceeding $8 \mathrm{~m} \mathrm{~s}^{-1}$ over southern Illinois and Indiana and over northern Missouri. Note in the entrance region isallobaric motion is fairly weak and spatially inconsistent 

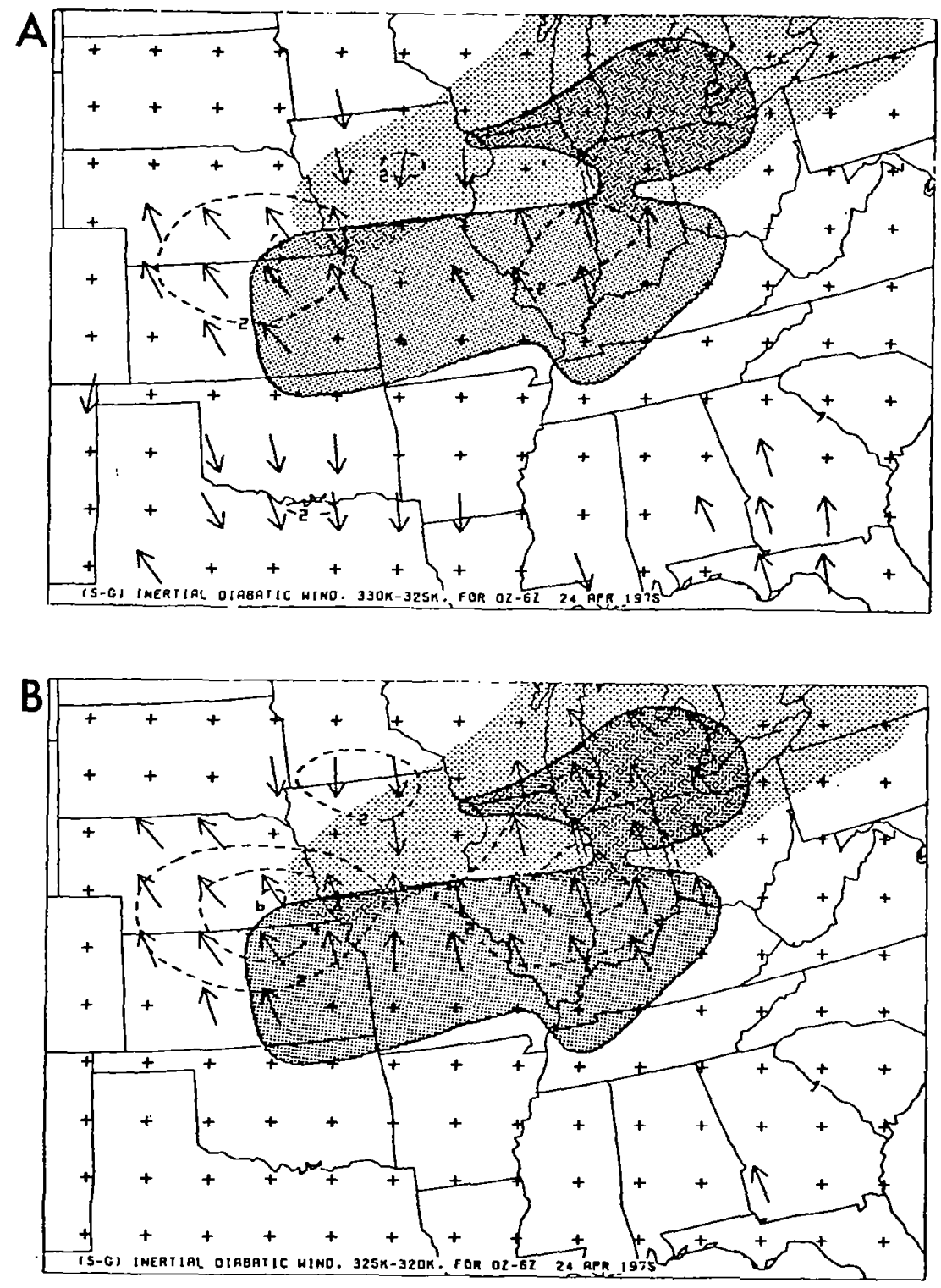

Figure 24: Semi-geostrophic inertial diabatic wind vectors and isotachs (dashed, $\mathrm{m} \mathrm{s}^{-1}$ ) for (a) $325 \mathrm{~K}$ to $330 \mathrm{~K}$ isentropic layer and (b) $320 \mathrm{~K}$ to $325 \mathrm{~K}$ isentropic layer. Time period and format for jet streak and MCC $A$ same as in Figure 12. 

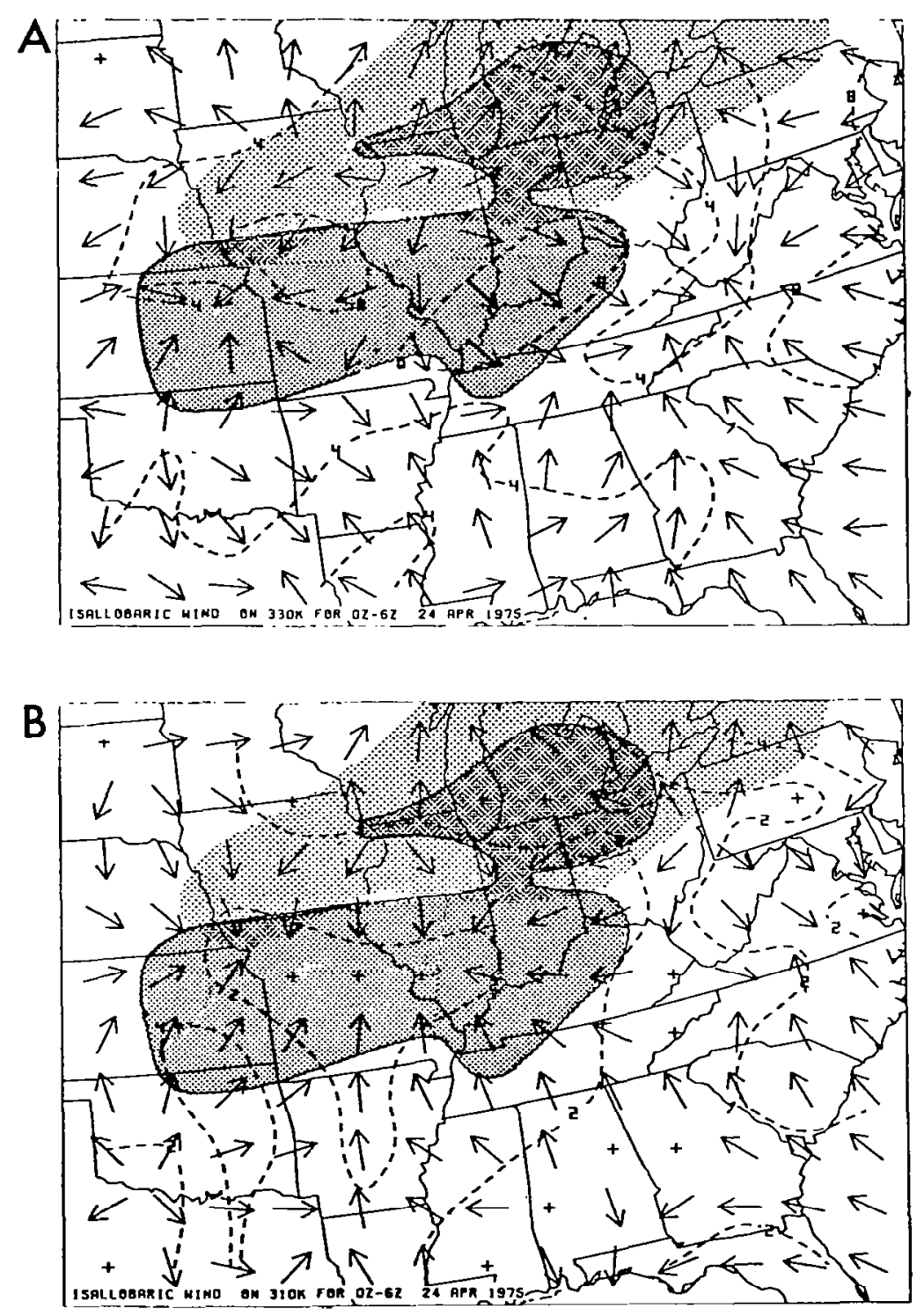

Figure 25: Isallobaric wind vectors and isotachs (dashed, $\mathrm{m} \mathrm{s} \mathrm{s}^{-1}$ ) for (a) $330 \mathrm{~K}$ isentropic surface and (b) $310 \mathrm{~K}$ isentropic surface. Time period and format for jet streak and MCC $A$ same as in Figure 12. 
over northern Iowa while further east, over Wisconsin and Michigan, this flow becomes more intense and is directed from the southwest. At lower levels, the isallobaric wind converges into the convective region over Missouri although wind speeds are quite weak (see the wind distribution on the $310 \mathrm{~K}$ surface in Figure 25b).

In this diagnostic study, the surface pressure tendency component of isallobaric motion (term $A$ of $(13)$ ) is calculated from the difference of the direct calculations of the integrated pressure tendency component (term B of (13)) and the observed pressure gradient force tendency. Uccellini (1977) found that direct calculation of the surface pressure tendency term is spatially inconsistent with the average tendencies calculated from rawinsonde information. Figure 26 displays the surface pressure tendency component while the $330 \mathrm{~K}$ and $310 \mathrm{~K}$ integrated pressure tendency components of isallobaric motion are shown in Figures $27 \mathrm{a}$ and $27 \mathrm{~b}$ respectively. At the $330 \mathrm{~K}$ level, the integrated pressure tendency term clearly dominates over the surface pressure tendency term. Note the strong divergence in the integrated pressure tendency component within the northern flank of MCC A over northern I11inois. The weak surface pressure tendency wind, while noisy, does exhibit convergence over this same region along with weak divergence farther south over Missouri and southern Illinois. On the $310 \mathrm{~K}$ isentropic surface the integrated pressure tendency is again the dominant component of isallobaric motion; note that the direction field of the integrated pressure tendency component on $310 \mathrm{~K}$ opposes that of the surface 


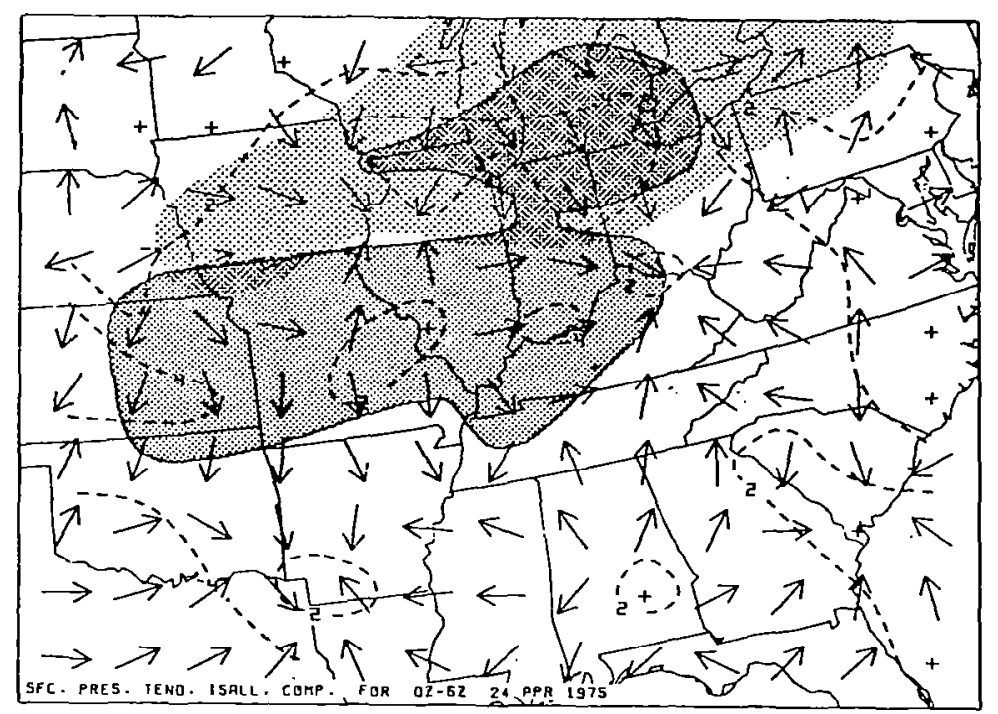

Figure 26: Surface pressure tendency isallobaric component vectors and isotachs (dashed, $m s^{-1}$ ). Time period and format for jet streak and MCC $A$ same as in Figure 12. 

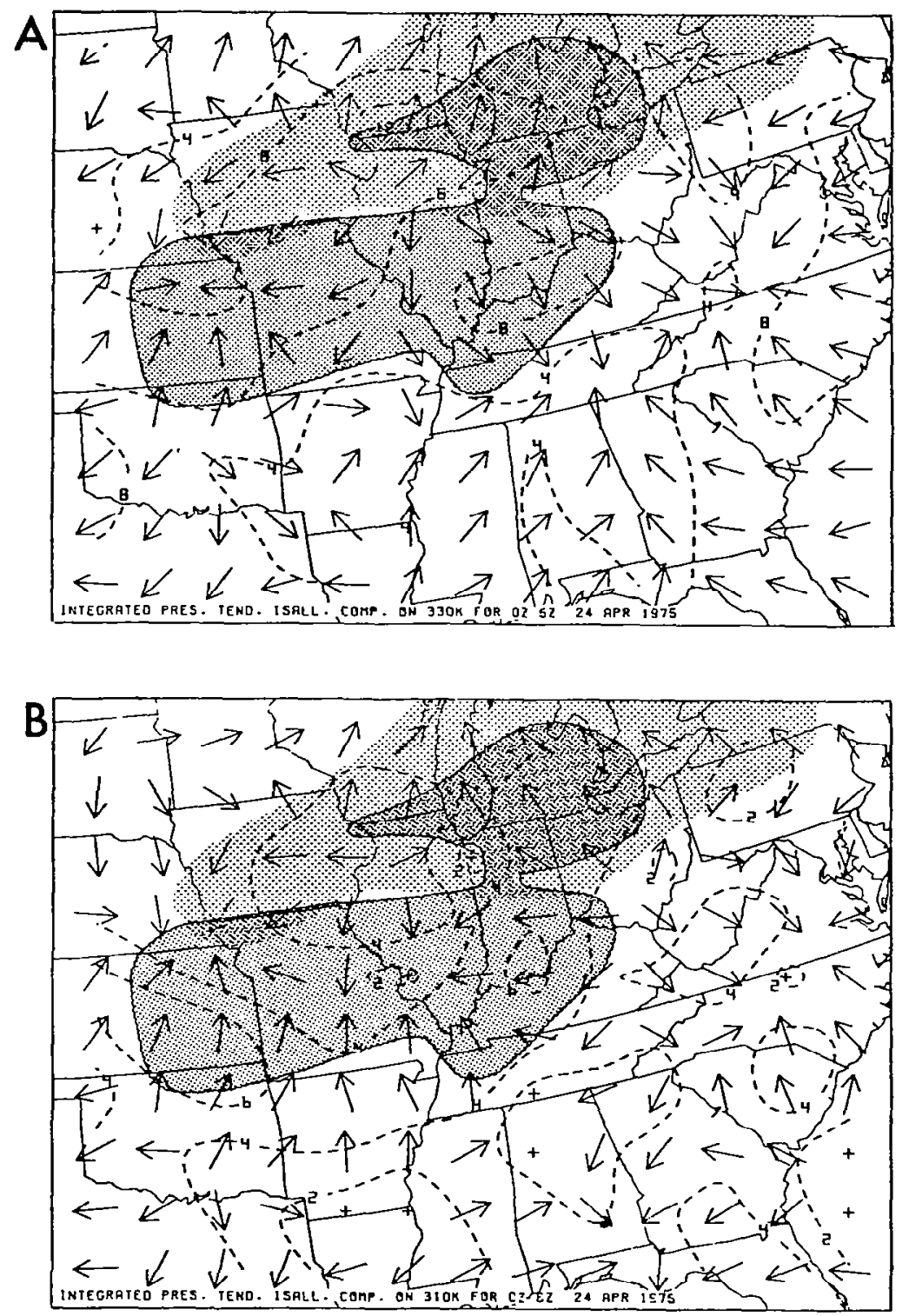

Figure 27: Integrated pressure tendency isallobaric component vectors and isotachs (dashed, $\mathrm{m} \mathrm{s}^{-1}$ ) for (a) $330 \mathrm{~K}$ isentropic surface and (b) $310 \mathrm{~K}$ isentropic surface. Time period and format for jet streak and MCC A same as in Figure 12. 
pressure tendency component since the former shows convergence into MCC A over Missouri and southern Illinois and divergence farther north over northern Illinois.

The structure of the adiabatic and diabatic components of isallobaric wind (see (19) and (21)) on the $330 \mathrm{~K}$ and $310 \mathrm{~K}$ levels is pointed out in Figures 28a, b and 29a, b, respectively. Note that over western Iowa in the entrance region, both components of isallobaric motion on $330 \mathrm{~K}$ are extremely large (greater than $35 \mathrm{~m} \mathrm{~s}^{-1}$ ), however, the diabatic and adiabatic components oppose each other in direction and are comparable in speed. This opposition exists in other locations where both components are strong. The diabatic component, which diverges out of the MCC region at upper levels over Indiana, is structured such that it transports mass from the anticyclonic to the cyclonic side of the jet streak in the entrance region; this direction conforms to the structure expected in the adiabatic propagation of jet streaks. The adiabatic isallobaric wind component, in contrast, converges into the MCC at upper levels over Indiana and transports mass from the cyclonic side to the anticyclonic side of the jet streak. On $310 \mathrm{~K}$, both the adiabatic and diabatic components are somewhat noisy, however, the adiabatic component converges into a region on the southern flank of MCC A over Arkansas while the diabatic component diverges away from this region. Although magnitudes are weaker than for $330 \mathrm{~K}$, note that at this lower level the two components again generally oppose each other. For the realization of quasi-steady state pressure distribution 

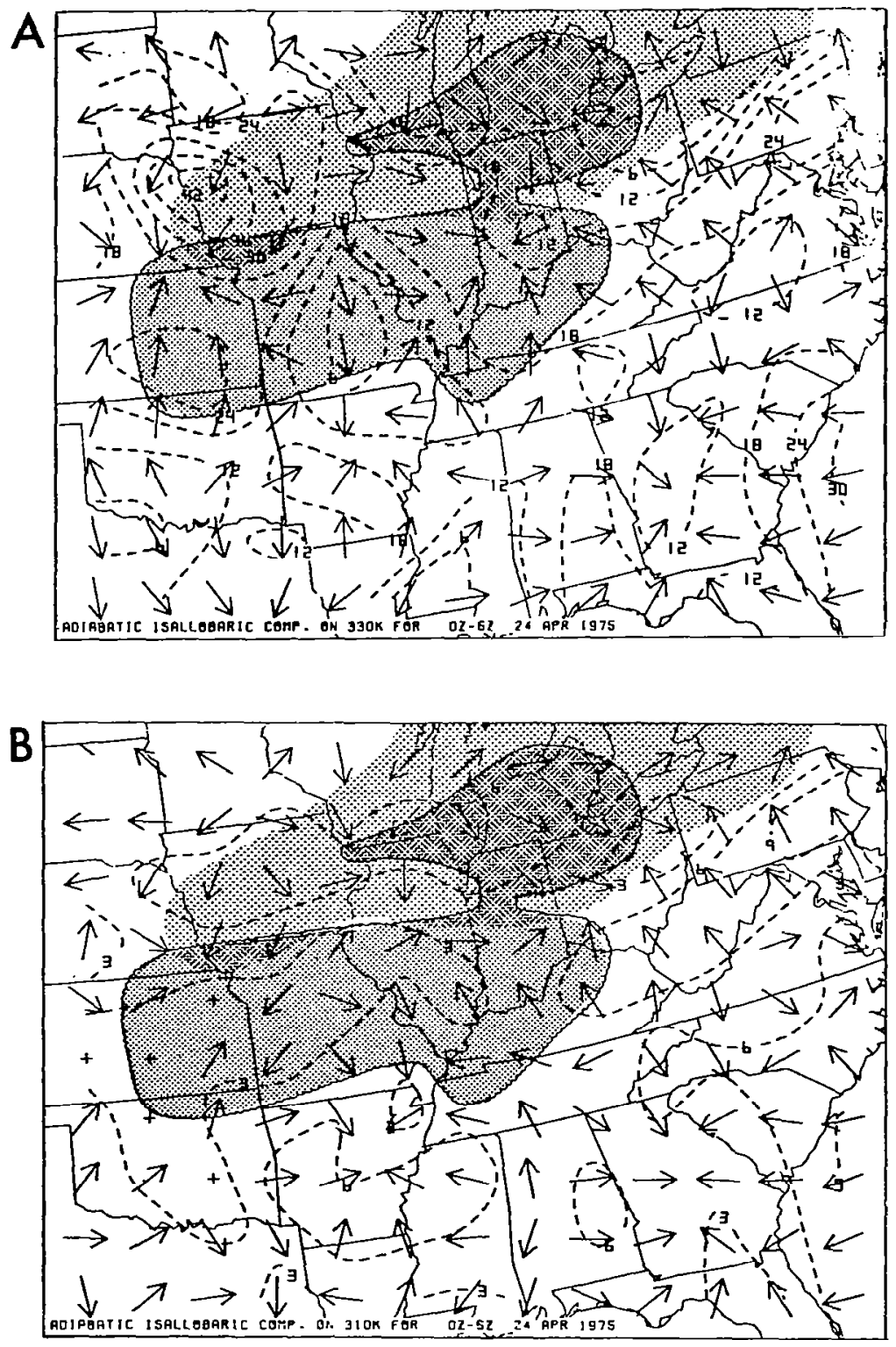

Figure 28: Adiabatic isallobaric component vectors and isotachs (dashed, $\mathrm{m} \mathrm{s}^{-1}$ ) for (a) $330 \mathrm{~K}$ isentropic surface and (b) $310 \mathrm{~K}$ isentropic surface. Time period and format for jet streak and MCC A same as in Figure 12. 

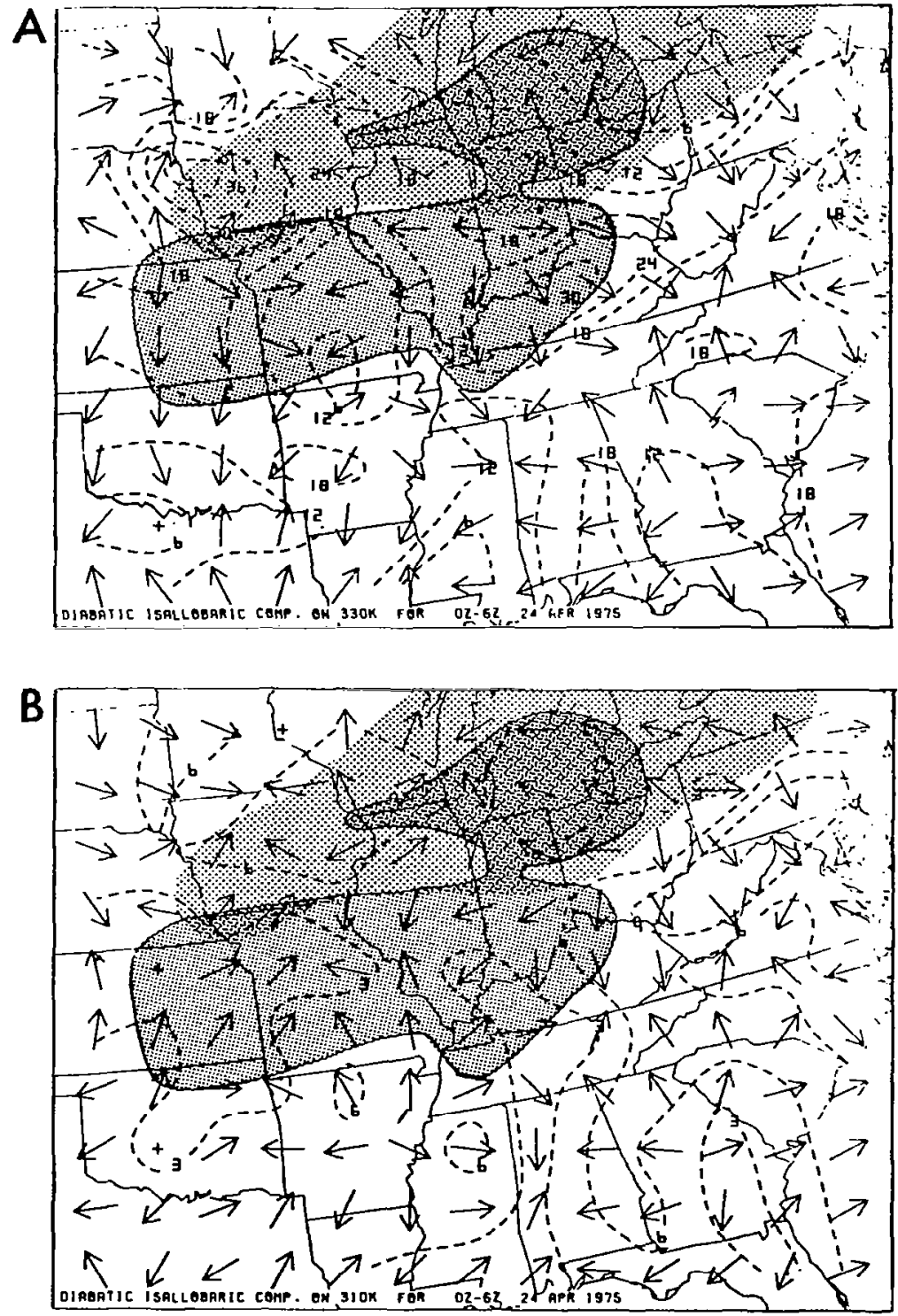

Figure 29: Diabatic isallobaric component vectors and isotachs (dashed, $\mathrm{m} \mathrm{s} \mathrm{s}^{-1}$ ) for (a) $330 \mathrm{~K}$ isentropic surface and (b) $310 \mathrm{~K}$ isentropic surface. Time period and format for jet streak and MCC $A$ same as in Figure 12 . 
during the severe convection throughout the storm complex, diabatic vertical mass transport is compensated for by quasi-horizontal adiabatic mass transport. While the adiabatic and diabatic modes of isallobaric motion offset each other at lower and upper levels, the diabatic mode dominates at upper levels since in general the upper level flow displays divergence at this level. At lower levels, the adiabatic mode dominates since the flow at this level is generally convergent. Vertical mass transport within the storm complex, forced by diabatic latent heating, must result in the sinking of mid-and upper tropospheric isentropic surfaces to higher pressure levels. The increased pressure on these isentropes and thus the increase of temperature in these regions creates a diabatically-induced isallobaric wind directed away from the convective region. This isallobaric wind, however, transports mass away from the MCC which reduces the pressure in upper isentropic layers and in turn forces isentropic surfaces within the MCC to rise to lower pressure levels. This mass transport in the upper levels away from the region of convection results in the sinking of isentropes in the environment. The changing pressure distribution on these isentropic surfaces, associated with the adiabatic heating of the troposphere by subsidence in the environment and adiabatic cooling by ascent within the MCC, produces an adiabatically-induced isallobaric wind directed inward toward the MCC at lower and upper tropospheric levels.

The general opposition of the adiabatically- and diabaticallyinduced components of the isallobaric wind, with dominance by the dia- 
batic component at upper levels, suggests that the sense of the upper branch of the MCC's mass circulation in the entrance region of the jet streak is determined by diabatic processes. The dominance of the diabatic component at upper levels is suggested mathematically by (24), since the strength of this motion is inversely proportional to pressure. For instance, for a given gradient of heat addition per unit mass $\left(Q_{m}\right)$, the magnitude of diabatically-induced isallobaric motion will be four times stronger at $200 \mathrm{mb}$ than at $800 \mathrm{mb}$. Note that the integral form for (24) implies that the diabatic isallobaric component increases with height through the vertical extent of heating within the atmosphere; this also suggests that the diabatically-induced component should be the dominant mode of isallobaric motion in upper tropospheric Tevels.

The accuracy of semi-geostrophic theory in describing ageostrophic motion over this six hour time period is examined by calculating the difference between the actual and semi-geostrophic forms for ageostrophic motion, mathematically expressed by

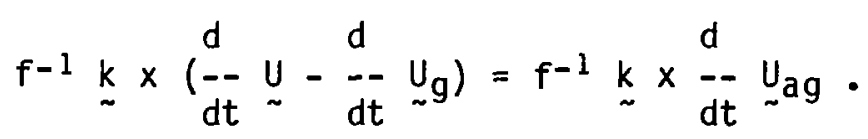

This difference is determined by summing the various components for ageostrophic motion in both forms and then subtracting the semigeostrophic form from the observed form. Figure 30 displays this difference for the $330 \mathrm{~K}$ isentropic surface. The three regions where differences are large are two areas in the entrance region north of the 


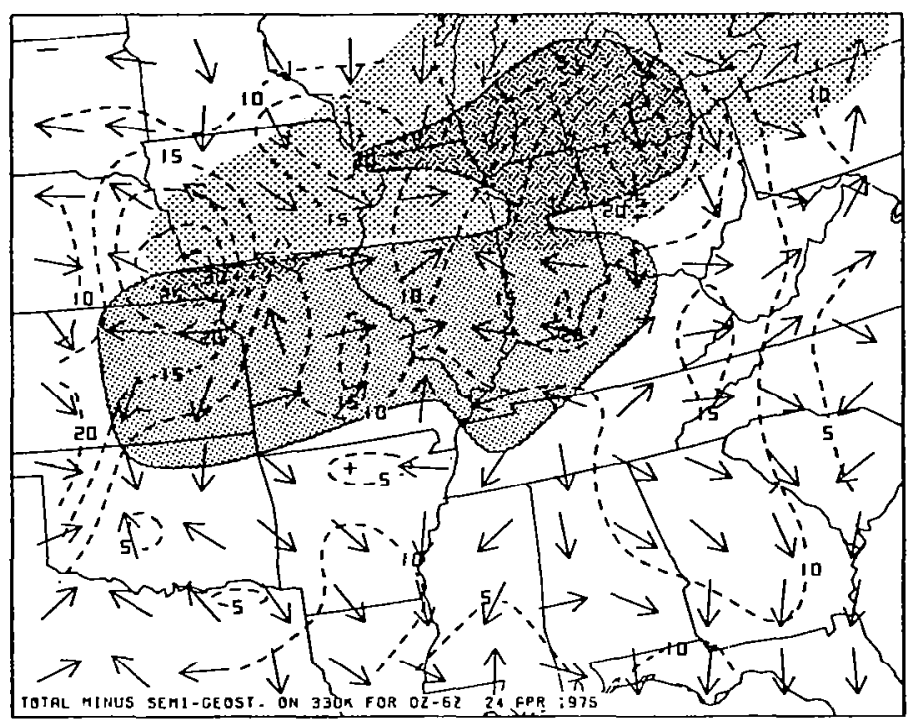

Figure 30: Difference between actual and semi-geostrophic forms of ageostrophic motion vectors and isotachs (dashed, $\mathrm{m} \mathrm{s}^{-1}$ ) for $330 \mathrm{~K}$ isentropic surface. Time period and format for jet streak and MCC A same as in Figure 12.

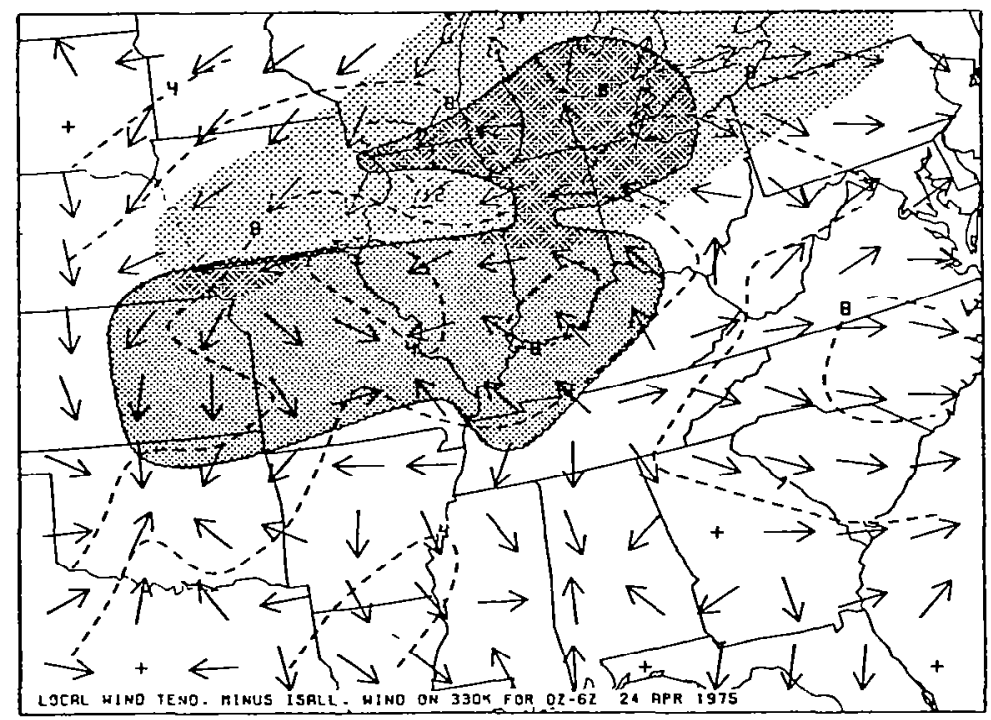

Figure 31: Difference between local wind tendency and isallobaric wind vectors and isotachs (dashed, $\mathrm{m} \mathrm{s}^{-1}$ ) for $330 \mathrm{~K}$ isentropic surface. Time period and format for jet streak and MCC A same as in Figure 12. 
convection, one over southeastern Nebraska and the other over northeastern Iowa; the third region is over northern Ohio. In all three locations the difference exceeds $20 \mathrm{~m} \mathrm{~s}^{-1}$. The results indicate that the major source of these large differences stems from the discrepancy between the actual and semi-geostrophic forms for the inertial advective component. The difference between the local wind tendency and isallobaric wind components,

$$
f^{-1} \underline{\sim} \times\left(\frac{\partial}{\partial t_{\theta}} \tilde{U}-\frac{\partial}{\partial t_{\theta}} \underset{g}{U_{g}}\right)=f^{-1} k \times\left(\frac{\partial}{\partial t_{\theta}} \underset{\sim}{U_{a g}}\right),
$$

is substantially smaller on $30 \mathrm{~K}$ (see Figure 31 ) than the difference of the two forms for total ageostrophic motion. This result displays the limitations of the employment of semi-geostrophic theory over shorter time scales within which a rapid evolution in the ageostrophic wind structure occurs.

b. Jet streak-MCC interaction case of 002 to $06 Z 25$ April 1975

1) Structure of the isentropic mass circulation

The pattern of the time-averaged horizontal mass flux divergence on $330 \mathrm{~K}$ and $305 \mathrm{~K}$ is presented in Figures $32 \mathrm{a}$ and $32 \mathrm{~b}$ respectively. Note that the mesoscale mass circulation driven by MCC B forces strong upper level horizontal mass flux divergence within the convective region and horizontal mass flux convergence at lower isentropic levels. The vertical profile of time-areally-averaged horizontal mass flux divergence over MCC B is illustrated in Figure 33 (see Figure 32a for the location of the eighteen grid points utilized for the areal-averaged 

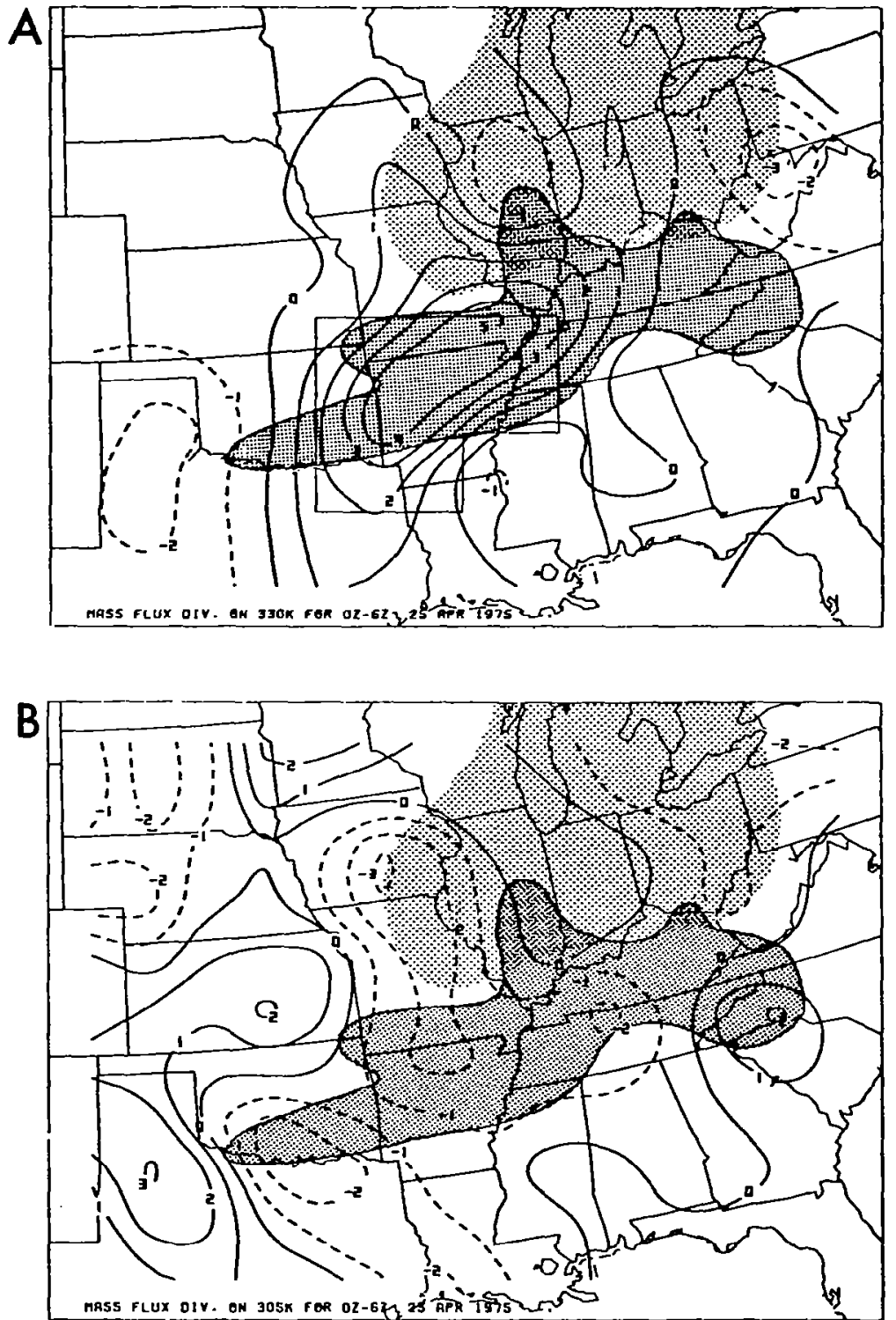

Figure 32: Time-averaged horizontal mass flux divergence for (a) $330 \mathrm{~K}$ isentropic surface and (b) $305 \mathrm{~K}$ isentropic surface (positivesolid, negative-dashed, $\times 10^{1} \mathrm{~g} \mathrm{~m}^{-2} \mathrm{~s}^{-1}$ ) computed for $00 Z$ to $06 Z 25$ April 1975. Grid points used in areal averaging for Figure 33 are enclosed with solid line in (a). Mesoscale convective complex $B$ and observed wind speeds greater than $40 \mathrm{~m} \mathrm{~s}^{-1}$ on $330 \mathrm{~K}$ at $06 \mathrm{Z} 25$ April 1975 are stippled. 


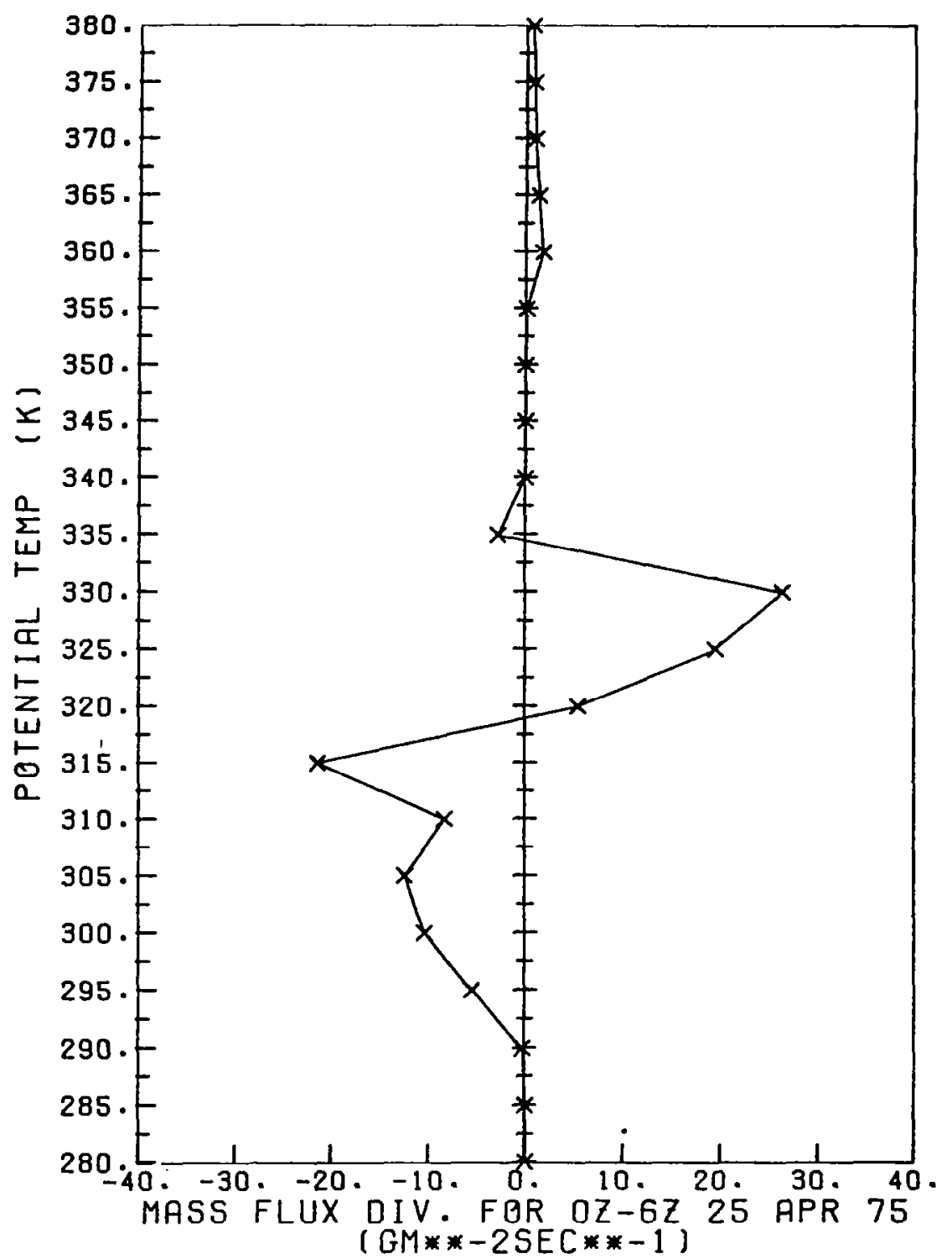

Figure 33: Vertical profile of time-areally-averaged horizontal mass flux divergence $\left(\mathrm{g} \mathrm{m}^{-2} \mathrm{~s}^{-1}\right)$ through MCC B for $00 \mathrm{Z}$ to $06 \mathrm{Z} 25$ April 1975 time interval (see Figure 32a for location of grid points used in areal averaging). 
divergence). In Figure 33, vigorous horizontal mass flux divergence in the $320 \mathrm{~K}$ to $330 \mathrm{~K}$ isentropic layer tends to be compensated for by convergence in the $295 \mathrm{~K}$ to $320 \mathrm{~K}$ layer. A comparison of Figure 13 and Figure 33 points out that the average mass circulation within MCC $B$ is more intense than in MCC A twenty-four hours earlier, since the extremum in the horizontal mass flux divergence profiles are larger for the former .

Examination of the mass tendency around MCC B in lower and upper tropospheric layers (Figures $34 \mathrm{a}$ and $34 \mathrm{~b}$ respectively) indicates that, like the first jet streak-MCC interaction case, net mass increase in lower layers tends to be balanced by net mass decrease in upper layers. Positive mass tendencies in lower layers implies that horizontal mass transport into the storm region dominates diabatic vertical mass flux out of this region. In upper layers, horizontal mass flux divergence outward dominates the vertical mass flux convergence upward into the layer and results in negative mass tendencies. The arrangement of a net increase of mass in the low troposphere with a net decrease of mass aloft implies overall static destabilization in this region.

The diabatic heating distribution, depicted on $320 \mathrm{~K}$ in Figure 35 , shows that the region of strong diabatic heating corresponds closely to the location of MCC $B$. Heating of $14 \mathrm{~K}(6 \mathrm{hr} .)^{-1}$ is observed over southeastern Missouri in the vicinity of a squall line which moved through this region over the six hour time interval. The weak diabatic cooling north and northwest of the MCC location may partly stem from 

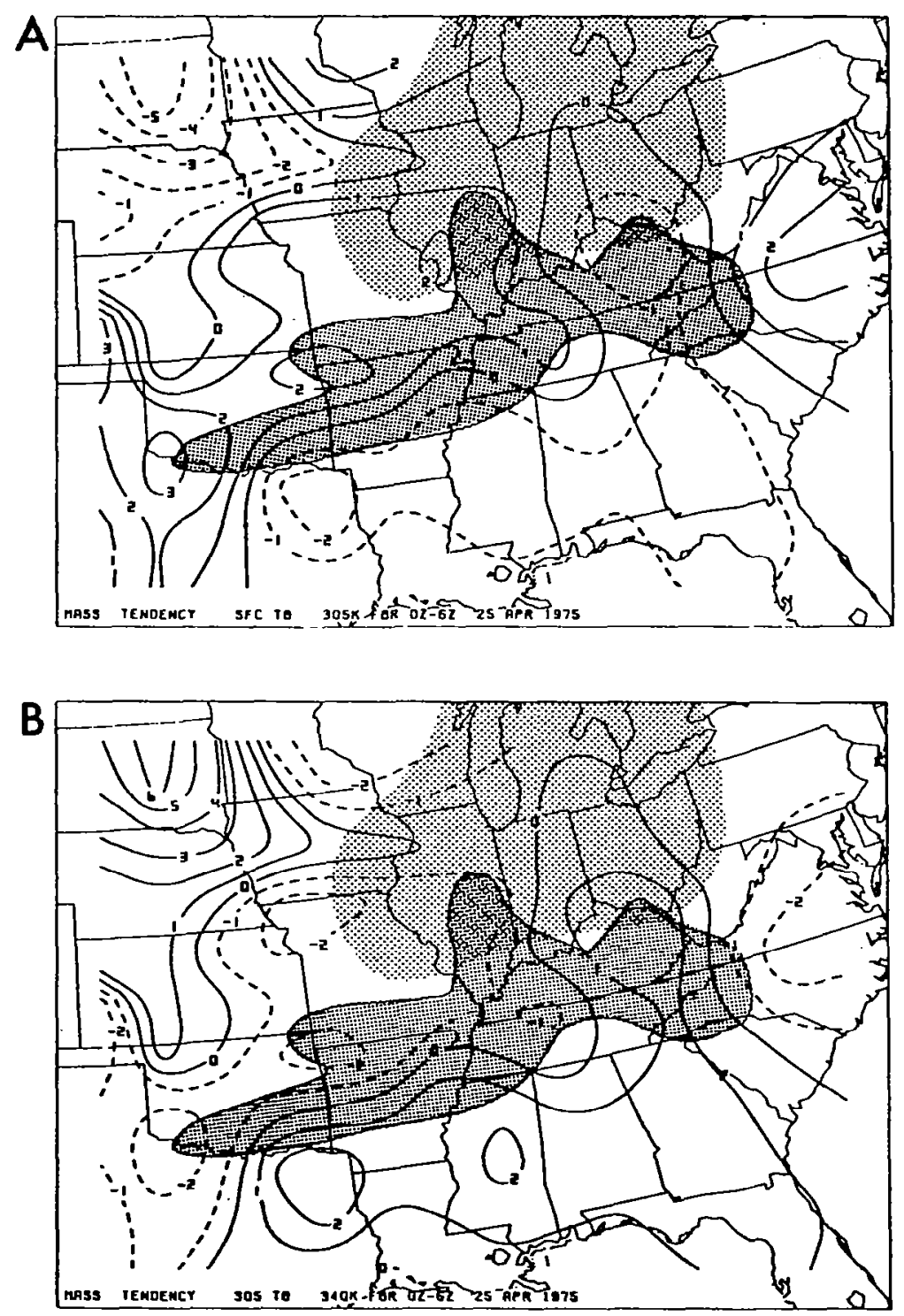

Figure 34: Mass tendency (positive-solid, negative-dashed, $\times 10^{1} \mathrm{~g} \mathrm{~m}^{-2} \mathrm{~s}^{-1}$ ) for (a) surface to $305 \mathrm{~K}$ isentropic layer and (b) $305 \mathrm{~K}$ to $340 \mathrm{~K}$ isentropic layer. Time period and format for jet streak and MCC B same as in Figure 32. 


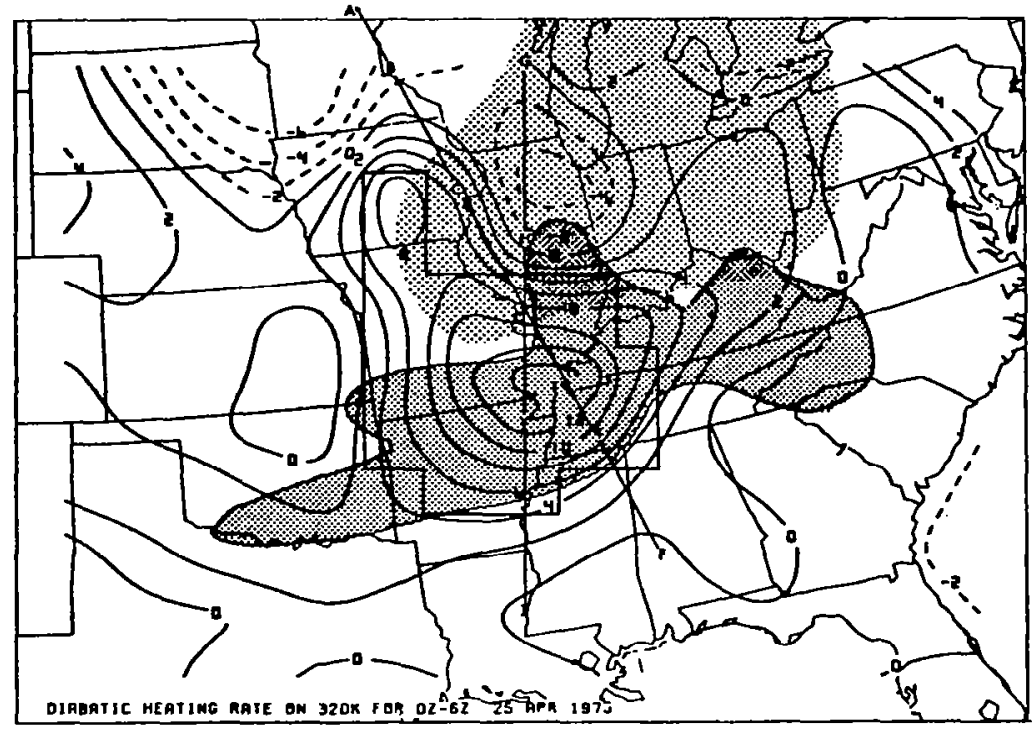

Figure 35: Diabatic heating rate $(d \theta / d t)$ (positive-solid, negativedashed, deg. $\left.K(6 \mathrm{hr} .)^{-1}\right)$ for $320 \mathrm{~K}$ isentropic surface. Time period and format for jet streak and MCC B same as in Figure 32. Grid points used in areal averaging for Figure 36 are enclosed with solid line and location of vertical cross sections in Figures $37 a, b$ are indicated by solid line segments $A-B-C-D-E-F$ and $G-H-I-J$.

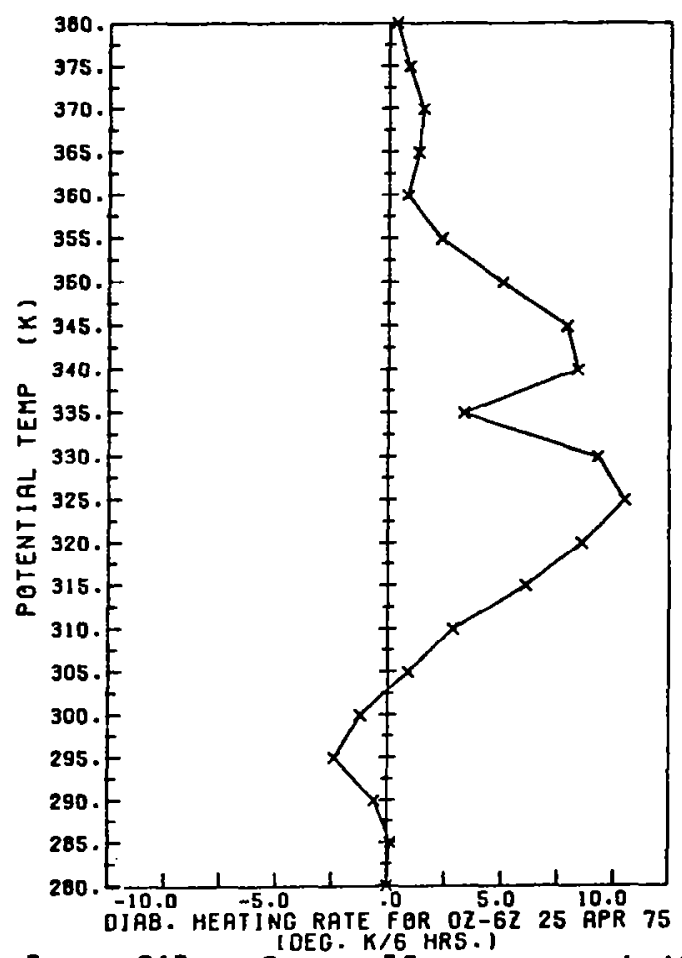

Figure 36: Vertical profile of areally-averaged diabatic heating rate (deg. K (6 hr. $\left.)^{-1}\right)$ through MCC B for $00 Z$ to $06 Z 25$ April 1975 time interval (see Figure 35 fór location of grid points used in areal averaging). 
the sources of computational errors similar to the ones described in the first case. A vertical profile of diabatic heating areallyaveraged over eighteen grid points covering the convective complex is displayed in Figure 36 (see Figure 35 for location of grid points). Note that heating in Figure 36 is maximized between $315 \mathrm{~K}$ and $330 \mathrm{~K}$ while diabatic cooling, possibly caused by the evaporation of falling precipitation, is found in the $290 \mathrm{~K}$ to $300 \mathrm{~K}$ isentropic layer. In a comparison, the average diabatic heating rates for MCC B are larger than for MCC A (see Figure 16).

A problem that can occur in diagnosis of the diabatic heating rates from the isentropic mass structure is illustrated in Figures 36 and 16. Both figures display a secondary heating maximum located in the $340 \mathrm{~K}$ to $350 \mathrm{~K}$ isentropic layer. At these isentropic levels, located near and above the tropopause, strong static stability dictates that the amount of mass between isentropic surfaces must be small. Since diabatic heating rates $(d \theta / d t)$ are obtained by dividing the diabatic mass flux $(\rho \mathrm{J} d \theta / d t)$ by the mass $(\rho J)$, the small values of the mass in the stratosphere likely unrealistically inflate sources of error in estimates of diabatic heating at these higher levels.

A vertical cross section through the jet streak and MCC B is represented in Figures 37a and 37b for 00Z 25 April and 06225 April respectively (see Figure 35 for location of cross sections). Maximum winds in the jet core are observed to increase from $45 \mathrm{~m} \mathrm{~s}^{-1}$ to $55 \mathrm{~m} \mathrm{~s}^{-1}$ over this six hour time period. In the structure of the isen- 

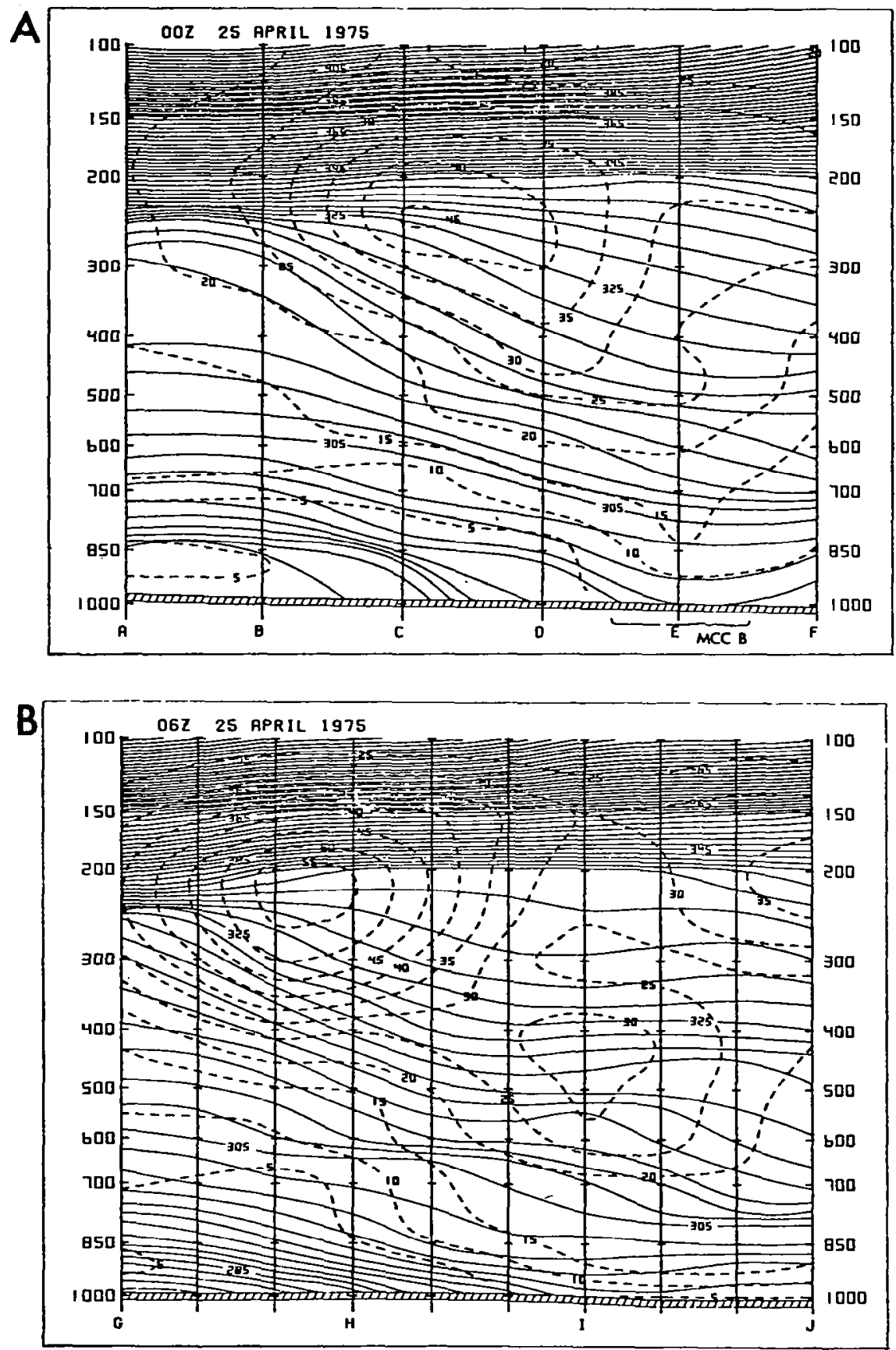

Figure 37: Vertical cross section through jet streak and MCC B depicting observed wind isotachs (dashed, $\mathrm{m} \mathrm{s}^{-1}$ ) and isentropes (solid, deg. K) for (a) $00 Z 25$ April 1975 and (b) 06225 April 1975. Vertical coordinate is pressure (mb) (see Figure 35 for location of cross sections). 
tropic surfaces within MCC B, a slight dip is evident near $850 \mathrm{mb}$ in Figure $37 \mathrm{~b}$. This feature is probably linked with the strong diabatic latent heating and general warming of the low troposphere within the storm complex.

In summary, just like the previous case of jet streak-MCC interaction, the isentropic mass circulation within MCC B is characterized by low level horizontal mass flux convergence and upper level horszontal mass flux divergence linked by a vertical branch forced through diabatic processes. In this second case, however, the mesoscale mass circulation is more intense since magnitudes for horizontal and vertical mass flux divergence are larger than for the previous jet streak-MCC interaction event. Note that the relative locations of MCC $A$ and MCC $B$ with respect to the jet streaks are similar. Since both convective regions are located south of the jet streak entrance region, this convective scale mass circulation in both cases interacts with the secondary circulation of their respective jet streaks.

2) Structure of the ageostrophic motion field

Figure 38, which depicts the time-averaged ageostrophic motion field for this case on $330 \mathrm{~K}$, shows southerly and southeasterly ageostrophic winds exceeding $10 \mathrm{~m} \mathrm{~s}^{-1}$ over Illinois and Missouri in the entrance region of the jet streak. Note that this flow structure suggests divergence from the region of MCC B. Ageostrophic motion for this case is slightly weaker than for the first event, as evidenced by comparing Figures 18 and 38 . 


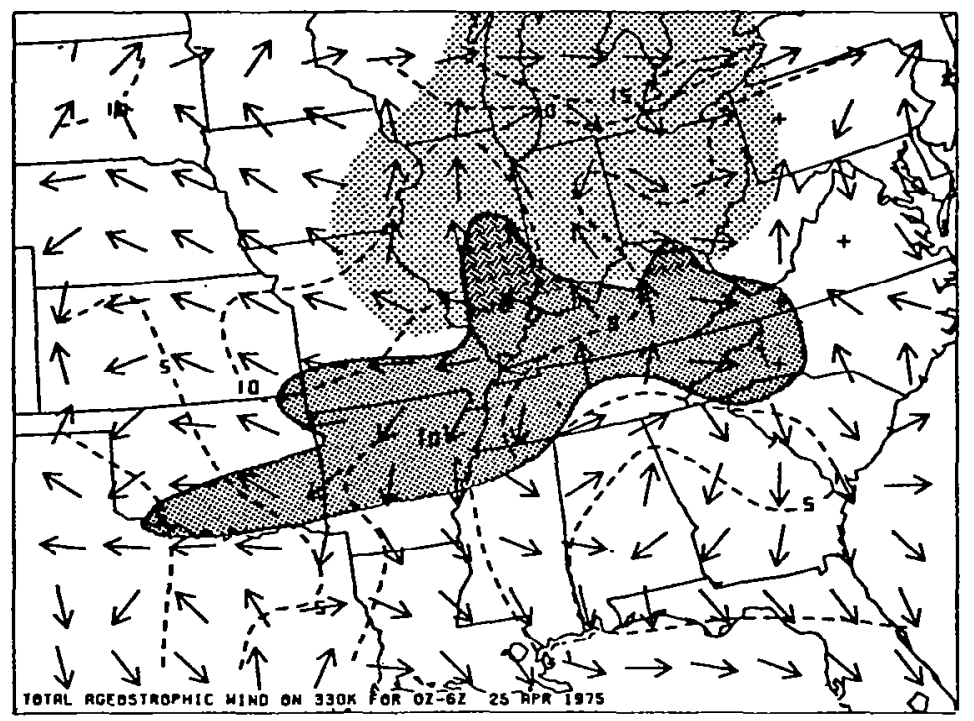

Figure 38: Time-averaged total ageostrophic wind vectors and isotachs (dashed, $\mathrm{m} \mathrm{s}^{-1}$ ) for $330 \mathrm{~K}$ isentropic surface. Time period and format for jet streak and MCC B same as in Figure 32.

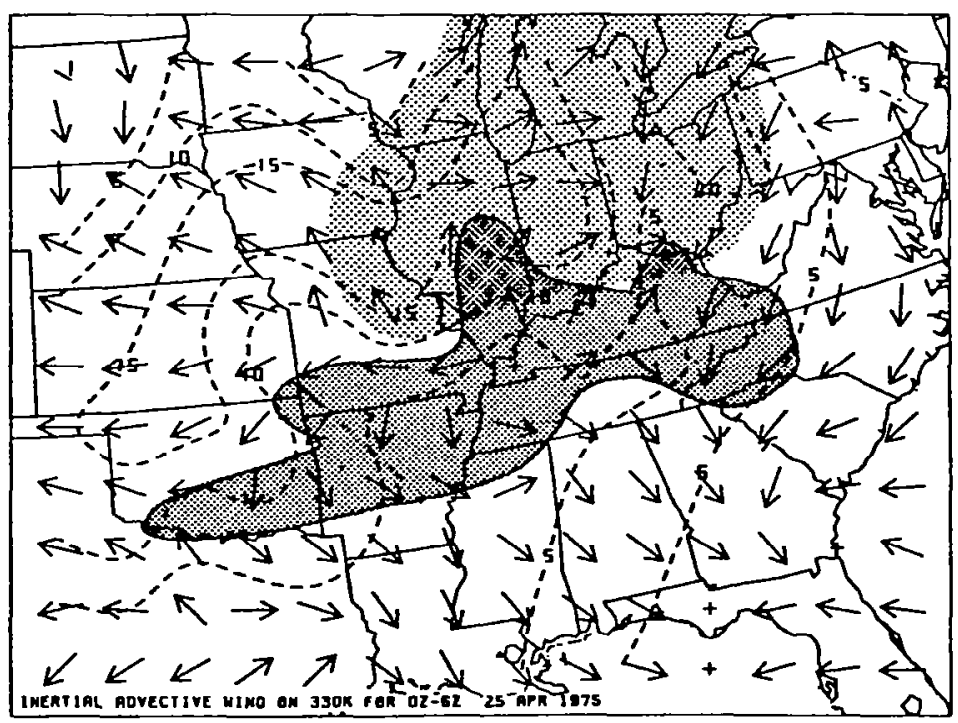

Figure 39: Time-averaged inertial advective wind vectors and iśotachs (dashed, $\mathrm{m} \mathrm{s}^{-1}$ ) for $330 \mathrm{~K}$ isentropic surface. Time period and format for jet streak and MCC B same as in Figure 32. 
The direction field of the time-averaged inertial advective wind pattern on $330 \mathrm{~K}$ displayed in Figure 39 , while slightly noisy in the entrance region, depicts strong south and southeasterly winds exceeding $15 \mathrm{~m} \mathrm{~s}^{-1}$ over southern Illinois, northern Missouri and southern Iowa. A comparison of Figures 19 and 39 indicates that, unlike the case twenty-four hours earlier, the inertial advective component does provide an important contribution to the total ageostrophic wind field in this region. Note the divergence of inertial advective ageostrophic motion on the $330 \mathrm{~K}$ isentropic surface within MCC B.

Figure 40 illustrates the local wind tendency component of ageostrophic motion on the $330 \mathrm{~K}$ isentropic surface over the six hour time period for this case. Strong easterly and northeasterly winds are present in the entrance region with values over Illinois exceeding $12 \mathrm{~m} \mathrm{~s}^{-1}$. In the entrance region the intensity of the local wind tendency component at jet streak level is less than the intensity of the inertial component and is directed orthogonal to both the total ageostrophic motion and the inertial advective component.

The inertial diabatic component of ageostrophic motion for the $320 \mathrm{~K}$ to $325 \mathrm{~K}$ isentropic layer is displayed in Figure 41 . Note that southeasterly wind speeds exceed $4 \mathrm{~m} \mathrm{~s}^{-1}$ in a region extending from central Missouri to northeastern Illinois; this area corresponds to the entrance region of the jet streak. Wind magnitudes as large as $10 \mathrm{~m} \mathrm{~s}^{-1}$ appear over northeastern Missourt. A comparison of Figure 21 and Figure 41 shows that mid-and upper level inertial diabatic wind 


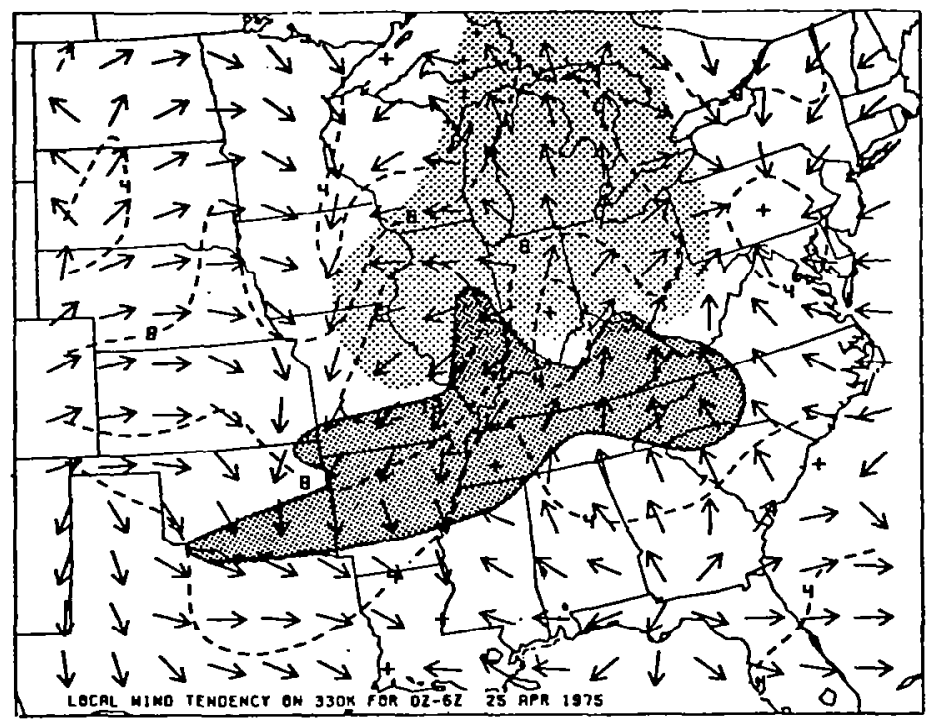

Figure 40: Local wind tendency vectors and isotachs (dashed, $m \mathrm{~s}^{-1}$ ) for $330 \mathrm{~K}$ isentropic surface. Time period and format for jet streak and MCC B same as in Figure 32 .

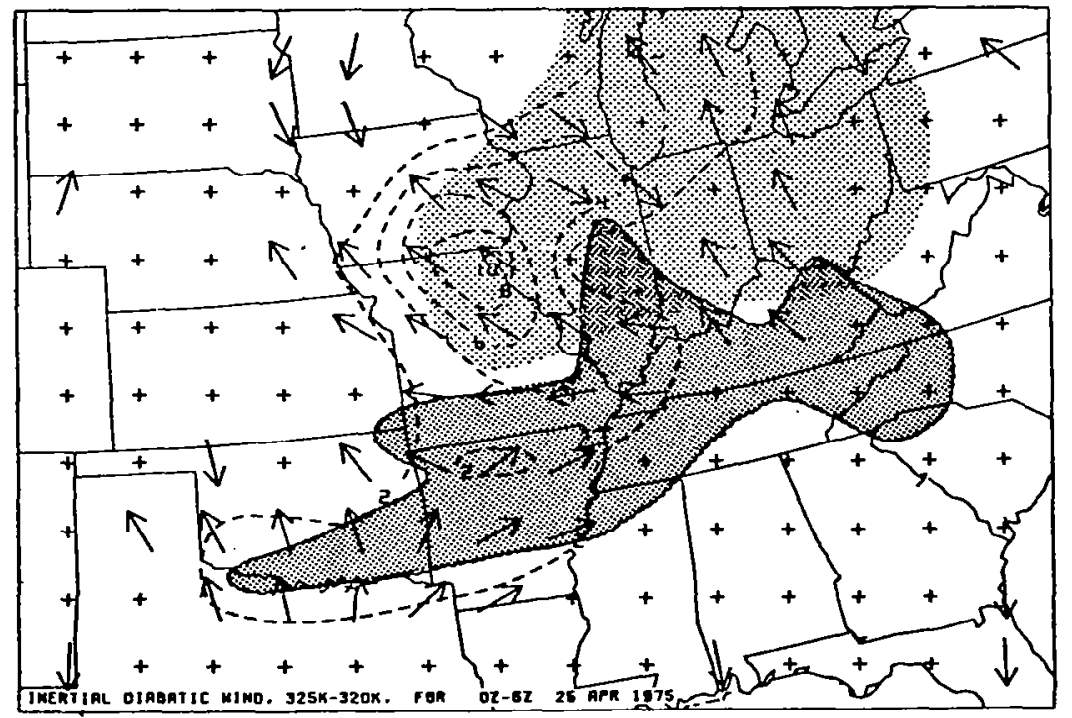

Figure 41: Inertial diabatic wind vectors and isotachs (dashed, $\mathrm{m} \mathrm{s}^{-1}$ ) for $320 \mathrm{~K}$ to $325 \mathrm{~K}$ isentropic layer. Time period and format for jet streak and MCC $B$ same as in Figure 32. 


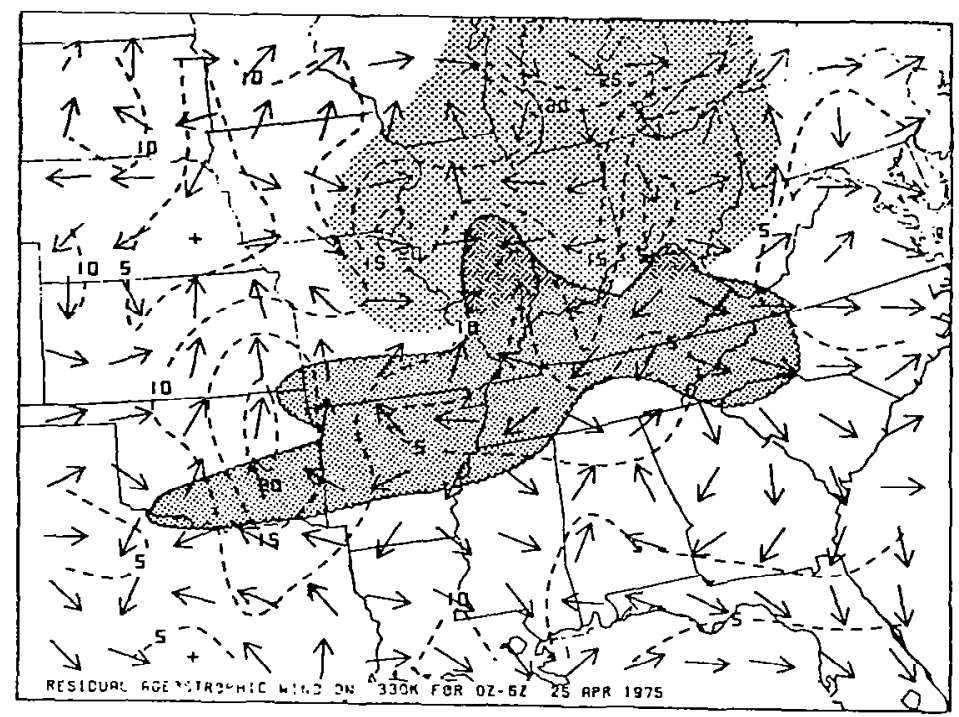

Figure 42: Residual ageostrophic wind vectors and isotachs (dashed, $\left.\mathrm{m} \mathrm{s} \mathrm{s}^{-1}\right)$ for $330 \mathrm{~K}$ isentropic surface. Time period and format for jet streak and MCC B same as in Figure 32. 
magnitudes are slightly larger for this case than for the previous case.

The direction field of the time-averaged residual ageostrophic wind, depicted on $330 \mathrm{~K}$ in Figure 42, exhibits a great deal of noise in the entrance region; however, in northern Illinois and Indiana the wind speed does exceed $15 \mathrm{~m} \mathrm{~s}^{-1}$. The more random nature of the direction in the ageostrophic motion in this field is likely associated with either errors in the data or in computational approximations. A comparison of Figures 41 and 42 points out the large discrepancy between the noisy residual term and the inertial diabatic wind structure. Stronger inertial diabatic wind intensity would have likely been obtained with higher time and space resolution in the data, as explained in the first case. The favorable location of the strongest values for this term indicates that it provides a significant contribution to the total ageostrophic motion field in the entrance region for this second jet streak-MCC interaction event.

3) Ageostrophic motion estimated through the semi-geostrophic momentum approximation

The time-averaged semi-geostrophic form for $330 \mathrm{~K}$ inertial advective ageostrophic motion is depicted in Figure 43. Just as with the first case of jet streak-MCC interaction, a large difference generally appears between the actual and semi-geostrophic forms for this component of ageostrophic motion (see Figure 39). The direction field of the semi-geostrophic wind component is quite noisy. Note the poor com- 


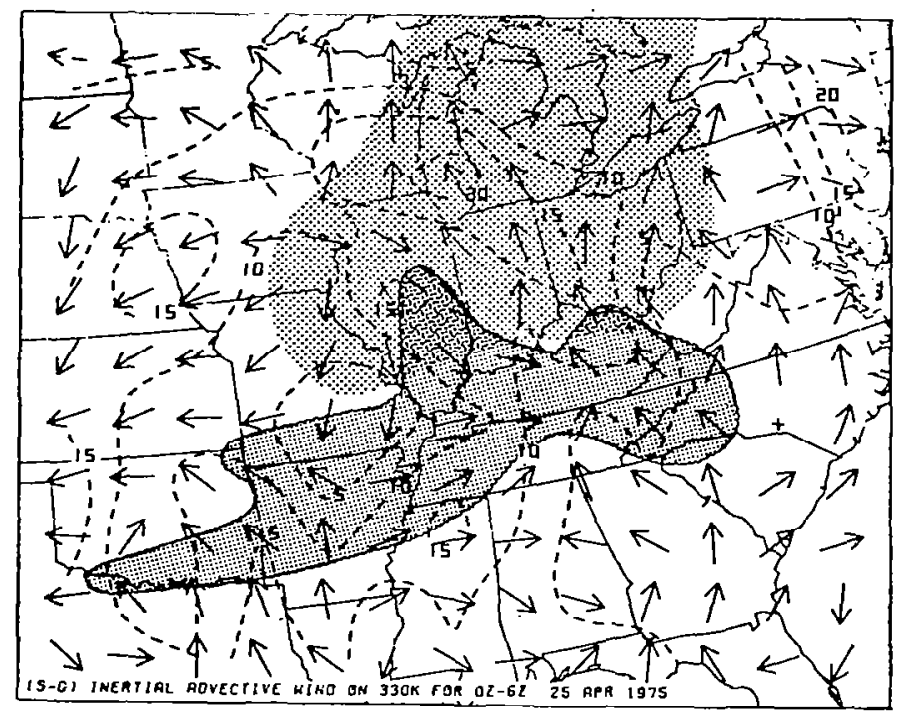

Figure 43: Time-averaged semi-geostrophic inertial advective wind vectors and isotachs (dashed, $\mathrm{m} \mathrm{s}^{-1}$ ) for $330 \mathrm{~K}$ isentropic surface. Time period and format for jet streak and MCC B same as in Figure 32.

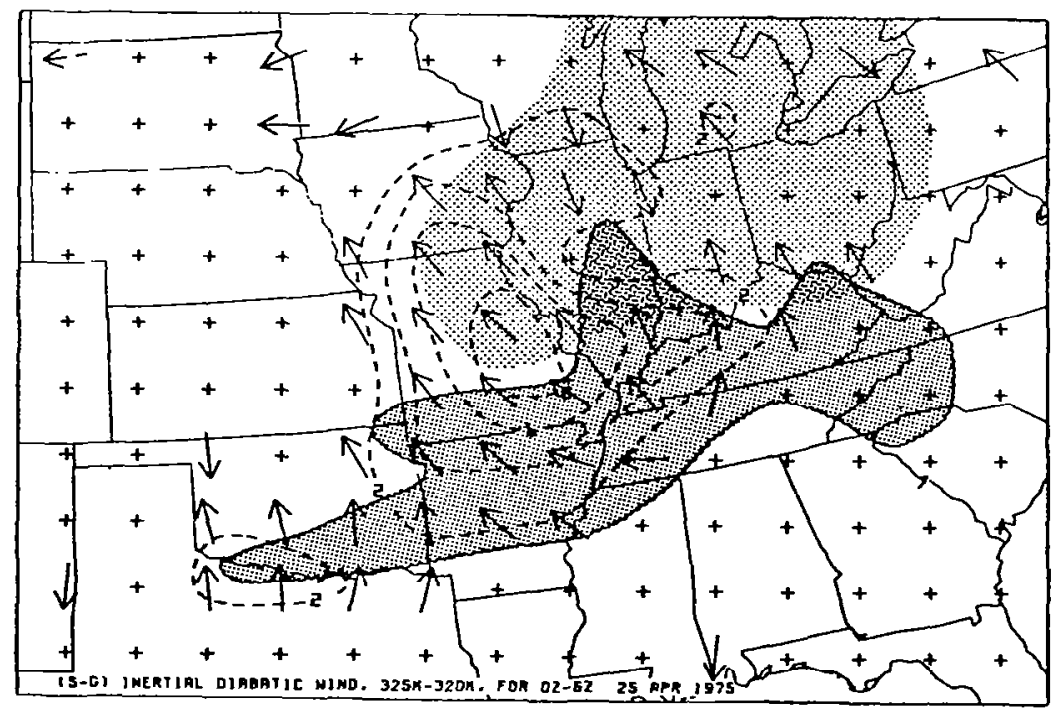

Figure 44: Semi-geostrophic inertial diabatic wind vectors and isotachs (dashed, $\mathrm{m} \mathrm{s}^{-1}$ ) for $320 \mathrm{~K}$ to $325 \mathrm{~K}$ isentropic layer. Time period and format for jet streak and MCC B same as in Figure 32. 
parison to actual inertial advective motion in the western flank of the entrance region over Illinois and Missouri where northerly semigeostrophic inertial advective winds are observed.

Just like the first case, the difference between the semigeostrophic form of inertial diabatic motion (see Figure 44) and the actual form of inertial diabatic motion (see Figure 41 ) in the $320 \mathrm{~K}$ to $325 \mathrm{~K}$ isentropic layer is smal1. In both cases, southeasterly winds are present in the entrance region extending from Ohio to Kansas with magnitudes greater than $8 \mathrm{~m} \mathrm{~s}^{-1}$ over Missouri.

The structure of the semi-geostrophic isallobaric wind is shown on the $330 \mathrm{~K}$ level in Figure 45a. Immediately apparent in this figure is the strong upper level divergence of this component from the MCC located over southern Illinois. Figure 45b depicts isallobaric motion at $310 \mathrm{~K}$ along with the well developed convergence pattern into the MCC. Although the magnitude of the isallobaric wind at $330 \mathrm{~K}$ is not quite as intense as in the previous case, its divergence and convergence pattern at $330 \mathrm{~K}$ and $310 \mathrm{~K}$ respectively is more pronounced.

The surface pressure tendency component of isallobaric motion, depicted in Figure 46, converges into MCC B. This term, however, is weak in intensity in comparison with the integrated pressure tendency term at $330 \mathrm{~K}$ (see Figure 47a). Upper level velocity divergence out of the MCC due to the integrated pressure tendency component is quite pronounced. Note that wind speeds exceed $4 \mathrm{~m} \mathrm{~s}^{-1}$ throughout the region of strongest divergence. The dominance of the integrated pressure tenden- 

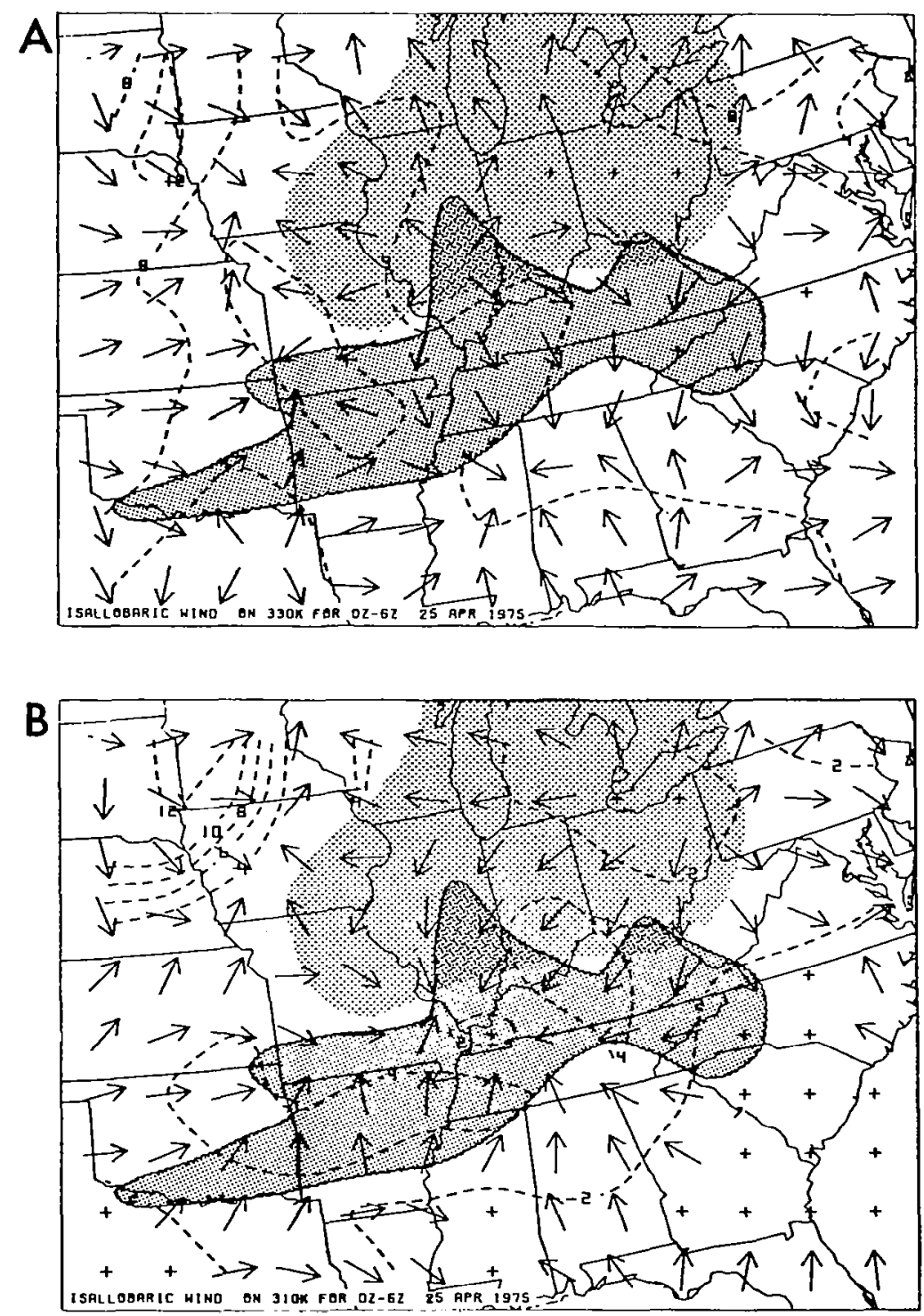

Figure 45: Isallobaric wind vectors and isotachs (dashed, $\mathrm{m} \mathrm{s}^{-1}$ ) for (a) $330 \mathrm{~K}$ isentropic surface and (b) $310 \mathrm{~K}$ isentropic surface. Time period and format for jet streak and MCC B same as in Figure 32. 


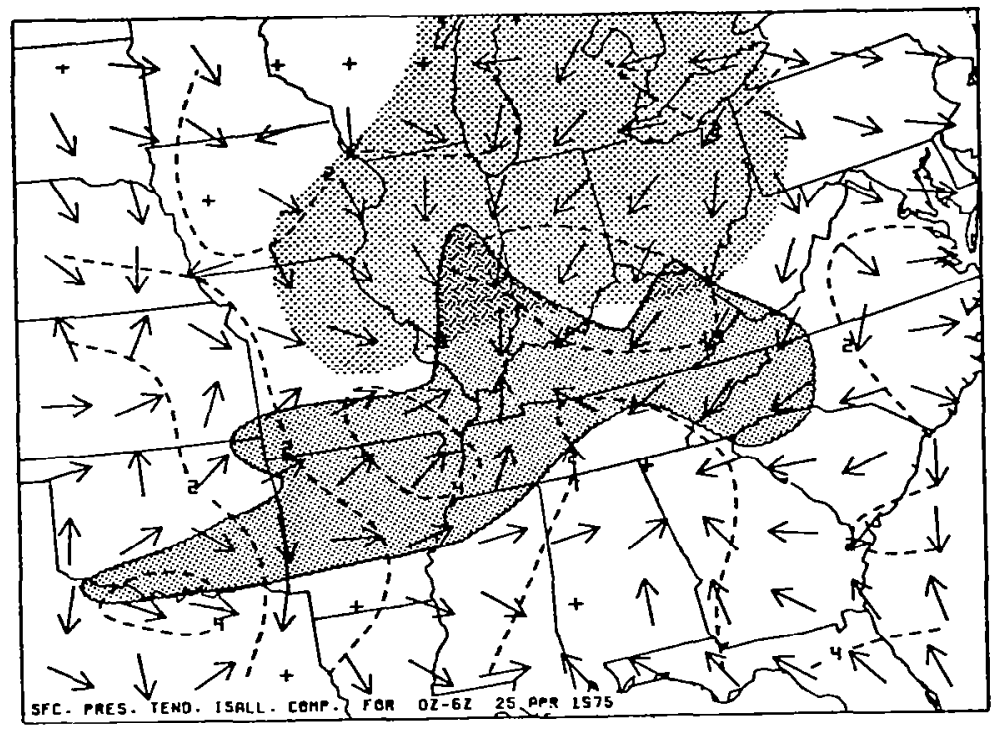

Figure 46: Surface pressure tendency isallobaric component vectors and isotachs (dashed, $m s^{-1}$ ). Time period and format for jet streak and MCC $B$ same as in Figure 32. 

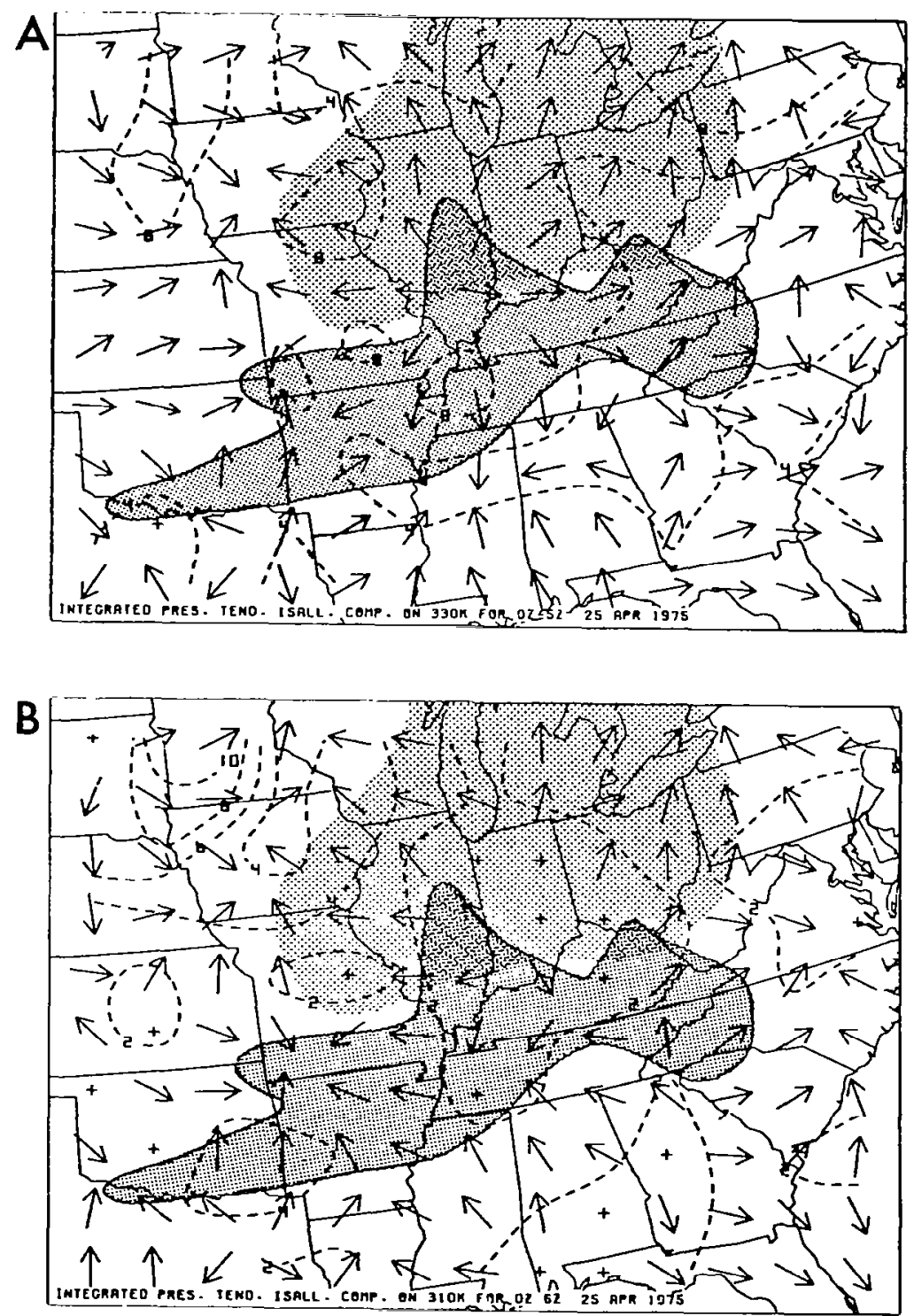

Figure 47: Integrated pressure tendency isallobaric component vectors and isotachs (dashed, $m s^{-1}$ ) for (a) $330 \mathrm{~K}$ isentropic surface and (b) $310 \mathrm{~K}$ isentropic surface. Time period and format for jet streak and MCC $B$ same as in Figure 32. 
cy term on $330 \mathrm{~K}$ for both jet streak-MCC interaction events points out that mass redistribution within mid-and lower level isentropic layers, accomplished primarily through ageostrophic motion, is mainly responsible for altering the pressure gradient force on isentropic surfaces throughout the atmospheric column. Figure 47b portrays the integrated pressure tendency component on $310 \mathrm{~K}$; note that, unlike the previous case, this term is not the dominant component of isallobaric motion at this level and features no convergence/divergence pattern within the MCC or entrance region.

The adiabatic and diabatic components of isallobaric motion on $330 \mathrm{~K}$ and $310 \mathrm{~K}$ are depicted in Figures $48 \mathrm{a}, \mathrm{b}$ and $49 \mathrm{a}$, b, respective1y. Just like the case twenty-four hours earlier, the two individual components on $330 \mathrm{~K}$ are very strong in magnitude in many locations but generally oppose each other in direction. The adiabatic component strongly converges into MCC B at upper levels, with values nearly attaining $60 \mathrm{~m} \mathrm{~s}^{-1}$ in southern 111 inois near the center of the convergence. The diabatic component exhibits equally strong magnitudes at upper levels in and around the convective complex, however its wind field is divergent. On $310 \mathrm{~K}$, the adiabatic component shows strong convergence into MCC B while the diabatic component exhibits equally strong divergence away from this same region. For each component, magnitudes exceed $12 \mathrm{~m} \mathrm{~s}^{-1}$ over southern Illinois, however, an opposition in the direction field is observed here. Since the total isallobaric wind field diverges away from MCC $B$ at upper levels and converges into 

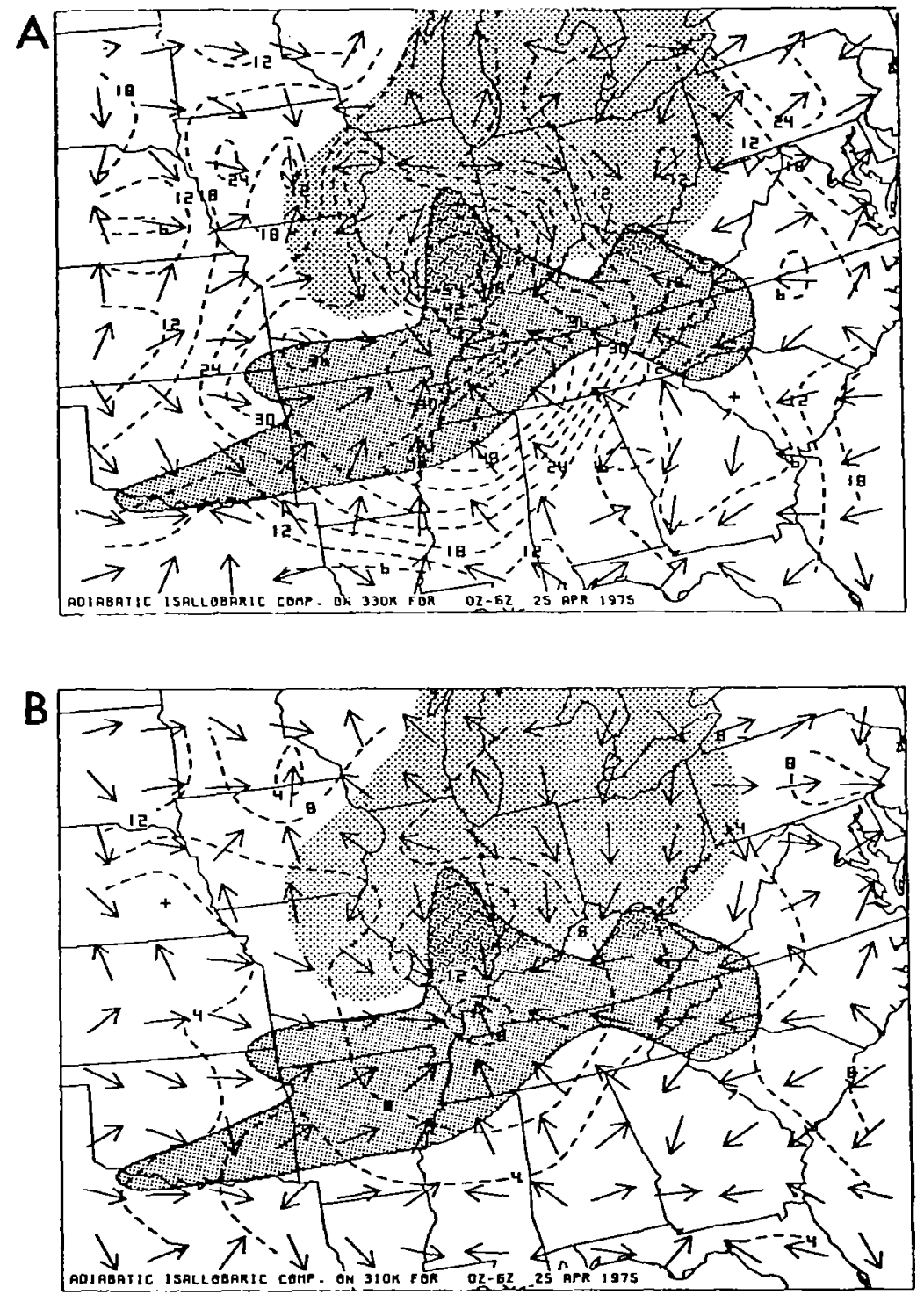

Figure 48: Adiabatic isallobaric component vectors and isotachs (dashed, $m \mathrm{~s}^{-1}$ ) for (a) $330 \mathrm{~K}$ isentropic surface and (b) $310 \mathrm{~K}$ isentropic surface. Time period and format for jet streak and MCC B same as in Figure 32. 

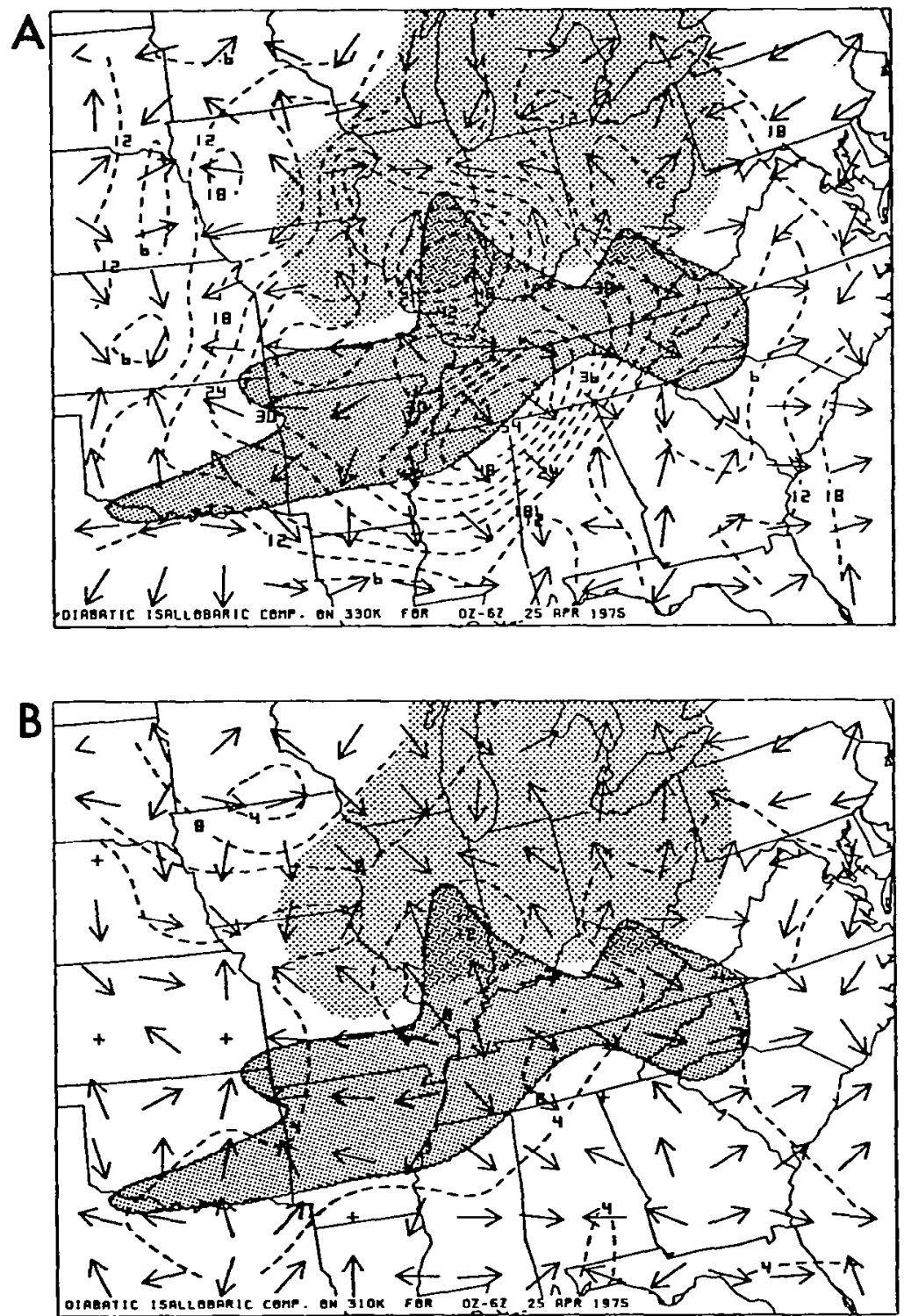

Figure 49: Diabatic isallobaric component vectors and isotachs (dashed, $\mathrm{m} \mathrm{s}^{-1}$ ) for (a) $330 \mathrm{~K}$ isentropic surface and (b) $310 \mathrm{~K}$ isentropic surface. Time period and format for jet streak and MCC $B$ same as in Figure 32. 
the convection at lower levels, the diabatic component slightly dominates the adiabatic component at upper levels while the adiabatic component is dominant at lower levels. This condition is indicative of the delicate balance between adiabatic and diabatic modes of forcing. Note that the convergence (divergence) in the adiabatic (diabatic) component of ageostrophic motion is stronger for this case than for the case twenty-four hours earlier.

The accuracy of semi-geostrophic theory is again examined in this second case of jet streak-MCC interaction. A comparison of the difference field between the actual and semi-geostrophic forms for ageostrophic motion, depicted on $330 \mathrm{~K}$ in Figure 50, points out that large magnitudes again occur in many regions. The difference exceeds $30 \mathrm{~m} \mathrm{~s}^{-1}$ over eastern Oklahoma while it is greater than $15 \mathrm{~m} \mathrm{~s}^{-1}$ over northern Nebraska and exceeds $25 \mathrm{~m} \mathrm{~s}^{-1}$ in the entrance region and northern flank of MCC B over central Illinois. Again, this large difference stems mainly from the discrepancy in the actual and semi-geostrophic forms for the inertial advective ageostrophic component. However, differences are also larger in the comparison of the local wind tendency and isallobaric wind components on $330 \mathrm{~K}$ (see Figure 51) for this case than for the previous case; this difference contributes to some of the discrepancies illustrated in Figure 50. The contribution by the local tendency of the ageostrophic wind $\left(f^{-1} \underset{\sim}{k} \times \partial \bigcup_{a g} / \partial t_{\theta}\right)$ exceeds $12 \mathrm{~m} \mathrm{~s}^{-1}$ in northeastern 0klahoma and in central Illinois. Once again, as expected, semi-geostrophic theory does not adequately describe ageostro- 


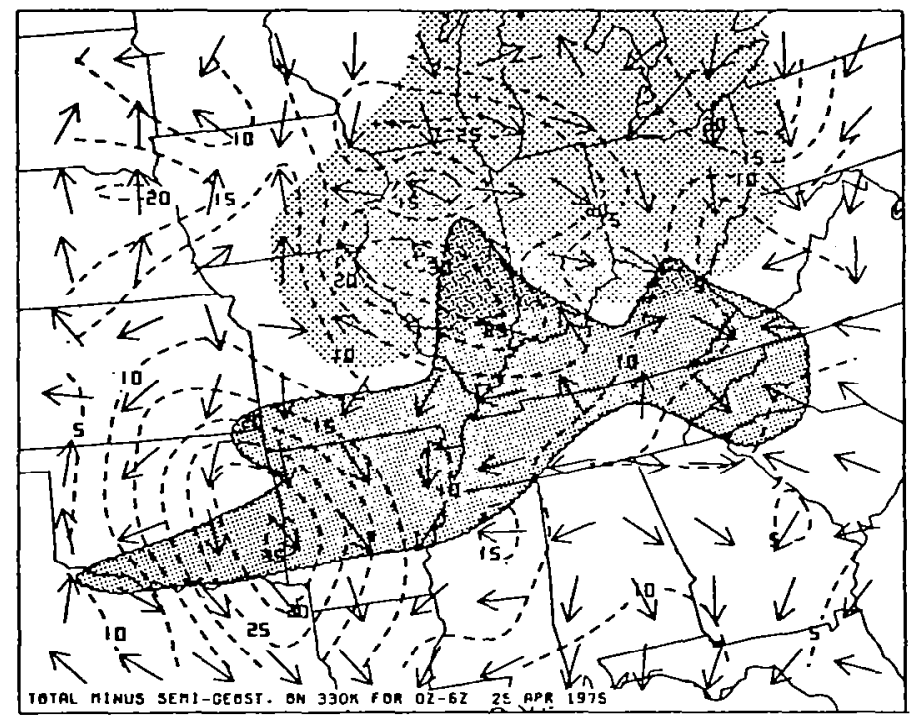

Figure 50: Difference between actual and semi-geostrophic forms of ageostrophic motion vectors and isotachs (dashed, $\mathrm{m} \mathrm{s}^{-1}$ ) for $330 \mathrm{~K}$ isentropic surface. Time period and format for jet streak and MCC B same as in Figure 32.

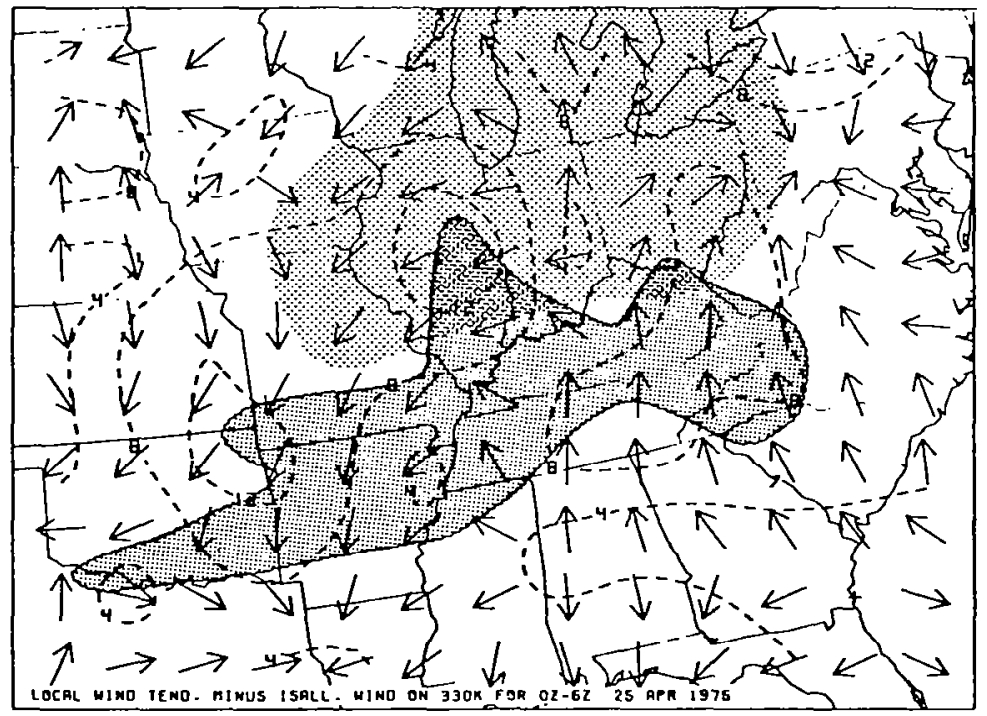

Figure 51: Difference between local wind tendency and isallobaric wind vectors and isotachs (dashed, $\mathrm{m} \mathrm{s}^{-1}$ ) for $330 \mathrm{~K}$ isentropic surface. Time period and format for jet streak and MCC B same as in Figure 32. 
phic motion in this region of jet streak-MCC interaction where the time scale of the convection is short relative to the time scale of adjustment.

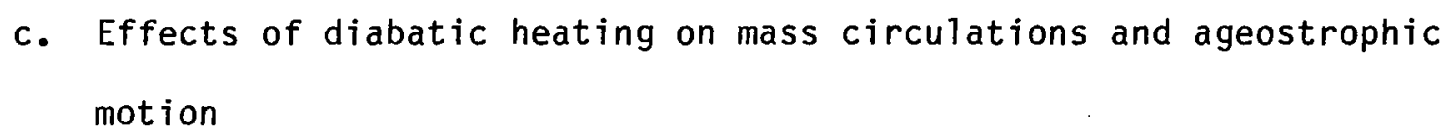
motion

The results of this study show that diabatically-induced ageostrophic motion is significant at upper tropospheric levels in the jet streak entrance region. In each case of jet streak-MCC interaction, the values of both the total isallobaric wind and the inertial diabatic wind are comparable with the values of the inertial advective wind in the upper branch of direct mass circulation in the entrance region. In this section, the effects of these diabatic components of ageostrophic motion on the direct mass circulation and on subsequently increasing wind speeds in the jet streak is examined. Also, the role diabatic heating plays in actually creating isallobaric and inertial diabatic ageostrophic motion is investigated.

The south and southeasterly direction of the isallobaric wind and the inertial diabatic components of ageostrophic motion in the upper tropospheric entrance region for both jet streak-MCC interaction events indicates that these two ageostrophic wind components act to transport mass transverse to the jet streak from the anticycionic side to the cyclonic side at this level. Since both of these components of ageostrophic motion are directed nearly the same as the pre-existing inertial advective wind within the upper branch of the direct circulation, 
the increase in the intensity of the total ageostrophic wind at this level through diabatic processes leads to an intensification of the direct mass circulation. This suggests a mechanism for the acceleration of wind speeds in the jet streak downstream. The effect of stronger transverse ageostrophic motion in the acceleration of winds and generation of kinetic energy in the jet streak can be physically explained through the isentropic kinetic energy equation

$$
\frac{d k}{d t}=\underset{\sim}{-U_{a g} \cdot \nabla_{\theta} \psi_{m}}+\underset{\sim}{U} \cdot \underset{\sim}{F},
$$

where $k$ is the specific kinetic energy of the horizontal wind field. Ageostrophic winds, which flow toward lower pressure $\left(\psi_{m}\right)$ in the entrance region, generate kinetic energy at jet streak level through acceleration within the jet core. The additional momentum generated through the ageostrophic imbalance towards lower pressure in the upper branch of the direct circulation is unbalanced and thus will inertially turn anticyclonically with some period proporional to the one-half pendulum day (Haltiner and Martin, 1957). At $45^{\circ}$ north latitude, this period is approximately 17 hours indicating that over a time interval of approximately four and one-quarter hours the ageostrophic wind, with its downstream movement, will rotate approximately ninety degrees and be orientated along the direction of the mean flow in the jet core. Thus, as indicated in Figure 52, the rotation of the ageostrophic wind vector creates a component of total velocity which increases wind speeds within the jet streak. The stronger the initial ageostrophic 

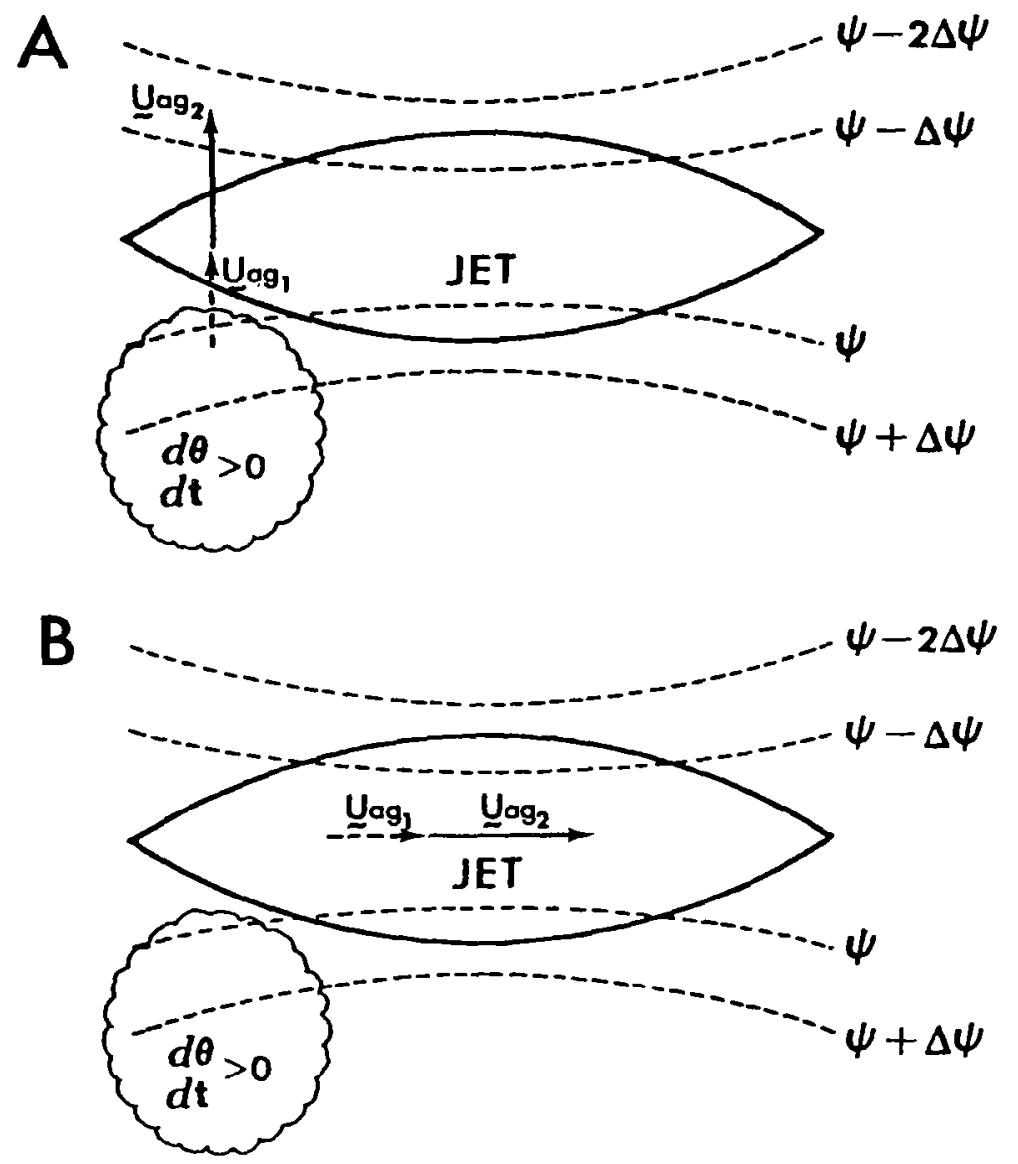

Figure 52: (a) schematic showing diabatically-induced ageostrophic motion (Uagl) directed in same sense as pre-existing inertial advective wind (Uag2). (b) schematic of jet streak with increased velocity due to inertial rotation of ageostrophic motion. 
motion in the upper branch of the entrance region, the stronger the increase in wind speeds downstream in the jet core.

These results have demonstrated that diabatic heating forces ageostrophic motion in the isentropic framework through both isallobaric and inertial diabatic effects. Figure 53 illustrates the effect of diabatic heating in the MCC in creating isallobaric motion. With the development of the MCC, the gradient of the heating distribution will form a diabatic component of the isallobaric ageostrophic wind through intensification of the pressure gradient force on isentropic surfaces in mid-and upper levels of some regions and reduction of the pressure gradient force in other regions. The isentropes in the region of strong diabatic heating drop to higher pressure levels in association with a general increase of temperature in the region of convection. Within a vertically-sheared geostrophic current of uniform direction, the warming of the troposphere in the region of convection increases the thermal wind to the left of the current and decreases the thermal wind to the right of the current. The upper level isallobaric winds, forced diabatically, are a manifestation of these processes and lead to an increase in the horizontal mass divergence from the MCC in the upper levels. In the entrance region of the jet streak the motion realized through diabatic forcing is directed in the same sense as the upper branch of the direct circulation. With the mass flux divergence created by isallobaric motion aloft, the surface pressure tendency subsequently becomes negative immediately beneath the MCC and becomes posi- 


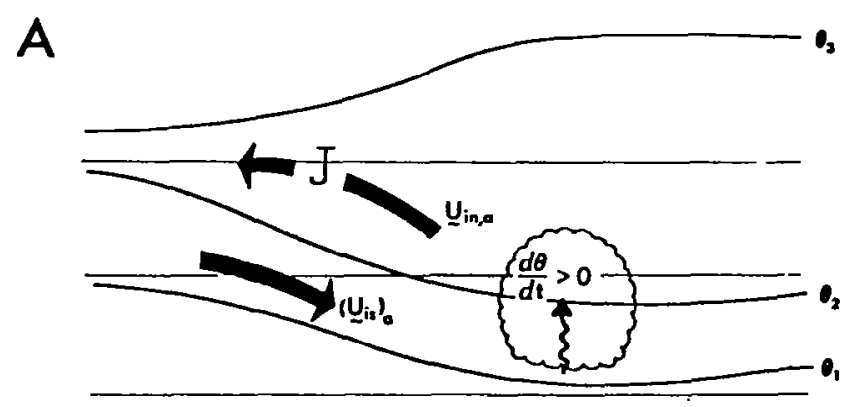

B

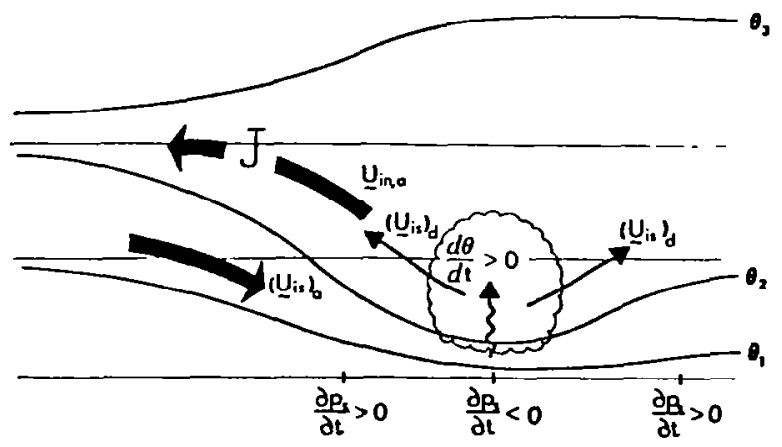

C

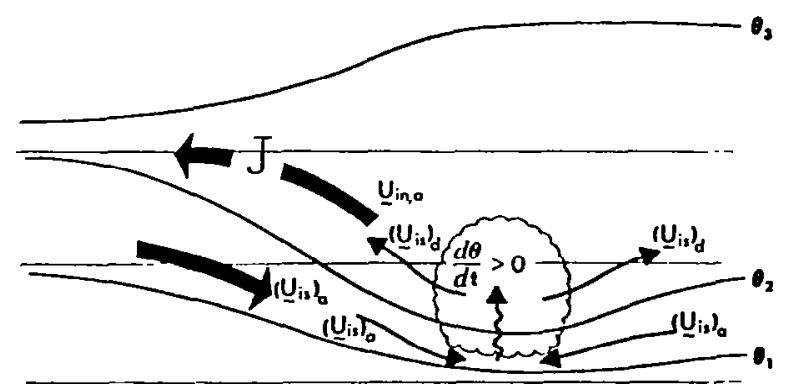

Figure 53: Vertical cross section schematic normal to jet streak (J) showing (a) location of developing MCC in relation to direct circulation in entrance region, (b) upper level isallobaric wind [ $\left.\left(\cup_{j}\right)_{d}\right]$ forced by differential diabatic heating in mature MCC with resulting surface pressure tendencies and (c) resultant lower level adiabatically-induced isallobaric wind $\left[\left(\underline{U}_{i s}\right)_{a}\right]$ convergence into MCC. 
tive in regions flanking the convection. The changing surface pressure field due to the redistribution of mass results in an adiabatic component of the isallobaric wind at low levels which converges into the MCC and is coupled with the isallobaric wind at high levels that forces divergence from the MCC. Beneath the jet, this ageostrophic flow is in the same direction as the pre-existing lower branch of the direct circulation. This mesoscale circulation within the MCC therefore acts to intensify the thermally-direct mass circulation in the entrance region of the jet streak.

The concept that lower level isallobaric winds converge into the MCC and upper level isallobaric winds diverge away from the MCC has been physically verified by the results of this case study and provides a physical basis for the forcing of this component of ageostrophic motion by the combination of adiabatic and diabatic processes. For each jet streak-MCC interaction event, the adiabatic isallobaric mode converged into the MCC at lower and upper levels while the diabatic isallobaric mode diverged away from the MCC at lower and upper levels. The sense of the net circulation is determined by the diabatic forcing within the MCC at the mesoscale and the direct circulation within the jet streak at the synoptic scale. Such a circulation represents an adjustment of the mass-momentum and pressure distributions whereby the horizontal branches of the mass circulation become directly linked with the vertical branches. The diabatic isallobaric mode strengthens the upper branch of the direct mass circulation in the entrance region of 
the jet streak while the adiabatic isallobaric mode strengthens the lower branch of this circulation since the upper level divergence and lower level convergence fields within the MCC are directed in the same sense as the pre-existing ageostrophic motion field in the entrance region. The combination of the results from this study of processes in the entrance region of the jet streak show that: 1) a diabaticallyinduced isallobaric wind exists within the isentropic structure, 2) the isallobaric motion field associated with the MCC produces a direct circulation and 3 ) the diabatic mode dominates the adiabatic mode of isallobaric motion at upper levels while the reverse is true at lower levels. The diabatically-induced isallobaric wind provides the physical basis for the findings of Maddox and Ninomiya that jet streaks are intensified through diabatic processes.

The fact that the sense of diabatically-induced ageostrophic motion through isallobaric processes is the same as the upper branch of the direct circulation associated with the jet streak is in all likelihood determined by the inertial diabatic ageostrophic motion. In the vertically-sheared flow of the entrance region diabatic heating will produce inertial diabatic ageostrophic motion in mid- and upper levels. Thus, in the entrance region of the jet streak where both diabatic heating rates and vertical wind shears are strong, the vertical mass transport associated with the diabatic heating serves to transport momentum upward where horizontal momentum is now less than the geostrophic momentum balance of the higher level. Thus, the momentum in the 


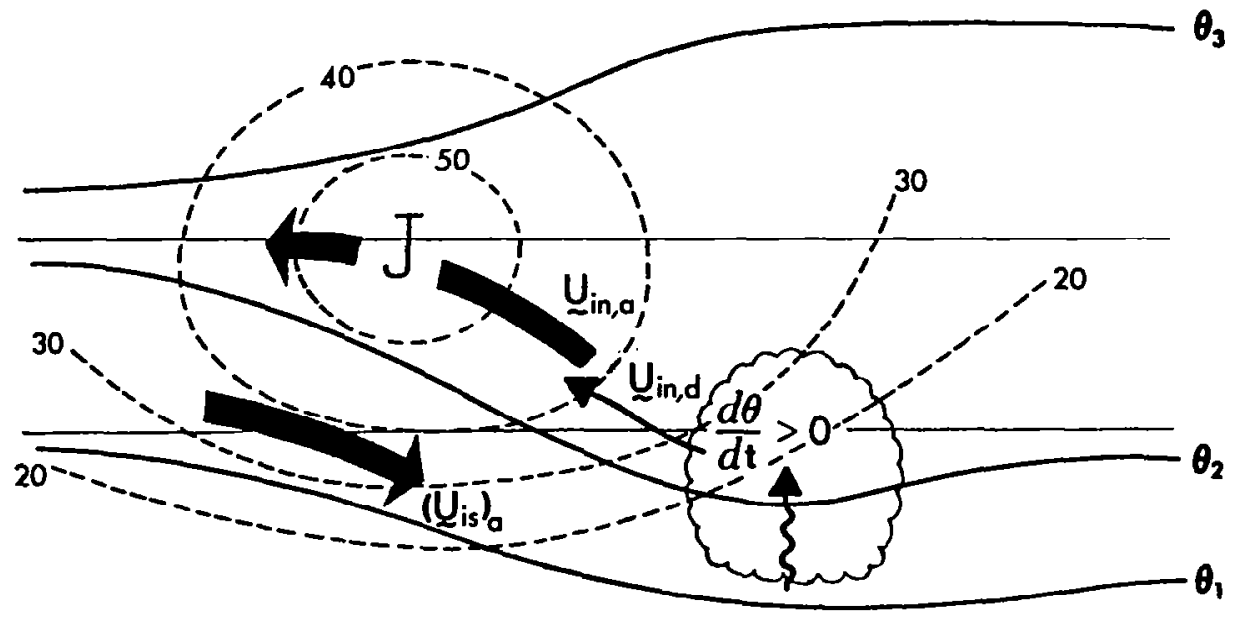

Figure 54: Vertical cross section schematic normal to jet streak (J) showing pre-existing direct circulation in entrance region and source of inertial diabatic wind $\left(U_{i n, d}\right)$ through combination of diabatic heating and vertical wind shear in MCC. Dashed lines indicate typical observed wind speeds $\left(\mathrm{m} \mathrm{s}^{-1}\right)$ in vicinity of jet core. 
regions of upward diabatic mass transport is subgeostrophic and is accelerated into the direction of the pressure gradient force towards lower $\psi_{m}$ values, thereby generating kinetic energy and intensifying the jet streak. Inertial diabatic motion is directed from the anticyclonic side to the cyclonic side of the jet streak at upper tropospheric levels (see Figure 54) in the same sense as the thermally-direct mass circulation of the larger scale. This orientation of inertial diabatic motion in the entrance region produces a diabatically-induced mass circulation which systematically generates kinetic energy at the larger scale in the upper branch of the entrance region. The increase in $k i-$ netic energy accumulates downstream in the jet streak through massmomentum adjustment due to anticyclonic rotation through inertial accelerations. 


\section{Conclusions}

Twice during the AVE. IV experiment, the wind speed within upper tropospheric polar jet streaks increased by some $15 \mathrm{~m} \mathrm{~s}^{-1}$ over a time period of six hours or less; during corresponding intervals of time mesoscale convective complexes southwest of each jet streak intensified and expanded in areal extent. Large precipitation amounts from both MCC events dictate that substantial diabatic latent heating occurred within these severe storms. The case studies of each jet streak-MCC interaction event in this study establishes physical evidence for the direct link between diabatic heating within each MCC and the intensification of winds within each jet streak.

Analyses of each jet streak-MCC interaction event revealed that intense mesoscale mass circulations existed within both storm systems. Strong horizontal mass flux divergence away from the MCC at upper levels in the troposphere was generally balanced by strong horizontal mass flux convergence into the MCC at lower levels, both of which were linked to the strong vertical diabatic mass flux within the MCC. The intensity of winds within the core of the downstream jet streak is linked with the strength of the ageostrophic motion directed towards lower pressure within the upper branch of the direct mass circulation in the entrance region. From this fact, the results demonstrate for these cases that with diabatic heating located in the rear-right flank of the jet streak, the kinetic energy of the downstream jet streak's diabatically-induced ageostrophic wind components intensifies the thermally-direct mass circulation. 
The following are results and conclusions from the AVE IV case studies of jet streak-MCC interaction:

(i) A relative comparison of the components of ageostrophic motion indicates that the magnitudes of diabatically-induced ageostrophic wind components were significant at mid- and upper tropospheric levels during periods of intense convective activity near the entrance region of the jet streak.

(ii) The isallobaric component of the ageostrophic motion field was primarily responsible for driving the mesoscale mass circulation within each MCC. An explicit separation of isallobaric motion into three components; a surface pressure tendency component an adiabatic thermal wind component and a diabatic thermal wind component, reveals that these adiabatic and diabatic thermal wind components were in opposition to each other in lower and upper tropospheric levels. Diabatically-induced isallobaric motion produced by diabatic heating within the MCC increased the horizontal temperature contrast between the convective region and the environment and forced motion away from the MCC at lower and upper tropospheric levels. The adiabatically-induced isallobaric wind decreased the horizontal temperature contrast between the MCC and the environment and forced motion into the MCC at lower and upper leve1s. This adiabatically-induced decrease in horizontal temperature contrast occurs through adiabatic cooling by upward vertical motion with the MCC and adiabatic warming by subsidence in the environment. The agreement between the sense of the isallobaric mass circula- 
tion and the actual mass circulation establishes that the diabatic component dominated the adiabatic component in upper tropospheric levels, while the reverse was true in lower tropospheric levels over the period of the case study.

(iii) The isallobaric component of ageostrophic motion in both lower and upper tropospheric levels was directed in the same sense as the lower and upper branches of the direct mass circulation in the entrance region of the jet streaks and thus provided a mechanism for jet streak intensification through generation of upper tropospheric kinetic energy.

(iv) The inertial diabatic component of ageostrophic motion, produced through heating within a vertically-sheared momentum structure, attained magnitudes of $10 \mathrm{~m} \mathrm{~s}^{-1}$ in the upper tropospheric entrance region and was an important source of kinetic energy generation for the jet streak.

(v) As expected from theoretical considerations, the semigeostrophic approximation for ageostrophic motion was not adequate for the description of ageostrophic motion in the regions of convection due to the rapid evolution in the ageostrophic wind structure and the relatively large values for spatial derivatives of the ageostrophic motion.

(vi) The intensities of the horizontal and vertical mass flux divergences, and thus the mesoscale mass circulation, were stronger within MCC B (the second case) than within MCC A (the first case). In agreement with these features, the convergence and divergence of isal- 
lobaric motion and adiabatic and diabatic modes of isallobaric notion, and mid-and upper level Inertfal diabatic wind speeds were more intense for MCC $B$.

In this AVE IV case study, the estinates of the ageostrophic motion and its components were occasionally inconststent both spatfally and temporally. Accurate estimates of ageostrophtc motion structure from observations requires that both the wind and mass fields be analyzed accurately, since observations are discrete and contain bias and random errors and the sampling of the rawinsonde network in time and space is not optimal. Use of higher spatial and temporal resolution to resolve and predict the mesoscale will 11kely requtre improved accuracy of observations and an increase of sampling in time and space.

In future research of scale interaction the application of hydrodynamic stablitty criterta is needed in order to study, for given forcIng, the response of transverse circulations around the jet streak in the regions of reduced inertial and static stablitty which are associated with outbreaks of severe weather. A detalled study of this type of Interaction will require analysis of model simulation of the processes In order to spectfy accurately several physical processes which may only be computed through residual calculations from observational ana1yses. 


\section{REFERENCES}

Barnes, S. L., 1973: Mesoscale objective map analysis using weighted time-series observations. NOAA Tech. Mem., ERL NSSL-62, 66 pp. Brunt, D., and C. K. M. Douglas, 1928: Mem. Royal Meteor. Soc., 3, No. 22.

Cahtr, J. J., 1971: Implications of circulations in the vicinity of jet streaks at subsynoptic scales. Ph.D. Thesis, Penn. State Untv., $170 \mathrm{pp}$.

Eliassen, A., 1949: The quasi-static equations of motion with pressure as a dependent variable. Geofys. Publ., 17, 5-44. - 1959: On the formation of fronts in the atmosphere. Rossby Mem. Vol.. The atmosphere and the sea in motion. Rockefeller Institute Press, N.Y., 277-286.

- 1962: On the vertical circulation in frontal zones. Geofys. Pub1., 24, 147-160.

Fritsch, J. M., and R. A. Maddox, 1980: Analyses of upper troposphertc wind perturbations assoctated with mid-latitude mesoscale convective complexes. Proc. Elghth Conf. Wea. Forecasting Anal., 339-345.

Fucik, N. F., and R. E. Turner, 1975: Data for NASA's AVE IV experiment: $25 \mathrm{mb}$ sounding data and synoptic charts. NASA TM X-64952, G. C. Marshall Space Flight Center, Alabaina, 458 pp.

Ga11, R. E., and D. R. Johnson, 1977: Predfction of a quast-steady propagating jet core with an isentropic numerical model. Univ. of Wisc. Project Report, in print. 
REFERENCES, cont.

Haltiner, G. J., and F. L. Martin, 1957: Dynamical and Physical Meteorology. McGraw-Hill, 194-198.

Hi11, K., and R. E. Turner, 1977: NASA's Atmospheric Variability

Experiments (AVE). Bu71. Amer. Meteor. Soc., 58, 170-172.

Hoskins, B. J., 1975: The geostrophic momentum approximation and the semi-geostrophic equations. J. Atmos. Sci., 32, 233-242.

Maddox, R. A., 1979: The evolution of middle and upper tropospheric features during a period of intense convective storms. Preprints Eleventh Conf. Severe Local Storms., 41-48. - 1980: A satellite based study of mid-1atitude, mesoscale convective complexes. Proc. Eighth Conf. Wea. Forecasting Anal., 329-338.

D. J. Perkey, and J. M. Fritsch, 1980: The evolution of upper-tropospheric features during the development of a mid-latitude, mesoscale convective complex. Proc. Eighth Conf. Wea. Forecasting and Anal., 233-239.

Newton, C. W., and H. R. Newton, 1959: Dynamical interactions between large convective clouds and environment with vertical wind shear. J. Meteor., 16, 483-496.

Ninomiya, K., 1971a: Dynamical analysis of outflow from tornado-producing thunderstorms as revealed by ATSD III pictures. J. Appl. Meteor., 10, 275-294. 


\section{REFERENCES, cont.} , 1971b: Mesoscale modification of synoptic situations from thunderstorm development as revealed by ATS III and aerological data. J. Appl. Meteor., 10, 1103-1121. Palmen, E., and C.W. Newton, 1969: Atmospheric Circulation Systems, Academic Press, New York, Chap. 4, 5, 8, 9, and 13. Peterson, R. E., 1981: A study of bias and random error distributions for atmospheric structure and quasi-Lagrangian budget statistics. Ph.D. Thesis, in preparation, Univ. of Wis.-Madison. Riehl, J., J. Badner, J. E. Hovde, N. E. LaSeur, L. L. Menas, W. D. Palmer, M. J. Schroeder, L. W. Snellmann and others; 1952: Forecasting in Middle Latitudes. Meteor. Monogr., No. 5, 80 pp. Sechrist, F., and D. R. Johnson, 1970: On the isentropic representation of storms, dynamic destabilization and squall line formation. 51st Annual Meeting Amer. Geophys. Union, Wash., D.C., Abstract, EOS Transaction, A. G. U., 51, 4, 294. , and T. M. Whittaker, 1979: Evidence of jet streak vertical circulation. Mon. Wea. Rev., 107, 1014-1021. Uccellini, L. W., 1977: The coupling of upper and lower tropospheric jet streaks and implications for the development of severe convective storms. Ph.D. Thesis, Univ. of Wis.-Madison, $130 \mathrm{pp}$. 


\section{REFERENCES, cont.} , and D. R. Johnson, 1979: The coupling of upper and lower tropospheric jet streaks and implications for the development of severe convective storms. Mon. Wea. Rev., 107, 682-703.

Wilson, G. S., 1980: Thunderstorm-environment interactions determined with three-dimensional trajectories. NASA Ref. Pub. 1054, G. C. Marshall Space Flight Center, Alabama, 153 pp. 


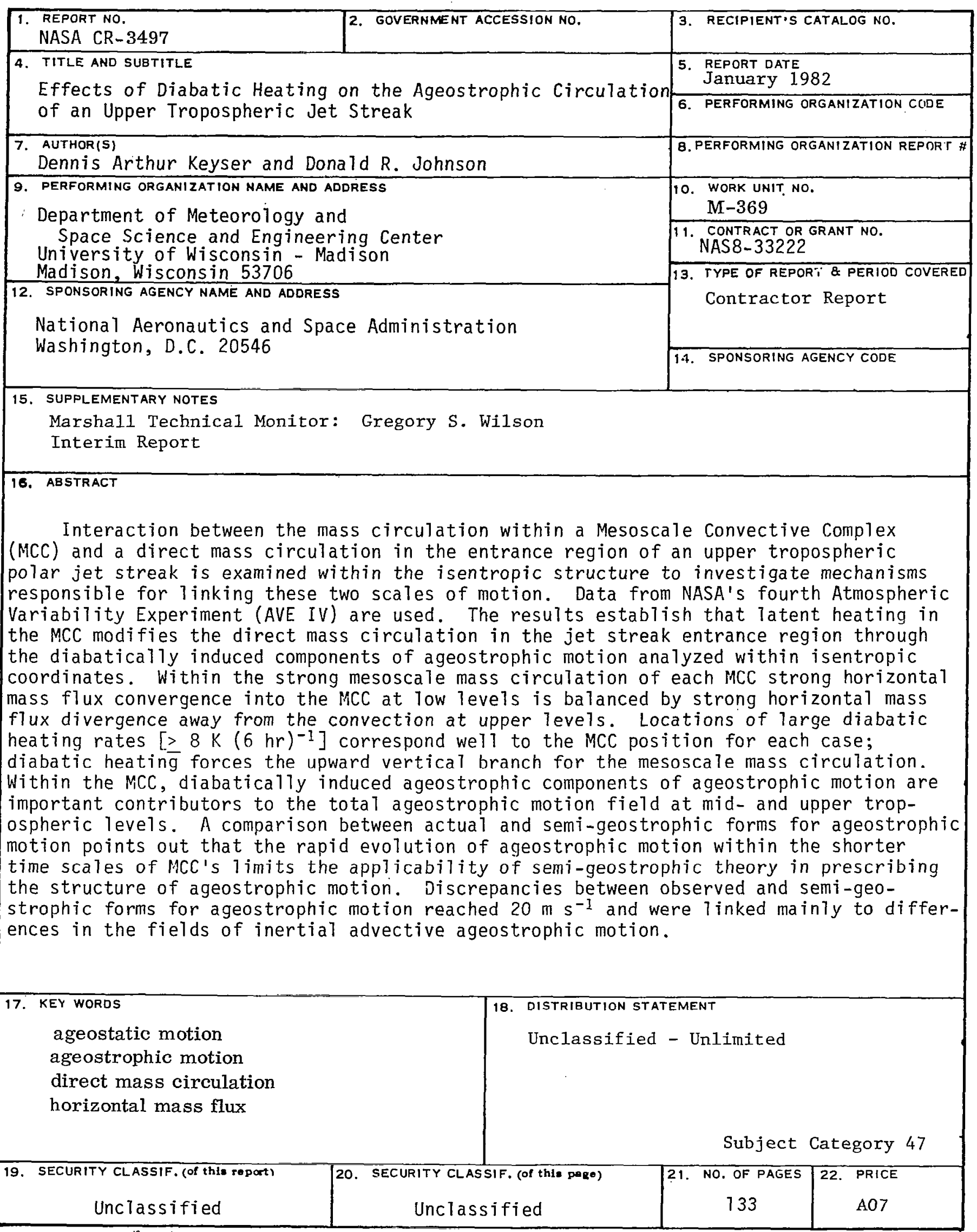

